\title{
EFFECTS OF REAL FLUID PROPERTIES ON AXIAL TURBINE MEANLINE DESIGN AND OFF-DESIGN
}

\author{
ANALYSIS \\ by \\ Cameron MacLean \\ A thesis submitted to the Faculty of Graduate Studies and Research \\ in partial fulfillment of the requirements for thee degree of
}

\section{Master of Applied Science}

In Aerospace Engineering

Ottawa-Carleton Institute for Mechanical \& Aerospace Engineering

\author{
Department of Mechanical \& Aerospace Engineering \\ Carleton University \\ Ottawa, Ontario, Canada
}

CCameron MacLean

January 2012 
Library and Archives

Canada

Published Heritage

Branch

395 Wellington Street

Ottawa ON K1A ON4

Canada
Bibliothèque et

Archives Canada

Direction du

Patrimoine de l'édition

395 , rue Wellington

Ottawa ON K1A ON4

Canada
Your file Votre référence

ISBN: 978-0-494-87800-2

Our file Notre référence

ISBN: $978-0-494-87800-2$

\section{NOTICE:}

The author has granted a nonexclusive license allowing Library and Archives Canada to reproduce, publish, archive, preserve, conserve, communicate to the public by telecommunication or on the Internet, loan, distrbute and sell theses worldwide, for commercial or noncommercial purposes, in microform, paper, electronic and/or any other formats.

The author retains copyright ownership and moral rights in this thesis. Neither the thesis nor substantial extracts from it may be printed or otherwise reproduced without the author's permission.
AVIS:

L'auteur a accordé une licence non exclusive permettant à la Bibliothèque et Archives Canada de reproduire, publier, archiver, sauvegarder, conserver, transmettre au public par télécommunication ou par l'Internet, prêter, distribuer et vendre des thèses partout dans le monde, à des fins commerciales ou autres, sur support microforme, papier, électronique et/ou autres formats.

L'auteur conserve la propriété du droit d'auteur et des droits moraux qui protege cette thèse. $\mathrm{Ni}$ la thèse ni des extraits substantiels de celle-ci ne doivent être imprimés ou autrement reproduits sans son autorisation.
In compliance with the Canadian Privacy Act some supporting forms may have been removed from this thesis.

While these forms may be included in the document page count, their removal does not represent any loss of content from the thesis.
Conformément à la loi canadienne sur la protection de la vie privée, quelques formulaires secondaires ont été enlevés de cette thèse.

Bien que ces formulaires aient inclus dans la pagination, il n'y aura aucun contenu manquant. 
The undersigned hereby recommend to

the Faculty of Graduate Studies and Research

acceptance of this thesis entitled

\title{
Effects of Real Fluid Properties on Axial Turbine Meanline
}

\section{Design and Off-Design Analysis}

\author{
submitted by \\ Cameron MacLean \\ in partial fulfillment of the requirements for the degree of \\ Master of Applied Science in Aerospace Engineering
}

$\begin{array}{ll} & \text { Professor Steen A. Sjolander } \\ \text { Thesis Supervisor: } & \begin{array}{l}\text { Department of Mechanical \& Aerospace Engineering } \\ \end{array}\end{array}$

Department Chair:

Professor Metin I. Yaras

Department of Mechanical \& Aerospace Engineering

Carleton University

January 2012 


\begin{abstract}
The effects of real fluid properties on axial turbine meanline analysis have been investigated employing two meanline analysis codes, namely Turbine Meanline Design (TMLD) and Turbine Meanline Off-Design (TMLO). The previously developed TMLD code assumed the working fluid was an ideal gas. Therefore it was modified to use real fluid properties. TMLO was then developed from TMLD. Both codes can be run using either the ideal gas assumption or real fluid properties.
\end{abstract}

TMLD was employed for the meanline design of several axial turbines for a range of inlet conditions, using both the ideal gas assumption and real fluid properties. The resulting designs were compared to see the effects of real fluid properties. Meanline designs, generated using the ideal gas assumption, were then analysed with TMLO using real fluid properties. This was done over a range of inlet conditions that correspond to varying degrees of departure from ideal gas conditions. The goal was to show how machines designed with the ideal gas assumption would perform with the real working fluid. The working fluid used in both investigations was supercritical carbon dioxide.

Results from the investigation show that real fluid properties had a strong effect on the gas path areas of the turbine designs as well as the performance of turbines designed using the ideal gas assumption. Specifically, power output and the velocities of the working fluid were affected. It was found that accounting for losses tended to lessen the effects of the real fluid properties. 


\section{Acknowledgements}

I wish to express my utmost appreciation to my thesis supervisor Professor Sjolander. His guidance, immense knowledge, and continuous support throughout the duration of my work were invaluable.

I would like to thank all members of the Carleton community who aided me during my time here. Specifically, I wish to thank my colleagues and friends Steven Hall and Andrew Scribner for their insightful ideas and encouragement. Also, my thanks go to Mrs. Nancy Powell, Mrs. Christie Egbert, and Mrs. Marlene Groves for helping guide me through the administrative processes of my time at Carleton.

I also would like to thank Natural Resources Canada for their financial support which made this research possible.

Finally, I would like to express my sincere gratitude to my wife Tessa and my family for their immense love and support. 


\section{Table of Contents}

Acknowledgements.

Chapter 1 Introduction........................................................................................................................1

1.1 Motivation and Objectives .................................................................................

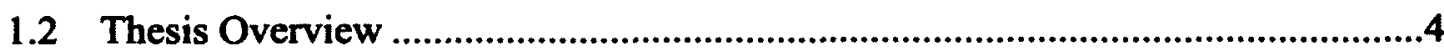

Chapter 2 Review of Previous Work ........................................................................................5

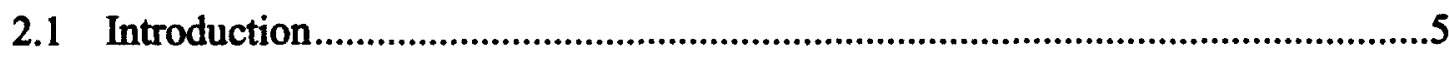

2.2 Flow Angle and Blade Geometry Nomenclature....................................................5

2.3 Flow in a Blade Passage ........................................................................................

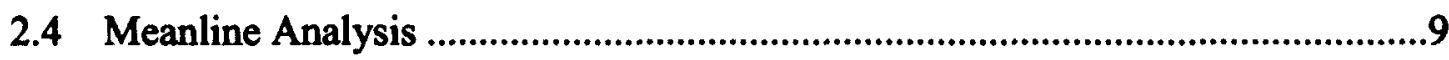

2.4.1 Meanline Analysis at the Design Point..................................................9

2.4.2 Meanline Analysis at Off-Design Operating Points ...............................13

2.5 Ainley \& Mathieson and Kacker \& Okapuu Loss Systems.................................15

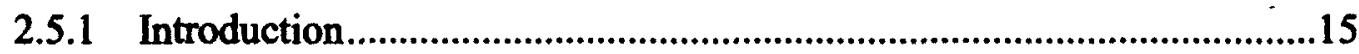

2.5.2 Profile Losses......................................................................................18

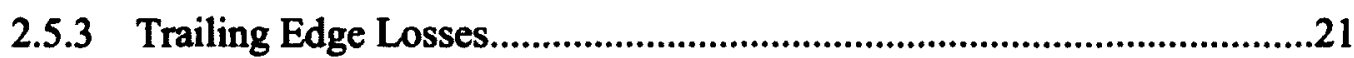




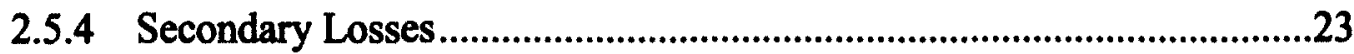

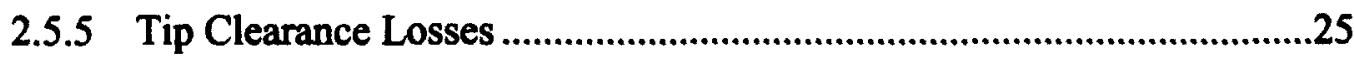

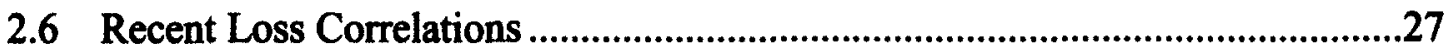

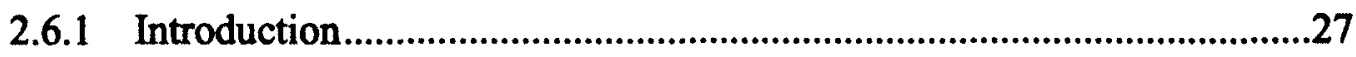

2.6.2 Zhu \& Sjolander Profile Loss Update........................................................28

2.6.3 Benner, Sjolander \& Moustapha Secondary Loss Update........................29

2.6.4 Yaras \& Sjolander and Kim \& Chung Tip Clearance Loss Updates......32

2.6.5 Benner, Sjolander \& Moustapha Off-Design Profile Loss

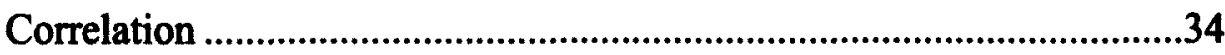

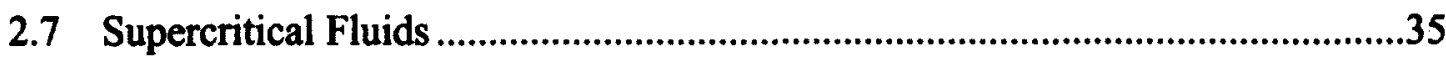

2.8 Designing a Turbomachine with Real Fluid Properties ........................................38

2.9 National Institute of Standards and Technology (NIST) .....................................42

2.10 Turbine Meanline Design (TMLD) ....................................................................44

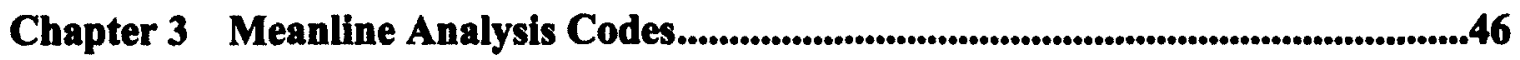

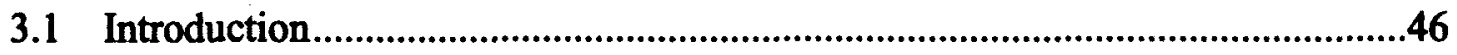

3.2 Modifications to Account for Real Fluid Properties..............................................47

3.3 Additional Modifications to the Turbine Meanline Design Code ........................51

3.3.1 TMLD Specific Modifications to Account for Real Fluid

Properties

3.3.2 Kacker \& Okapuu Unshrouded Blade Tip Clearance Total Pressure

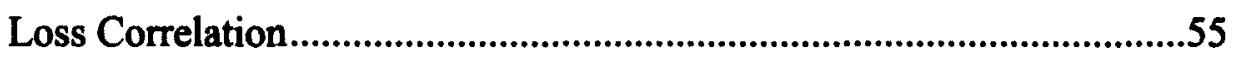

3.3.3 Design Point Total Pressure Loss Correlations …………........................58 
3.4 Development of the Turbine Meanline Off-Design (TMLO) Code

3.5 Off-Design Total Pressure Loss Correlations Used in TMLO .62

3.6 Overview of TMLD and TMLO Data Files .65

Chapter 4 Results and Discussion.......................................................................................70

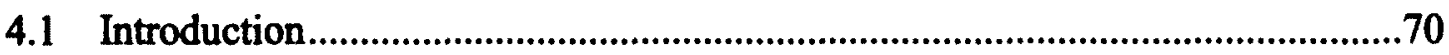

4.2 Manual Calculations for Single Stage Turbines ...................................................71

4.2.1 Meanline Design of Axial Turbines......................................................71

4.2.2 Effects of Real Fluid Properties on Turbines Designed for Ideal Working Fluids Assuming Isentropic Expansion ....................................74

4.3 Effects of Real Fluid Properties on Results from TMLD .....................................81

4.3.1 Effects of Real Working Fluids on Turbine Geometries .........................81

4.3.2 Convergence Times for Ideal and Real Working Fluids ..........................87

4.4 Off-Design Calculations Using TMLO ..............................................................89

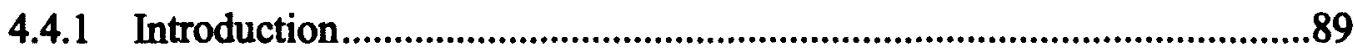

4.4.2 Effects of Real Working Fluids on Ideal Gas Machine Performance.....90

4.4.3 Single Stage Turbine Characteristic.......................................................94

4.4.4 Leading-Edge Wedge Angle and Diameter-to-Spacing Ratio.................99

Chapter 5 Conclusions and Recommendations....................................................................104

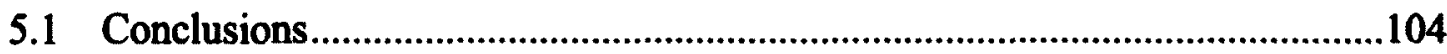

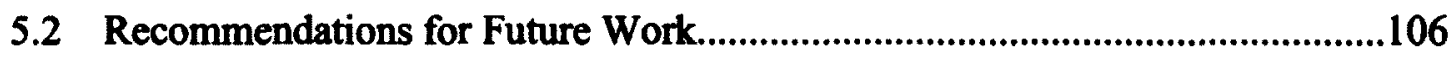

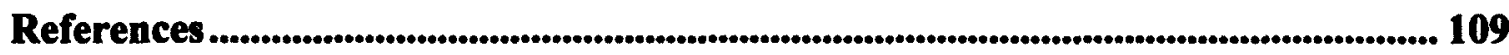


Appendix A TMLD Input File Format

Appendix B TMLO Blade Geometry Input Data File Format

Appendix C Example TMLD Output File

121

Appendix D Dependence of Total Enthalpy Drop on Blade Speed and Work

Coefficient.

.128

Appendix E Leading-Edge Wedge Angle and Leading-Edge Diameter-to-

Spacing Ratio Data 


\section{List of Tables}

Table 2.1 Differences Between Kacker \& Okapuu and Zhu \& Sjolander Profile

Loss Correlations

Table 2.2 REFPROP vs. GASP Near Carbon Dioxide's Critical Point ............................... 44

Table 3.1 Working Fluid Options in Latest Version of TMLD and TMLO...................... 50

Table 3.2 Working Fluid Options in TMLD's Input Data File...........................................66

Table 3.3 Total Pressure Loss Correlation Options in TMLD's Input Data File ............. 67

Table 4.1 Inlet Conditions of the Four Machines .............................................................. 74

Table 4.2 Inlet Conditions of the Four TMLD Machines .................................................... 81

Table 4.3 TMLD Convergence Time for Three Fluid Types ............................................... 89

Table 4.4 Differences in Flow Angles Between Manual Calculations and TMLO Results

Table 4.5 Change in $\Delta \mathrm{h}_{0}$ with Blade Speed ...................................................................99

Table A.1 Airfoil Leading-Edge Geometry Data .......................................................... 131 


\section{List of Figures}

Figure 1.1 Schematic of the 2008-2009 Carleton University Fourth-Year

Engineering Project Power Plant...........................................................................2

Figure 2.1 Airfoil Geometry Terminology (Adapted from Benner, 2003).......................... 6

Figure 2.2 Diagram of the Flow Through a Turbine Blade Passage (Adapted from Jeffries, 2000) ..........................................................................................8

Figure 2.3 Example Turbine Stage Demonstrating Mean Radius and Velocity

Triangles

Figure 2.4 Smith Chart (Smith, 1965) …........................................................................... 13

Figure 2.5 Example Off-Design Velocity Triangles for a Single Stage Axial Turbine.....14

Figure 2.6 Example Turbine Characteristic ....................................................................... 15

Figure 2.7 Example Axial Inflow Nozzle and Impulse Blade Geometry ........................... 18

Figure 2.8 Ainley and Mathieson Profile Loss Coefficient (Kacker and Okapuu, 1982)

Figure 2.9 Trailing Edge Loss [Energy] Coefficient Correlated Against Trailing Edge Thickness to Throat Opening Ratio (Reproduced from Kacker and Okapuu, 1982)

Figure 2.10 Aspect Ratio Functions for Aspect Ratios Less Than 2.0 25

Figure 2.11 Depiction of Penetration Depth on the Suction Surface of an Airfoil (Reproduced from Benner 2003). .31

Figure 2.12 Carbon Dioxide Phase Diagram (Adapted from Taylor, 1996) ..................... 36

Figure 2.13 Generalized Compressibility Chart (Adapted from Moran and Shapiro, 2004)

Figure 3.1 Example Axial Inflow Nozzle, Impulse and Low Turning Blade Geometries 
Figure 3.2 Excerpt from TMLD Output File with Warning on Profile Loss

Coefficient Indicating the Flow Angles are out of Correlation Range...............60

Figure 3.3 Excerpt from TMLO Output File with $\chi$ Out of Range Warning......................63

Figure 3.4 Excerpt from TMLD Output File with Failed Convergence Warning ............. 68

Figure 4.1 Design Velocity Triangles from Hand Calculations ........................................73

Figure 4.2 Velocity Triangles from Hand Calculations...................................................... 75

Figure 4.3 Total Enthalpy Drop Variation with Compressibility Factor ............................ 77

Figure 4.4 Incidence Angle Variation with Compressibility Factor.................................. 78

Figure 4.5 Mach Number Variation with Compressibility Factor...................................... 78

Figure 4.6 Non-Dimensional Coefficients Variation with Compressibility Factor........... 80

Figure 4.7 Cross-Sectional Areas of the 0.90 Inlet Compressibility Factor Machines......83

Figure 4.8 Cross-Sectional Areas of the 1.10 Inlet Compressibility Factor Machines..... 83

Figure 4.9 Cross-Sectional Areas of the Four TMLD Designed Machines........................ 84

Figure 4.10 Mach Number Values for the $Z=0.90$ Turbines ........................................... 85

Figure 4.11 Mach Number Values for the $Z=1.10$ Turbines ........................................... 85

Figure 4.12 Performance Parameters of the Four TMLD Designed Machines ................. 87

Figure 4.13 Design and Real Fluid Velocity Triangles for the 190 and I1 10

Machines.

Figure 4.14 TMLO and Manual Calculations Predicted Performance Parameters Normalized on Design Values.

Figure 4.15 Isentropic Efficiency Component of the R90 Machine Turbine

Characteristic

Figure 4.16 Massflow Rate Component of the R90 Machine Turbine Characteristic.......96

Figure 4.17 Change in $\Delta C_{W}$ with Blade Speed..............................................................98

Figure 4.18 Leading-Edge Wedge Angle versus Leading-Edge Diameter-to-Spacing Ratio .101 
Figure 4.19 Sensitivity of We and $d_{L E} / s$ on Off-Design Total Pressure Loss Coefficient 


\section{List of Symbols}

a = sonic velocity

$\mathrm{a}, \mathrm{b}, \mathrm{c}, \mathrm{n}=$ coefficients in Aungier's form of equation of state (Equation 2.46)

A $\quad=$ Area; Helmholtz energy

$\mathrm{AR} \quad=\frac{\mathrm{h}}{\mathrm{c}}=$ aspect ratio

c $\quad=$ airfoil chord length

C $=$ absolute velocity

$\mathrm{CR}=\frac{\cos \alpha_{1}}{\cos \alpha_{2}}=$ convergence ratio

$C_{D} \quad=$ discharge coefficient for tip gap

$\mathrm{C}_{\mathrm{L}} \quad=$ lift coefficient

$\mathbf{c}_{\mathbf{P}} \quad=$ specific heat at constant pressure

$\overline{\mathbf{c}}_{\mathrm{p}} \quad=$ Aungier's modified specific heat at constant pressure (Equation 2.43)

c $\quad=$ specific heat at constant volume

$\overline{\mathbf{c}}_{\mathrm{v}} \quad=$ Aungier's modified specific heat at constant volume (Equation 2.44)

$\mathrm{c}_{\mathrm{x}} \quad=$ airfoil axial chord length

$d_{\mathrm{LE}} \quad=$ airfoil leading edge diameter

$\mathrm{F}_{\mathrm{t}} \quad=$ non-dimensionalized tangential loading (Equation 2.29)

h = blade height; static enthalpy

$h_{0} \quad=$ stagnation enthalpy 


$$
\begin{aligned}
& \text { i } \quad=\alpha_{1}-\alpha_{1, \text { design }}=\text { incidence, in degrees } \\
& \mathrm{K}_{\mathrm{emp}}=\text { empirical constant in tip clearance loss correlation (Equation 2.35) } \\
& \mathrm{K}_{\mathrm{E}}, \mathrm{K}_{\mathrm{G}} \quad=\text { coefficients for effects of blade loading distribution on tip losses } \\
& \mathrm{K}_{\mathrm{m}}, \mathrm{K}_{\mathrm{in}}, \quad=\text { coefficients in modified profile loss correlation (Equation 2.26) } \\
& \mathbf{K}_{\mathrm{in,l},}, \mathbf{K}_{\mathrm{in}, \mathrm{N}} \\
& \mathrm{K}_{\mathrm{P}}, \mathrm{K}_{\mathbf{S}} \quad=\text { coefficients for compressibility effects in profile and secondary losses } \\
& \dot{\mathrm{m}} \quad=\text { massflow rate } \\
& \text { M = Mach number } \\
& \mathrm{N}=\text { rotational speed, in RPM } \\
& \text { - } \quad=\text { blade passage throat opening } \\
& \mathbf{P} \quad=\text { static pressure } \\
& \text { PR = total pressure ratio } \\
& \mathbf{P}_{0} \quad=\text { stagnation pressure } \\
& P_{c} \quad=\text { static pressure at critical point } \\
& P_{R} \quad=\frac{P}{P_{c}}=\text { reduced pressure } \\
& \mathrm{r}=\text { = radius, measured from machine centre line } \\
& \mathbf{R}=\text { gas constant of working fluid } \\
& \overline{\mathrm{R}} \quad \text { = Aungier's modified gas constant of working fluid (Equation 2.42) } \\
& \operatorname{Re}_{\mathrm{c}}=\frac{\rho c \mathrm{~V}}{\mu}=\mathrm{Reynolds} \text { number based on chord length } \\
& \text { s } \quad=\text { entropy } \\
& \mathrm{S} \quad=\text { airfoil pitch or spacing } \\
& \mathrm{T}=\text { static temperature }
\end{aligned}
$$




$$
\begin{aligned}
& \mathrm{T}_{0} \quad=\text { stagnation temperature } \\
& \mathrm{T}_{\mathrm{c}}=\text { static temperature at the critical point } \\
& T_{R} \quad=\frac{T}{T_{c}}=\text { reduced temperature } \\
& t_{\max }=\text { maximum thickness-to-chord ratio } \\
& \mathrm{t}_{\mathrm{TE}} \quad=\text { airfoil trailing-edge thickness } \\
& \mathbf{u} \quad=\text { internal energy } \\
& \mathrm{U} \quad=\text { blade speed } \\
& \mathbf{v} \quad=\text { specific volume } \\
& \mathrm{V} \quad=\text { velocity } \\
& \mathrm{W} \quad=\text { relative velocity } \\
& \dot{\mathrm{W}} \quad \text { = power } \\
& \text { We = airfoil leading-edge wedge angle, in degrees } \\
& \mathrm{Y}=\frac{\mathrm{P}_{01}^{n}-\mathrm{P}_{02}^{n}}{\mathrm{P}_{02}^{n}-\mathrm{P}_{2}^{n}}=\text { mass-averaged total pressure loss coefficient } \\
& \mathrm{Z}=\text { compressibility factor; Zweifel coefficient } \\
& \mathrm{Z}_{\mathrm{TE}} \quad=\text { secondary vortex penetration depth } \\
& \text { a } \quad=\text { absolute flow angle measured from axial direction, in degrees } \\
& \text { B = airfoil metal angle measured from axial direction, in degrees } \\
& \gamma \quad=\text { airfoil stagger angle measured from axial direction, in degrees; isentropic } \\
& \text { exponent } \\
& \bar{\gamma} \quad=\text { Aungier's modified isentropic exponent (Equation 2.45) } \\
& \delta \quad=\left|\alpha_{2}-\beta_{2}\right|=\text { deviation } \\
& \delta^{*} \quad=\text { boundary layer displacement thickness }
\end{aligned}
$$




$$
\begin{aligned}
& \eta \quad=\text { isentropic efficiency } \\
& \eta_{0} \quad=\text { stage efficiency with zero tip clearance losses } \\
& \lambda \quad=\text { function of inlet and outlet annulus geometry; tip unloading factor } \\
& \Lambda \quad=\frac{h_{2}-h_{1}}{\Delta h_{0}}=\text { degree of reaction } \\
& \mu \quad=\text { dynamic viscosity } \\
& \rho \quad=\text { static density } \\
& \tau \quad=\text { tip clearance } \\
& \tau^{\prime} \quad=\text { equivalent tip clearance for shrouded blades } \\
& \varphi \quad=\frac{C_{L}}{U}=\text { flow coefficient } \\
& \varphi^{2} \quad=\text { mass-averaged kinetic-energy loss coefficient } \\
& \chi \quad=\left(\frac{\mathrm{d}_{\mathrm{LE}}}{\mathrm{S}}\right)^{-0.05} \mathrm{We}^{-0.2}\left(\frac{\cos \beta_{1}}{\cos \beta_{2}}\right)^{-1.4}\left[\alpha_{1}-\alpha_{1, \text { design }}\right]=\text { Benner et al. incidence } \\
& \text { parameter } \\
& \chi^{\prime} \quad=\left(\frac{d_{L E}}{S}\right)^{-1.6}\left(\frac{\cos \beta_{1}}{\cos \beta_{2}}\right)^{-2}\left[\alpha_{1}-\alpha_{1, \text { design }}\right]=\text { Tremblay et al. incidence parameter } \\
& \Psi \quad=\frac{\Delta h_{0}}{U^{2}}=\text { work coefficient } \\
& \omega \quad=\text { relative flow angle measured from axial direction, in degrees }
\end{aligned}
$$

\section{Subscripts}

a

$$
=\text { axial direction }
$$




\begin{tabular}{|c|c|}
\hline $\mathbf{A M}$ & $=$ Ainley and Mathieson \\
\hline avg & $=$ average \\
\hline BSM & = Benner, Sjolander and Moustapha \\
\hline DC & $=$ Dunham and Came \\
\hline des & $=$ design value \\
\hline gap & $=$ tip gap \\
\hline h & $=$ hub of the gas path \\
\hline Imp & $=$ impulse blade \\
\hline KO & = Kacker and Okapuu \\
\hline $\mathbf{L T}$ & $=$ low turning blade \\
\hline m & $=$ meanline of the gas path; based on vector mean velocity \\
\hline Noz & $=$ nozzle blade \\
\hline $\mathbf{P}$ & $=$ profile \\
\hline SHOCK & $=$ leading-edge shock \\
\hline $\mathbf{t}$ & $=$ tip of the gas path \\
\hline tip & $=$ tip-leakage \\
\hline $\mathrm{TC}$ & $=$ tip clearance \\
\hline TET & $=$ trailing-edge thickness \\
\hline Total & $\begin{array}{l}=\text { combination of profile, secondary, tip clearance, and trailing-edge } \\
\text { thickness losses }\end{array}$ \\
\hline $\mathbf{s}$ & $=$ secondary \\
\hline W & $=$ whirl direction \\
\hline YS & $=$ Yaras and Sjolander \\
\hline
\end{tabular}


$1,2=$ airfoil inlet and outlet

\section{Superscripts}
- $\quad=$ mass-averaged
$0 \quad=$ reference state 


\section{Chapter 1 Introduction}

\subsection{Motivation and Objectives}

One of the Carleton University fourth-year engineering projects, with funding from Natural Resources Canada, has been designing a closed-loop, indirectly-fired power plant based on the Brayton cycle and using supercritical carbon dioxide $\left(\mathrm{S}-\mathrm{CO}_{2}\right)$ as the working fluid. The plant is shown schematically in Figure 1.1. It is essentially a closedcycle gas turbine engine with a recuperator. The plant exploits the properties of $\mathrm{S}-\mathrm{CO}_{2}$ near the critical point to create a compact power plant that can achieve good thermal efficiency with relatively low turbine inlet temperatures. Such a plant is attractive for use as the power module for the next generation of nuclear reactors, as well as with other heat sources such as biomass, solar and clean coal technology. However, at the temperatures and pressures encountered in the plant, the properties of the working fluid differ to varying degrees from ideal gas behaviour. The present study examines the effects of the non-ideal gas behaviour on the design and performance of the turbomachinery, with particular focus on axial turbines.

In the $\mathrm{S}-\mathrm{CO}_{2}$ Brayton cycle, the inlet conditions for the compressor are deliberately set very close to the critical point, which for $\mathrm{CO}_{2}$ is at approximately 73.9 bar and $304 \mathrm{~K}$ (Moran and Shapiro, 2004). Thus, the compressor experiences the largest influence of non-ideal gas behaviour. Nevertheless, throughout the turbine there are significant 


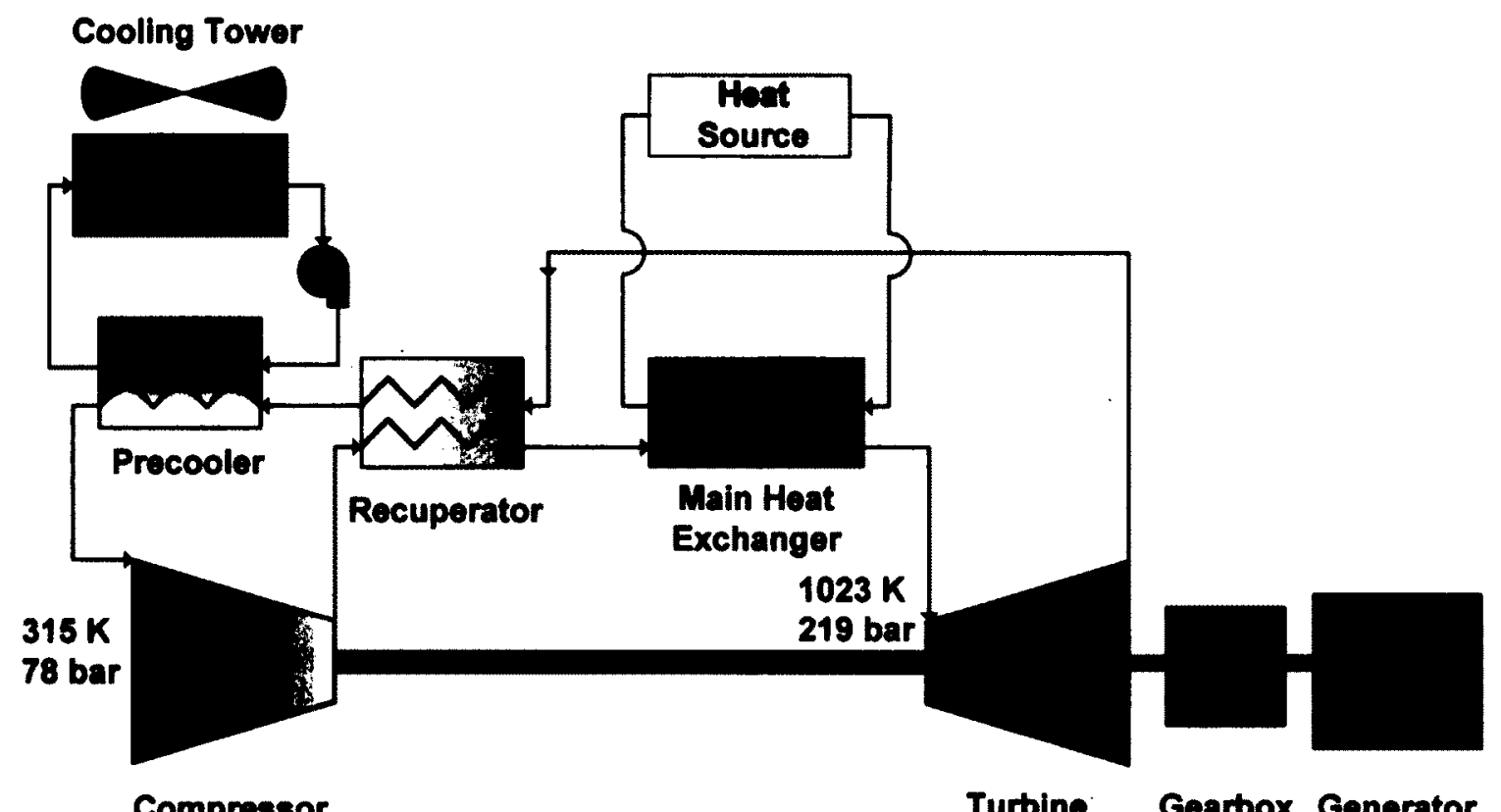

Figure 1.1 Schematic of the 2008-2009 Carleton University Fourth-Year Engineering Project Power Plant

deviations from ideal gas behaviour. Since the effect of real fluid properties on the compressor performance has been partially investigated by Stor (2010), the present work focuses on the turbine.

Meanline analysis is normally used in the early stages of the design of a turbomachine. In this analysis the fluid velocities needed to achieve the desired performance are determined at the mean radius, or meanline, of the machine. The flow is essentially treated as one-dimensional, with the conditions at the meanline taken as a reasonable average for the flow across the full blade span. In the present work, meanline analysis is used to investigate both the design point and the off-design behaviour of axial 
turbines for which the fluid inlet conditions were varied over a range of non-ideal conditions.

The starting point for the present work was an existing meanline code, called Turbine Meanline Design (TMLD), developed by Verhiel (1993) for the design-point analysis of axial turbines. The code allows multistage turbines to be analysed. It takes into account compressible flow effects and uses empirical correlations to predict the resulting machine efficiency. However, the code was developed for the analysis of the turbines in open-cycle gas turbine engines, for which the assumption of ideal gas behaviour is reasonable. Thus, for application to the $\mathrm{S}-\mathrm{CO}_{2}$ plant, it was first necessary to replace the ideal gas assumptions with real fluid properties. The required modifications proved to be very extensive since the ideal gas assumptions are used in numerous aspects of the analysis: for example, in determining local Mach numbers, in relating total to static conditions, and in relating the power output of the turbine to the pressure ratio across it.

After TMLD had been successfully converted to real fluid analysis, it formed the basis for the development of a second code, called TMLO (Turbine Meanline OffDesign), for use in calculating the complete operating characteristics of the turbine. The two codes were then used to investigate the effects of real fluid properties on both the design and off-design behaviour of several hypothetical single-stage turbines. 


\subsection{Thesis Overview}

Chapter 2 reviews the literature that is most relevant to the present investigation. It also introduces the terminology and nomenclature that will be used. Chapter 3 describes the modifications to the design-point code, TMLD, followed by the development of the off-design code, TMLO. Chapter 4 presents the results from the investigations of the effects of real fluid properties on stage performance. Finally, conclusions and recommendations for future work are given in Chapter 5. 


\section{Chapter 2 Review of Previous Work}

\subsection{Introduction}

This chapter provides an overview of previous research on meanline analysis and the use of real fluid properties in turbomachinery design. Section 2.2 provides the nomenclature used in this thesis. A description of the general flow features present in an axial turbine blade passage is given in Section 2.3. Section 2.4 introduces meanline analysis and describes how it is used for both design and off-design conditions. Sections 2.5 and 2.6 summarize the total pressure loss correlations used in the Turbine Meanline Design (TMLD) program. Section 2.7 introduces supercritical fluids and the compressibility factor. The next section describes three possible methods for incorporating real fluid properties in turbomachinery design codes. The fluid property data that is used in TMLD is summarized in Section 2.9. The chapter concludes with an overview of previous work on TMLD.

\subsection{Flow Angle and Blade Geometry Nomenclature}

Figure 2.1 illustrates the nomenclature used to describe the geometry of a blade row. All angles are measured relative to the axial direction with the direction of the blade speed taken as positive. 


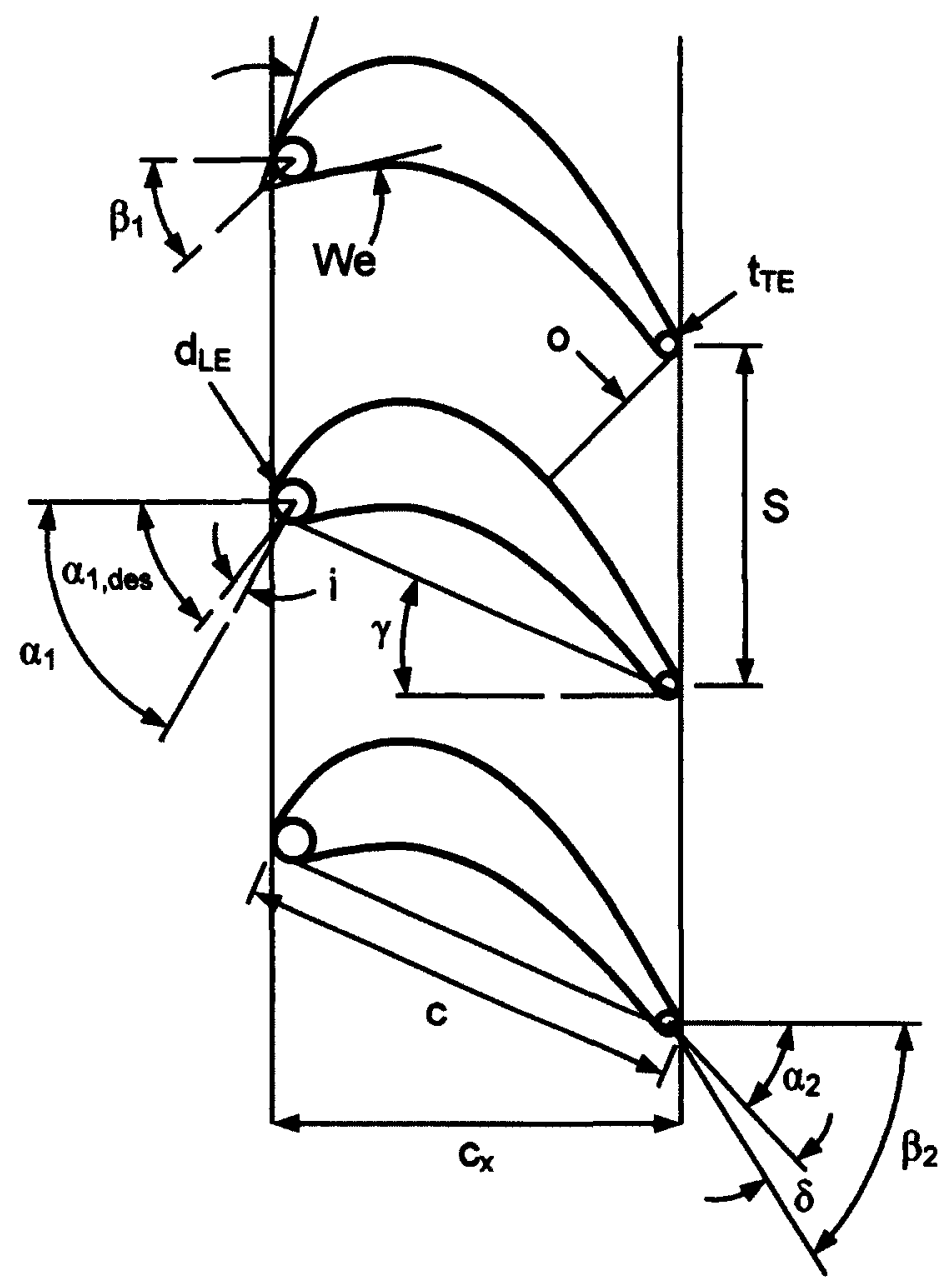

$\alpha_{1}$ : Inlet flow angle

i: Incidence

$\alpha_{2}$ : Outlet flow angle

c: True chord

$a_{1, \text { des: }}$ Design inlet flow angle

$c_{x}$ : Axial chord

$\beta_{1}$ : Inlet metal angle

$\gamma$ : Stagger angle

$\beta_{2}$ : Outlet metal angle

$\delta$ : Deviation

o: Throat opening

$t_{\mathrm{TE}}$ : Trailing edge thickness

S: Pitch (spacing)

$d_{L E}$ : Leading-edge diameter

We: Wedge angle

Figure 2.1 Airfoil Geometry Terminology (Adapted from Benner, 2003) 
The incidence angle, $i$, is defined as the difference between the actual inlet flow angle, $\alpha 1$, and the design inlet flow angle, $\alpha_{1, \text { des, }}$

$$
\mathrm{i}=\alpha_{1}-\alpha_{1, \mathrm{des}}
$$

The pressure difference across the blade at the trailing edge, pressure side to suction side, causes the flow exiting the blade passage to turn towards the axial direction. The difference between the trailing edge metal angle and the exit flow angle is known as the deviation, $\delta$,

$$
\delta=\left|\alpha_{2}-\beta_{2}\right|
$$

where, $\alpha_{2}$ is the exit flow angle and $\beta_{2}$ is the exit metal angle.

\subsection{Flow in a Blade Passage}

Figure 2.2 shows schematically the flow in a turbine blade passage. The tip-leakage vortex is created by fluid being forced through the tip gap by the pressure difference across the blade. The horse-shoe vortices are created by the separation of the inlet endwall boundary layer as it approaches the stagnation point on the leading edge of the blade. The separated fluid rolls up and forms a vortex on both the suction and pressure sides of the blade. The passage vortex is formed just downstream of the leading edge of the blade by the low momentum endwall fluid which is swept toward the suction side of the adjacent blade by the cross passage pressure gradient. As the endwall fluid 
approaches the adjacent blade it rolls up and forms the passage vortex. The pressure side leg of the horse-shoe vortex combines with the passage vortex as both are forced towards the suction side of the adjacent blade. The profile flow, i.e. the flow away from the endwalls, is primarily two-dimensional.

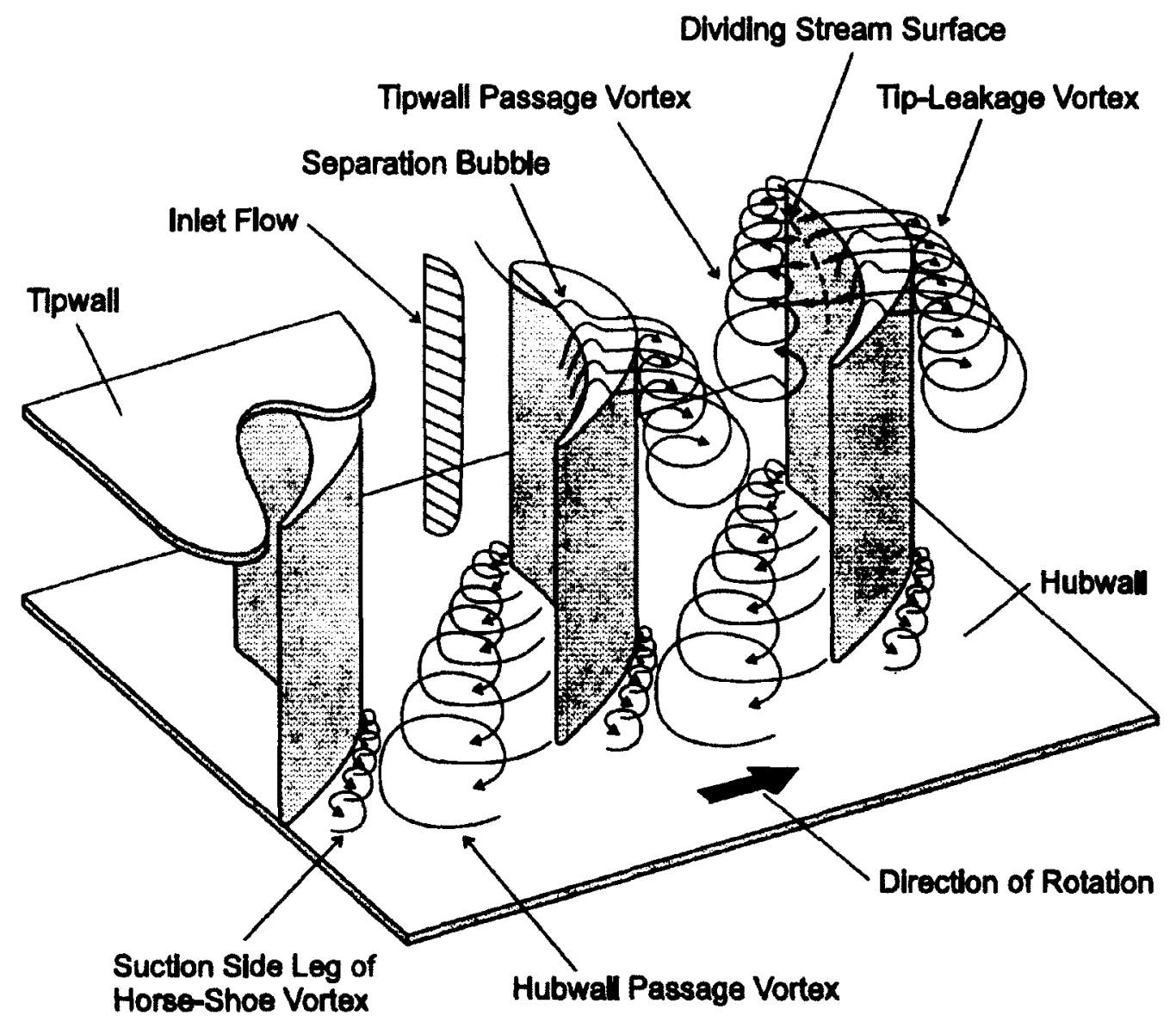

Figure 2.2 Diagram of the Flow Through a Turbine Blade Passage (Adapted from Jeffries, 2000) 


\subsection{Meanline Analysis}

\subsubsection{Meanline Analysis at the Design Point}

Meanline analysis is a one-dimensional analysis of the flow through a turbomachine that is performed at the mean radius of the gas path. When designing a turbine stage typically a power output, massflow rate and inlet temperature and pressure are specified. Meanline analysis is used in early stages of the design to estimate the velocity triangles, size of the machine, and rotational speed that will give the specified performance. The flow conditions at the mean radius are assumed to represent a reasonable average of the flow across the full span. The mean radius is often defined as the radius that splits the gas path area in half. That is:

$$
r_{m}=\sqrt{\frac{1}{2}\left(r_{h}^{2}+r_{t}^{2}\right)}
$$

where $r_{m}, r_{h}$, and $r_{t}$ are the mean radius, hub radius and tip radius respectively. The machine geometry arrived at from the meanline analysis then forms the basis for more detailed two- and three-dimensional analyses that are conducted as the design proceeds.

Figure 2.3 shows the cross section of an example turbine stage where the mean radius is indicated. This figure also shows the section through the flow and blades at the mean radius. Absolute velocities are designated $\mathrm{C}$, relative velocities $\mathrm{W}$ and $\mathrm{U}$ is blade speed. Subscripts a and $\mathrm{W}$ indicate velocity components in the axial and tangential directions. 
The velocity vectors are combined to form the velocity triangles at the mean radius, shown at the bottom of Figure 2.3.

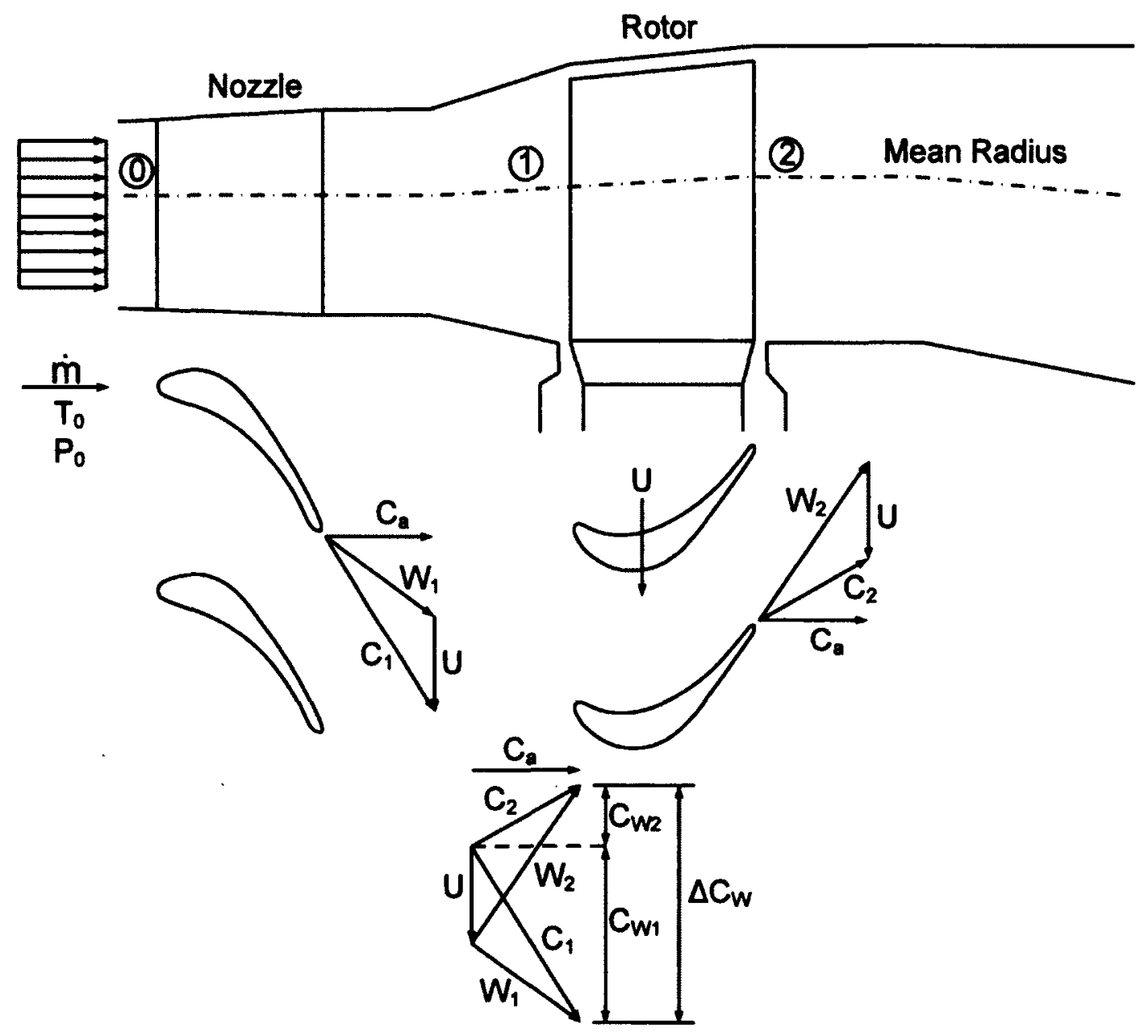

Figure 2.3 Example Turbine Stage Demonstrating Mean Radius and Velocity Triangles

In order to perform meanline analysis three non-dimensional performance parameters are required. These three parameters determine the shape of the velocity triangles. The first parameter is the work coefficient,

$$
\psi=\frac{\Delta \mathrm{h}_{0}}{\mathrm{U}^{2}}=\frac{\mathrm{C}_{\mathrm{w}_{2}}-\mathrm{C}_{\mathrm{w}_{1}}}{\mathrm{U}}
$$


where, $\Delta \mathrm{h}_{0}$ is the total enthalpy drop across the stage. The work coefficient is a measure of the stage loading. Increasing the work coefficient increases the amount of flow turning done through the stage. If the design blade speed and massflow rate are held constant and the work coefficient is increased the power output from the stage will increase. Often, both the power output and massflow rate are specified when designing a turbine. Therefore, the total enthalpy drop is also specified as it is related to the power output and massflow rate by,

$$
\Delta \mathrm{h}_{0}=\frac{\dot{\mathrm{W}}}{\dot{\mathrm{m}}}
$$

where, $\dot{W}$ and $\dot{\mathrm{m}}$ are power and massflow rate respectively. Thus, by selecting a value of work coefficient, power output, and massflow rate and making use of Equations 2.4 and 2.5 one also selects the blade speed at the mean radius.

The second non-dimensional performance parameter is the flow coefficient, given by,

$$
\varphi=\frac{C_{1}}{U}
$$

If the blade speed is held constant and the flow coefficient is increased the axial velocity, along with the absolute and relative velocities, also increases. This does not affect the whirl velocities, and therefore the power output, but it does decrease the flow angles. The increased velocities can also cause higher losses, as the losses scale on the dynamic pressure. 
There are a few options for the third non-dimensional performance parameter. Two common choices are the absolute flow angle at the stage exit and the degree of reaction. The degree of reaction is defined as:

$$
\Lambda=\frac{h_{2}-h_{1}}{\Delta h_{0}}=\frac{\frac{1}{2}\left[\left(U_{2}^{2}-U_{1}^{2}\right)+\left(W_{1}^{2}-W_{2}^{2}\right)\right]}{\Delta h_{0}}
$$

where, $h$ and $h_{0}$ are the static and total enthalpies respectively. The degree of reaction indicates how the stage pressure drop is split between the nozzle and rotor blade rows. The degree of reaction can range from $0-1$. Values near zero indicate that the majority of the pressure drop occurs through the nozzle blade row. As the degree of reaction increases more of the stage pressure drop occurs through the rotor blade row. If the degree of reaction is selected the exit angle is uncontrolled and can be calculated from the final velocity triangles, and vice versa. Controlling the exit angle is appealing when the flow discharges to a downstream duct. In this situation extra losses will be generated if the flow does not exit the stage axially.

Figure 2.4, the "Smith Chart", was produced to show the effect of work and flow coefficient selection on the efficiency of a compressible-flow axial turbine (Smith, 1965). The Smith Chart contains Rolls Royce efficiency data, from turbomachines developed prior to 1965 , to which curves of constant efficiency have been fitted. It should be noted that the efficiencies quoted on the figure were adjusted to represent the machines' performance as if they had zero tip clearance. The Smith Chart shows the approximate 
efficiency penalty due to increasing stage loading which can be used to aid in the selection of work and flow coefficients for a machine design.

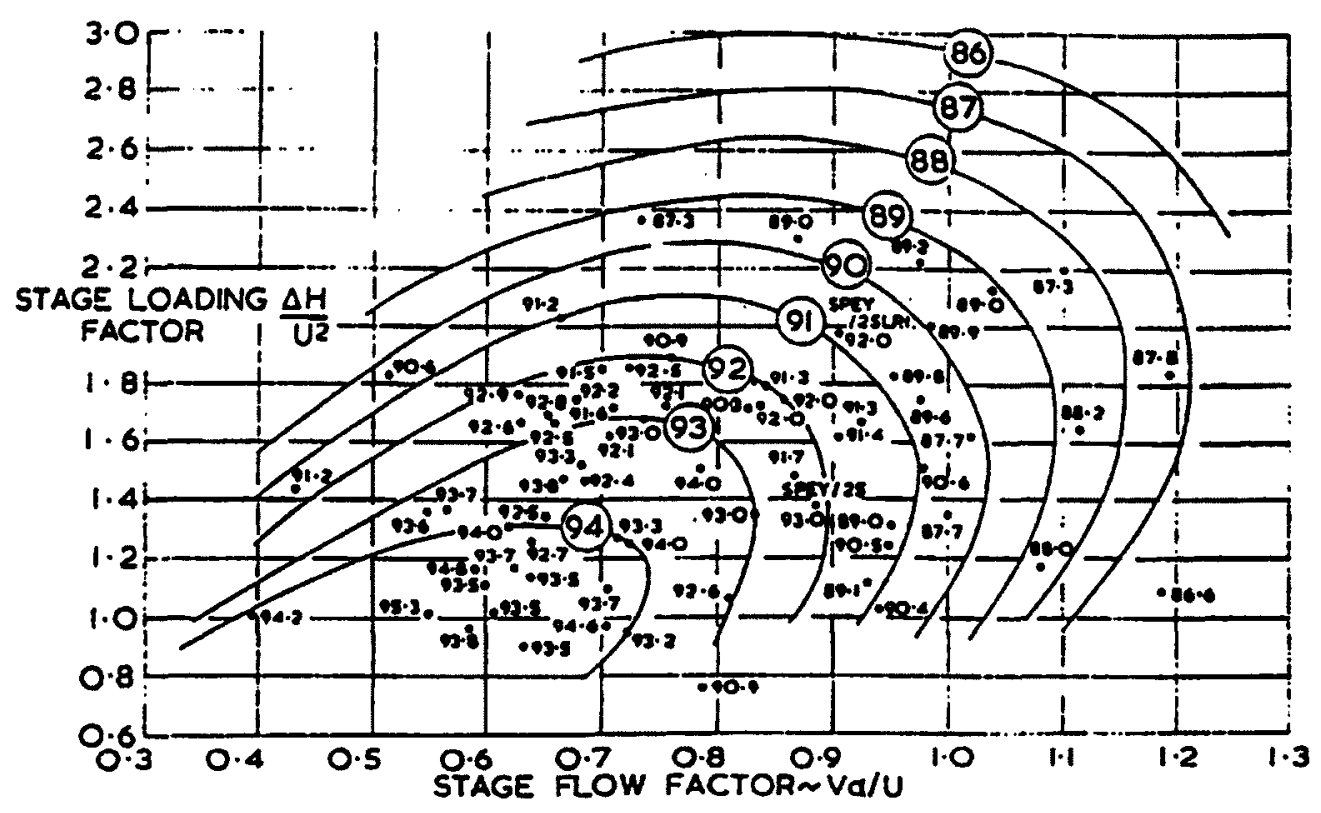

Figure 2.4 Smith Chart (Smith, 1965)

\subsubsection{Meanline Analysis at Off-Design Operating Points}

A machine is running at an off-design operating point when the Reynolds numbers, Mach numbers or incidence do not match the design values. Incidence is caused by a deviation from the design massflow rate or rotational speed. A machine running offdesign will have a different combination of efficiency, power output, and pressure ratio from when it is running at the design point.

The purpose of meanline off-design analysis is to estimate the performance of a meanline design at off-design operating points of massflow rate and rotational speed. The 
velocity triangles for each operating point are calculated using a specified massflow rate and rotational speed along with the metal angles that were determined in the meanline design analysis. The work coefficient, flow coefficient and degree of reaction for each operating point can be calculated from the off-design velocity triangles. Figure 2.5 shows the effect of reducing the massflow rate on the velocity triangles. The dashed vectors represent the design point and the solid vectors are the off-design velocity triangles.
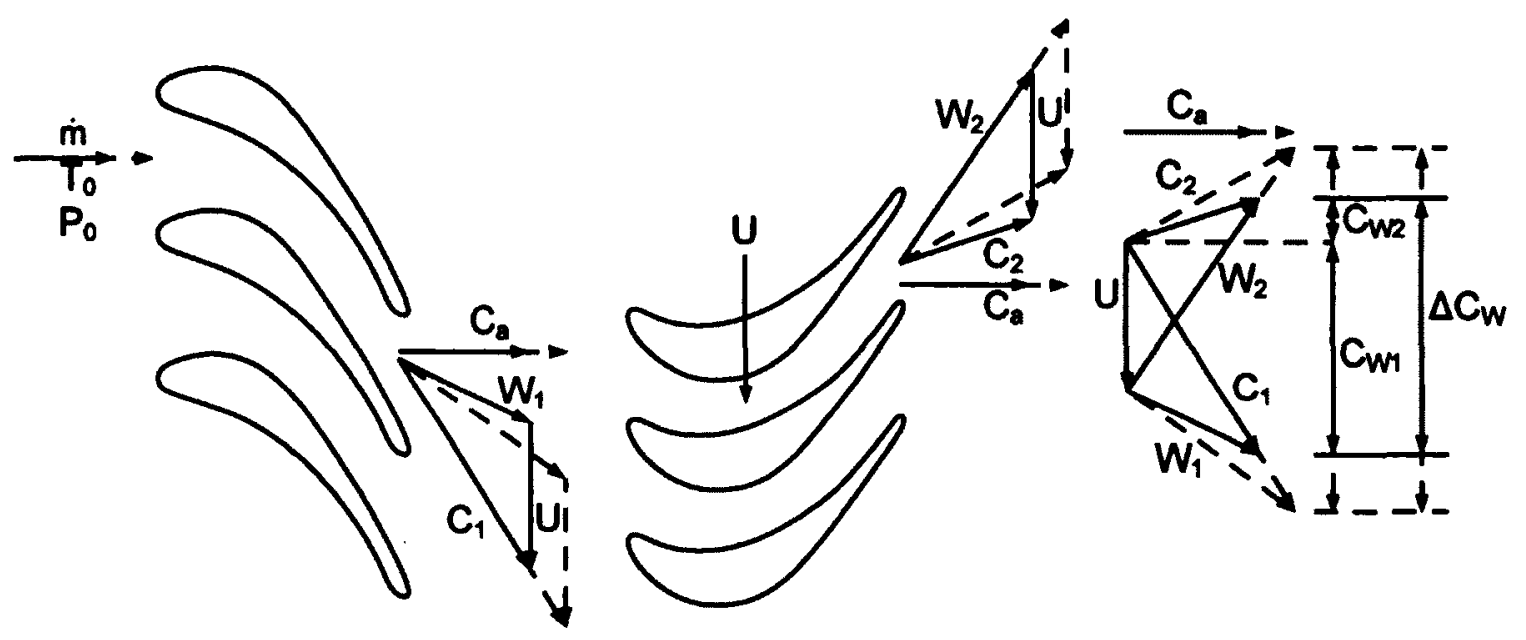

Figure 2.5 Example Off-Design Velocity Triangles for a Single Stage Axial Turbine

Using the off-design velocity triangles and total pressure loss correlations, discussed in Sections 2.5 and 2.6, one can estimate the power output, efficiency and pressure ratio at every operating point. A turbine characteristic, shown in Figure 2.6, is a graphical representation of the results from the off-design analysis. It uses curves of constant normalized rotational speed to show how the normalized massflow rate and efficiency vary with pressure ratio. 


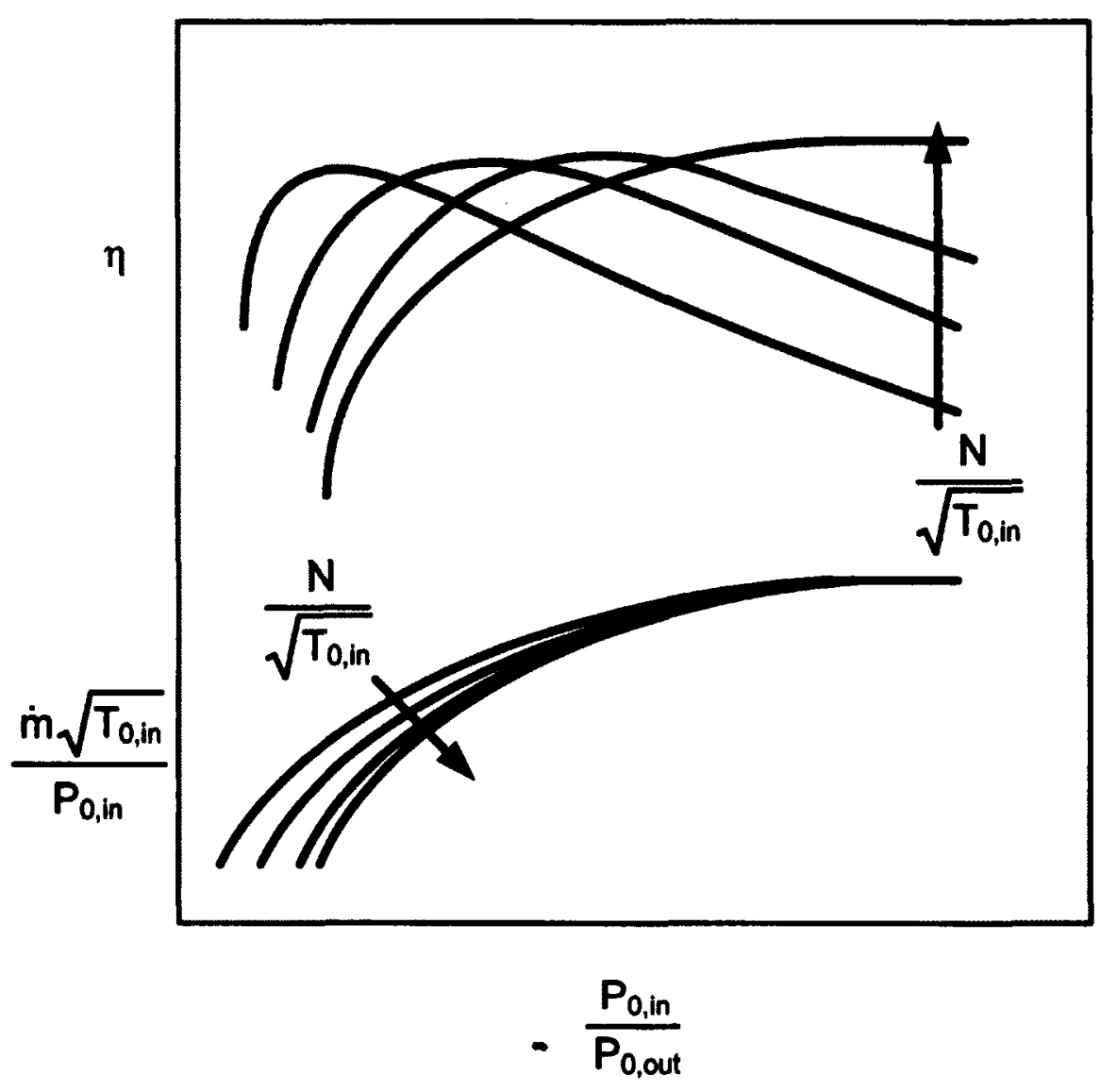

Figure 2.6 Example Turbine Characteristic

$\mathrm{N}$ is rotation speed, $\eta$ is efficiency, $T_{0}$ is total temperature at the rotor exit, $P_{0, \text { in }}$ and $P_{0, \text { out }}$ are the total pressures at the inlet and outlet of the stage, and $\dot{m}$ is massflow rate.

\subsection{Ainley \& Mathieson and Kacker \& Okapuu Loss Systems}

\subsubsection{Introduction}

Total pressure losses occur whenever entropy is generated. The major contributors to entropy generation through a turbine stage are boundary layers on the blades, shock 
waves and mixing out of the vortices caused by secondary flows and tip leakage. As entropy can not be measured directly, the pressure drop across a blade row is used as an indirect measure of the entropy generation. The turbine total pressure loss coefficient, $Y$, is defined as:

$$
\mathbf{Y}=\frac{\mathbf{P}_{01}^{n}-\mathbf{P}_{02}^{\prime \prime}}{\mathbf{P}_{02}^{n}-\mathbf{P}_{2}^{*}}
$$

where, $\mathrm{P}_{0}^{\prime \prime}$ and $\mathrm{P}^{n}$ are mass-averaged total and static pressures, and subscripts 1 and 2 denote inlet and outlet conditions.

Correlations have been developed between components of total pressure loss, flow parameters, e.g. Reynolds number, and the geometry of the blade rows. The correlations can be used to optimize the meanline design by varying the geometry and flow parameters to minimize the predicted losses. Certain loss systems have stood the test of time and are widely employed by many designers. In the case of turbine design the most commonly used loss system is an updated version of the Ainley and Mathieson system. The Turbine Meanline Design (TMLD) program uses an updated version of the Ainley and Mathieson loss system to predict the total pressure losses for a potential design. Only the Ainley and Mathieson system and recent updates to it are discussed in this thesis.

Ainley and Mathieson (1951) developed a loss system based on measurements in turbine nozzle and impulse cascade rows from the 1940s and early 1950s. The three 
major components of the pressure losses, namely the profile, secondary, and tip clearance losses, are added linearly to produce the overall total pressure loss:

$$
\mathrm{Y}_{\text {Total }}=\mathrm{Y}_{\mathrm{P}}+\mathrm{Y}_{\mathrm{S}}+\mathrm{Y}_{\mathrm{TC}}
$$

where, $Y_{P}, Y_{S}$, and $Y_{T C}$ are the profile, secondary, and tip clearance losses respectively.

Dunham and Came (1970) used loss measurements from the 1960s to update the Ainley and Mathieson loss system. The form of the individual correlations remained the same but slight modifications were added to account for the improvements in blade design. Dunham and Came also introduced a Reynolds number correction which was applied to the profile and secondary loss estimates.

An update to the design point portion of the Ainley and Mathieson loss system was performed by Kacker and Okapuu (1982). In the Ainley and Mathieson loss system the losses due to the trailing edge thickness are included in the profile loss correlation. Kacker and Okapuu opted to remove the trailing edge loss from the profile loss and make the trailing edge loss a separate component. The motivation for this change was the introduction of cooled blades. The thicker trailing edges of cooled blades produce greater loss than what the Ainley and Mathieson correlation could capture. Therefore, in the Kacker and Okapuu loss system there are four components:

$$
Y_{\text {Total }}=Y_{p} f\left(R e_{c}\right)+Y_{S}+Y_{\text {TET }}+Y_{T C}
$$

where, $\mathrm{f}\left(\mathrm{Re}_{\mathrm{c}}\right)$ is a Reynolds number correction and $\mathrm{Y}_{\mathrm{TET}}$ is trailing edge thickness loss. 


\subsubsection{Profile Losses}

Ainley and Mathieson's profile loss correlation uses a weighted average of the measured loss results for axial inflow nozzle and impulse cascades. Axial inflow nozzles produce the maximum flow acceleration through the blade passage and impulse blades produce zero acceleration for a given flow outlet angle. Therefore, all blade designs should fall within these two extremes. Examples of an axial inflow nozzle and an impulse blade are shown in Figure 2.7: $\mathrm{A}$ is area, the subscripts Noz and Imp denote the nozzle and impulse blades, and the subscripts 1 and 2 denote the inlet and exit of the blade row.

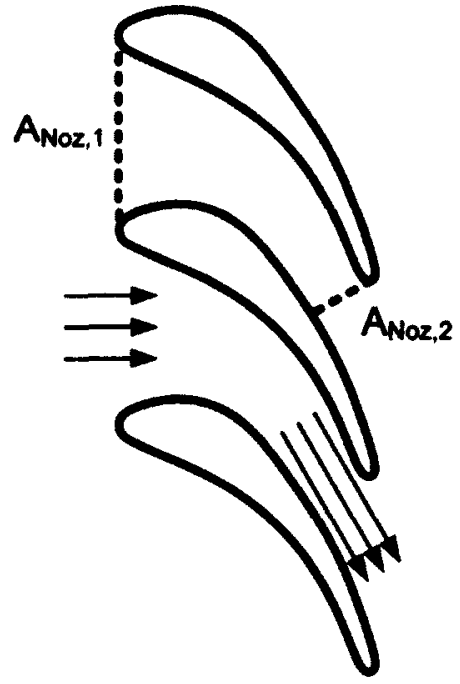

Nozzle
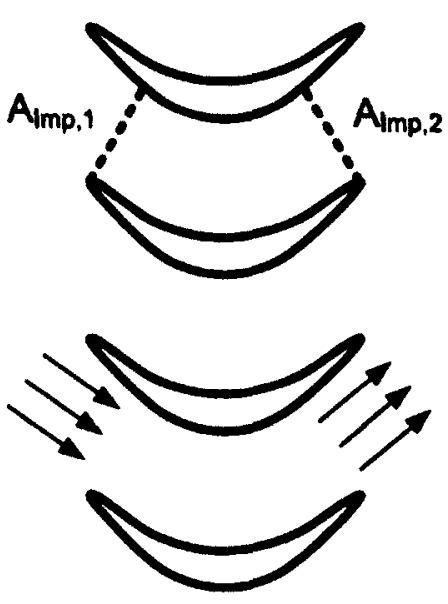

Impulse

Figure 2.7 Example Axial Inflow Nozzle and Impulse Blade Geometry

Figure 2.8 shows the Ainley and Mathieson profile loss data for both axial inflow nozzles and impulse blades. The profile loss coefficient is plotted against the spacing to chord ratio, $\mathrm{S} / \mathrm{c}$, with curves of constant exit flow angle. 


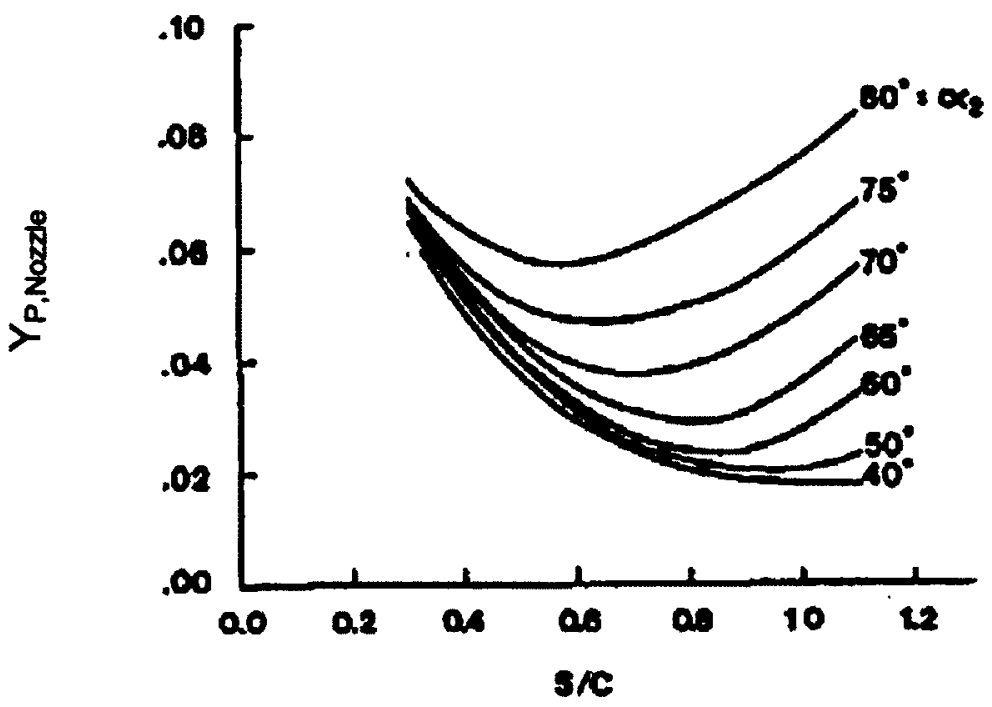

a. Axial Inflow Nozzle Blades, $\alpha_{1}=0^{\circ}, t_{\max } / c=0.2$

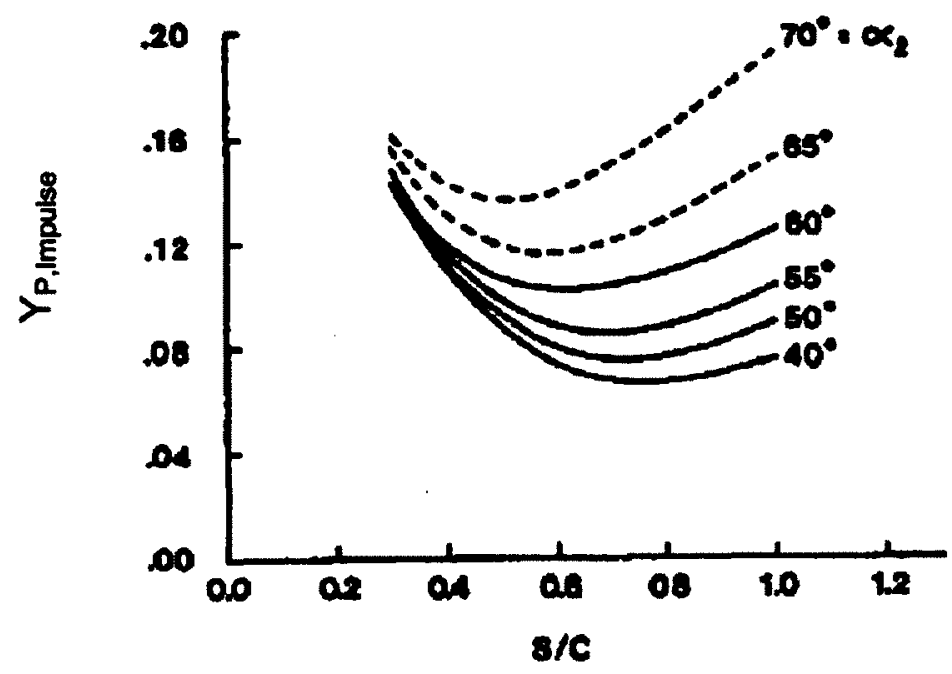

b. Impulse Blades, $\beta_{1}=\alpha_{2}, t_{\max } / c=0.2$

Figure 2.8 Ainley and Mathieson Profile Loss Coefficient (Kacker and Okapuu, 1982)

The profile loss coefficient for an arbitrary combination of inlet and outlet flow angles is calculated from: 


$$
Y_{P, A M}=\left[Y_{P, \text { oozze }}+\left(\frac{\beta_{1}}{\alpha_{2}}\right)^{2}\left(Y_{P, \text { impulse }}-Y_{P, \text { nozzle }}\right)\right]\left(\frac{t_{\max } / c}{0.2}\right)^{\frac{\beta_{1}}{a_{2}}}
$$

The profile losses predicted using the Ainley and Mathieson system accounted for boundary layer interaction, sudden expansion of the fluid at the trailing edge, and downstream mixing of the wake. Kacker and Okapuu found it desirable to separate the trailing edge and wake mixing losses from the profile losses. With the introduction of blade cooling the thickness of the trailing edge increased. Thicker trailing edges produce additional losses that are not accounted for by the Ainley and Mathieson correlation. Kacker and Okapuu applied a multiplication factor of 0.914 to Ainley and Mathieson's profile loss parameter, $\mathrm{Y}_{\mathrm{P}, \mathrm{AM}}$, to remove the estimated trailing edge contribution. They then introduced a separate trailing edge loss correlation which can predict the losses for either cooled or uncooled blades. They also concluded that advances in blade design had reduced the profile losses by about one third.

Kacker and Okapuu discuss the effects of compressibility on leading edge shock waves and channel flow acceleration. The acceleration of a subsonic flow through a blade passage increases as the Mach number increases. Flow acceleration tends to thin boundary layers and suppress local separations. Therefore, operating close to sonic conditions at the exit of the blade row will reduce the profile losses. The Kacker and Okapuu profile loss coefficient is given by:

$$
Y_{P, K O}=0.914\left(\frac{2}{3} Y_{P, A M} K_{P}+Y_{\text {SHOCK }}\right) f\left(R e_{c}\right)
$$


where, $\mathrm{K}_{\mathrm{P}}$ captures the effects of channel acceleration and $\mathrm{Y}_{\mathrm{SHOCK}}$ captures the losses due to leading edge shock waves.

Kacker and Okapuu modified the Dunham and Came Reynolds number correction which is applied to the predicted profile loss. The modified version is,

$$
\begin{aligned}
f\left(R e_{c}\right) & =\left(\frac{R e_{c}}{2 \times 10^{5}}\right)^{-0.4} \text { for } \operatorname{Re}_{c} \leq 2 \times 10^{5} \\
& =1.0 \quad \text { for } 2 \times 10^{5}<\operatorname{Re}_{c}<10^{6} \\
& =\left(\frac{\operatorname{Re}_{c}}{10^{6}}\right)^{-0.2} \quad \text { for } \operatorname{Re}_{c}>10^{6}
\end{aligned}
$$

where, $\operatorname{Re}_{\mathrm{c}}$ is the Reynolds number based on chord length.

\subsubsection{Trailing Edge Losses}

The working fluid experiences a sudden area expansion as it exits the blade passage due to the finite thickness of the trailing-edge. Kacker and Okapuu correlated the loss due to sudden expansion with the ratio of trailing-edge thickness to throat opening, $t_{T E} / 0$. They did this for both impulse and axial inflow nozzle cascades as shown in Figure 2.9.

The trailing edge loss for all blade designs between an impulse and axial inflow nozzle is calculated using a weighted average scheme similar to the one used for the profile losses. The loss is expressed in terms of a change in kinetic energy loss coefficient, $\Delta \varphi^{2}$ TET, given by, 


$$
\Delta \varphi^{2} \text { TET }=\Delta \varphi^{2} \text { TET, nozzle }+\left(\frac{\beta_{1}}{\alpha_{2}}\right)^{2}\left(\Delta \varphi^{2} \text { TET, impulle }-\Delta \varphi^{2} \text { TET, nozke }\right)
$$

where, $\alpha_{2}$ is the flow angle at the exit of the blade row and $\beta_{1}$ is the inlet metal angle of the blade row. The energy loss coefficient can be converted to a total pressure loss coefficient using the following,

$$
Y=\frac{\left[1-\frac{\gamma-1}{2} \mathbf{M}_{2}^{2}\left(\frac{1}{1-\Delta \varphi^{2}}-1\right)\right]^{\frac{\gamma}{\gamma-1}}-1}{1-\left(1+\frac{\gamma-1}{2} M_{2}^{2}\right)^{\frac{\gamma}{\gamma-1}}}
$$

where, $M_{2}$ is Mach number at the exit of the blade row and $\gamma$ is the ratio of specific heats.

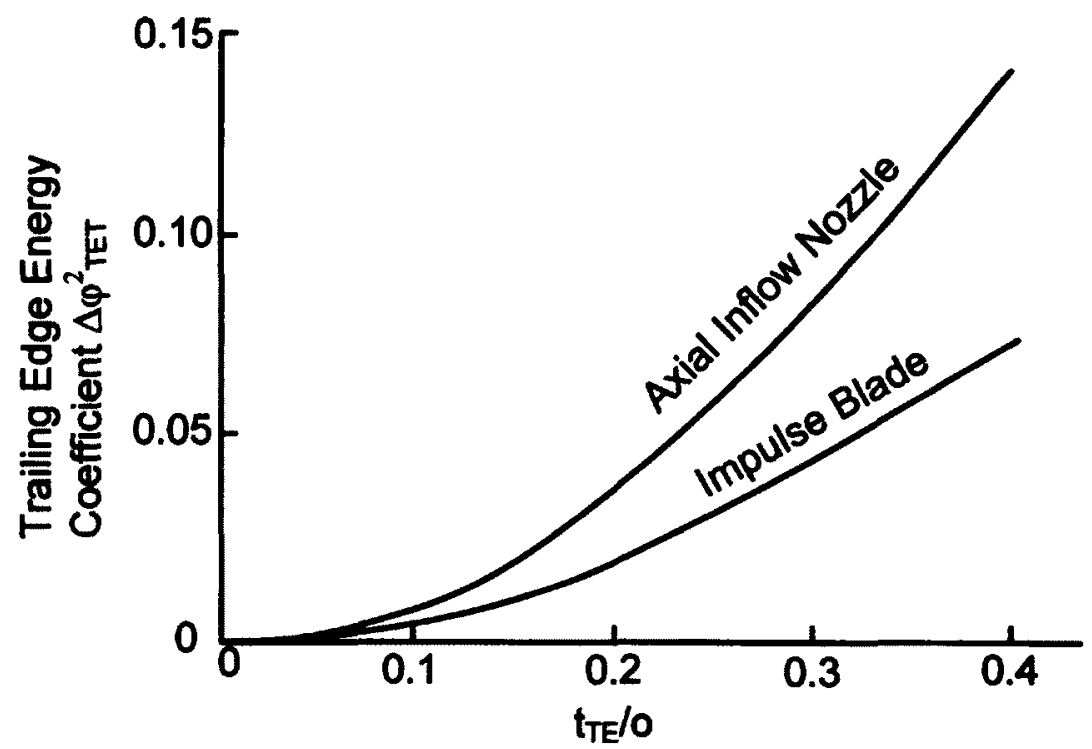

Figure 2.9 Trailing Edge Loss [Energy] Coefficient Correlated Against Trailing Edge Thickness to Throat Opening Ratio (Reproduced from Kacker and Okapuu, 1982) 
For incompressible flows Equation 2.15 reduces to:

$$
Y=\frac{1}{1-\Delta \varphi^{2}}-1
$$

\subsubsection{Secondary Losses}

Secondary losses are generated by viscous effects in the endwall boundary layer and from mixing out of the vortices that make up the secondary flow. Ainley and Mathieson's secondary loss correlation is expressed as:

$$
\begin{gathered}
Y_{s, A M}=\lambda\left(\frac{C_{L}}{S / c}\right)^{2} \frac{\cos ^{2} \alpha_{2}}{\cos ^{3} \alpha_{m}} \\
\frac{C_{L}}{S / c}=2\left(\tan \alpha_{1}+\tan \alpha_{2}\right) \cos \alpha_{m} \\
\alpha_{m}=\tan ^{-1}\left[\frac{1}{2}\left(\tan \alpha_{1}-\tan \alpha_{2}\right)\right]
\end{gathered}
$$

where, $\lambda$ is a function of inlet and outlet annulus geometry which is presented graphically in the Ainley and Mathieson (1951) paper, $\frac{C_{\mathrm{L}}}{\mathrm{S} / \mathrm{c}}$ is the lift coefficient over the spacing-tochord ratio, $\alpha_{1}, \alpha_{2}$ and $\alpha_{m}$ are the flow angles at the inlet, outlet and vector mean respectively. By substituting Equation 2.18 into Equation 2.17 one can see that the Ainley and Mathieson secondary loss correlation is a function of flow angles and $\lambda$ only. This approach has remained through both major modifications of the loss system. 
When Dunham and Came (1970) performed their update to the Ainley and Mathieson system they replaced the $\lambda$ term with a constant, a ratio of the inlet and outlet flow angles and the reciprocal of the blade aspect ratio. The Dunham and Came secondary loss correlation is:

$$
Y_{g, D C}=0.0334\left(\frac{c}{h}\right)\left(\frac{\cos \alpha_{2}}{\cos \beta_{1}}\right)\left(\frac{C_{L}}{S / c}\right)^{2} \frac{\cos ^{2} \alpha_{2}}{\cos ^{3} \alpha_{m}}
$$

where, $\mathrm{c}$ is chord and $\mathrm{h}$ is blade height. The authors noted that the correlation over predicted the losses for blades with an aspect ratio less than 2.0 .

Kacker and Okapuu modified the Dunham and Came secondary loss correlation in three ways. First, they implemented a different aspect ratio function for blades with an aspect ratio less than 2.0. Second, they separated the secondary losses from the trailing edge losses. In the Dunham and Came loss system the trailing edge loss coefficient was multiplied by the secondary loss coefficient. Kacker and Okapuu found that multiplying the secondary loss coefficient by a factor of 1.2 compensated for separating the trailing edge and secondary losses. Finally, in a similar fashion to the profile losses, Kacker and Okapuu included a term to capture the compressibility effects. Kacker and Okapuu's secondary loss correlation is given by:

$$
\mathrm{Y}_{\mathrm{s}, \mathrm{Ko}}=1.2\left(0.0334 \mathrm{f}(\mathrm{AR})\left(\frac{\cos \alpha_{2}}{\cos \beta_{1}}\right)\left(\frac{\mathrm{C}_{\mathrm{L}}}{\mathrm{S} / \mathrm{c}}\right)^{2} \frac{\cos ^{2} \alpha_{2}}{\cos ^{3} \alpha_{\mathrm{m}}}\right) \mathrm{K}_{\mathrm{s}}
$$




$$
\begin{aligned}
f(A R) & =\frac{1-0.25 \sqrt{2-h / c}}{h / c} & \text { for } h / c \leq 2.0 \\
& =\frac{1}{h / c} \quad & \text { for } h / c>2.0
\end{aligned}
$$

where, $K_{S}$ captures the compressibility effects. Figure 2.10 shows how the Dunham and Came function for aspect ratio behaves compared to the Kacker and Okapuu function for blades with an aspect ratio less than 2.0 .

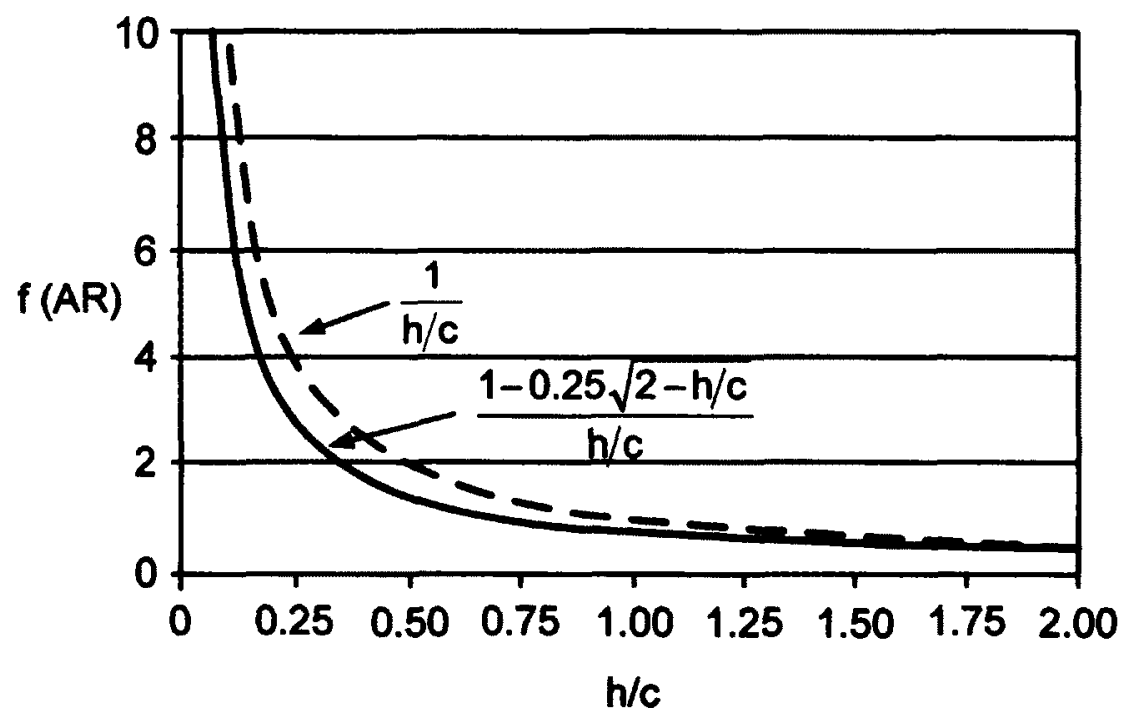

Figure 2.10 Aspect Ratio Functions for Aspect Ratios Less Than 2.0

\subsubsection{Tip Clearance Losses}

Tip clearance losses are generated in the tip gap and by the subsequent mixing out of the vortex that is formed from flow leakage between the rotor blade tip and the gas path 
wall. Minimizing the tip gap or using shrouded blades minimizes flow leakage and hence tip clearance losses. A shroud is a small segment at the tip of each blade. Each shroud links to the adjacent shroud forming a peripheral ring around the blade tips. The shrouds have a number of knife edges which act as seals by cutting small grooves into the gas path wall. Fluid leakage between the wall and the knife edges is still present but is significantly reduced compared to unshrouded blades. Kacker and Okapuu provide a correlation for both shrouded and unshrouded blades.

For shrouded blades the following correlation is used,

$$
\begin{gathered}
Y_{\mathrm{TC}}=0.37 \frac{\mathrm{c}}{\mathrm{h}}\left(\frac{\tau^{\prime}}{\mathrm{c}}\right)^{0.78}\left(\frac{\mathrm{C}_{\mathrm{L}}}{\mathrm{S} / \mathrm{c}}\right)^{2} \frac{\cos ^{2} \alpha_{2}}{\cos ^{3} \alpha_{\mathrm{m}}} \\
\tau^{\prime}=\frac{\tau}{\text { seals }^{0.42}}
\end{gathered}
$$

where $h$ is the blade height, $\tau$ is the height of the tip gap and "seals" represents the number of knife edges on the shroud.

For unshrouded blades the following equation is used,

$$
\frac{\Delta \eta}{\eta_{0}}=0.93 \frac{\tau}{h \cos \alpha_{2}} \frac{r_{1}}{r_{m}}
$$

where $\eta_{0}$ is the stage efficiency with zero tip clearance losses, $\Delta \eta$ is the change in the efficiency due to tip clearance and $r$ is radius. The subscripts $t$ and $m$ denote tip and meanline. The procedure for applying Equation 2.25 is iterative because neither $\Delta \eta$ nor $\alpha_{2}$ 
are known. Changing $\Delta \eta$ will change the shape of the velocity triangles thus changing $\alpha_{2}$. The iteration procedure is as follows:

1. Calculate the velocity triangles and stage efficiency with zero tip clearance.

2. Using Equation 2.25 calculate $\Delta \eta$ using the actual tip clearance.

3. Guess a value for $Y_{t c}$ and add it to the previous $Y_{\text {Total }}$.

4. Use the new $Y_{\text {Totoal }}$ to recalculate the velocity triangles.

5. Compare the new stage efficiency to the predicted efficiency $\left(\eta_{\text {predicted }}=\eta_{0}-\Delta \eta\right)$.

6. Modify $Y_{t c}$ and repeat steps $3-5$ until the efficiency has converged.

\subsection{Recent Loss Correlations}

\subsubsection{Introduction}

This section provides information on some of the more recent total pressure loss correlations. The correlations discussed in this section can be used in both turbine meanline analysis programs, i.e. Turbine Meanline Design (TMLD) and Turbine Meanline Off-Design (TMLO). Section 2.6.2 discusses the Zhu and Sjolander update to the Kacker and Okapuu profile loss correlation. Section 2.6.3 summarizes the Benner, Sjolander and Moustapha secondary loss correlation along with their update to the Kacker and Okapuu overall total pressure loss breakdown. Yaras and Sjolander's approach to estimating the tip clearance total pressure loss coefficient is introduced in Section 2.6.4. This section also includes an update by Kim and Chung to the Yaras and 
Sjolander tip clearance correlation. Finally, Section 2.6 .5 provides information on the Benner, Sjolander and Moustapha correlation for off-design total pressure losses.

\subsubsection{Zhu \& Sjolander Profile Loss Update}

Zhu and Sjolander (2005) presented an updated version of Kacker and Okapuu's profile loss correlation. The updated correlation addressed three areas of concern: the optimistic prediction of the profile losses for axial inflow nozzles, accurately capturing the effect of low Reynolds numbers, and the over prediction of the losses for blades with high maximum thickness to chord ratios. A comparison of the correlations is shown in Table 2.1. Equations 2.26 and 2.27 are the general form of both the Kacker and Okapuu and Zhu and Sjolander correlations.

$$
\begin{aligned}
& Y_{P}=0.914\left(K_{i m} Y_{P, A M} K_{P}+Y_{\text {SHOCK }}\right) f\left(\operatorname{Re}_{c}\right) \\
& Y_{P, A M}=\left[K_{i n, N} Y_{P, \text { nozzle }}+\left(\frac{\beta_{1}}{\alpha_{2}}\right)^{2}\left(K_{i,, I} Y_{P, \text { impulse }}-K_{i n, N} Y_{P, \text { nozzle }}\right)\right]\left(\frac{t_{m a x} / c}{0.2}\right)^{K_{m} \frac{\beta_{1}}{\alpha_{2}}}
\end{aligned}
$$

where, $\mathbf{K}_{\mathrm{m}}$ depends on the maximum thickness to chord ratio and $\mathbf{K}_{\mathrm{in}}, \mathbf{K}_{\mathrm{in,l}, \mathrm{l}}$ and $\mathbf{K}_{\mathrm{in,N}, \mathrm{N}}$ are coefficients applied to the Ainley and Mathieson profile loss predications to account for improvements in airfoil design.

As mentioned above, Zhu and Sjolander found that the loss predictions of axial inflow nozzle blades were optimistic. By removing the $2 / 3$ reduction that was applied to the Ainley and Mathieson pressure loss correlation, $K_{\text {in }}$, and replacing it with nozzle and 


\begin{tabular}{|c|c|}
\hline Kacker and Okapuu & Zhu and Sjolander \\
\hline $\begin{aligned} K_{i n} & =2 / 3 \\
K_{i n, I} & =1.0 \\
K_{i n, N} & =1.0\end{aligned}$ & $\begin{array}{c}\mathrm{K}_{\mathrm{in}}=1.0 \\
\mathrm{~K}_{\mathrm{in, \textrm {I }}}=2 / 3 \\
\mathrm{~K}_{\mathrm{in}, \mathrm{N}}=0.825\end{array}$ \\
\hline$K_{m}=1$ & $\begin{array}{l}K_{m}=1 \text { for } t_{\max } / c \leq 0.2 \\
K_{m}=-1 \text { for } t_{\max } / c>0.2\end{array}$ \\
\hline $\begin{aligned} f\left(\operatorname{Re}_{c}\right) & =\left(\frac{\operatorname{Re}_{c}}{2 \times 10^{5}}\right)^{-0.4} \text { for } \operatorname{Re}_{c} \leq 2 \times 10^{5} \\
& =1.0 \text { for } 2 \times 10^{5} \operatorname{Re}_{c}<10^{6} \\
& =\left(\frac{\operatorname{Re}_{c}}{10^{6}}\right)^{-0.2} \text { for } \operatorname{Re}_{c} \geq 10^{6}\end{aligned}$ & $\begin{aligned} \mathbf{f}\left(\operatorname{Re}_{\mathrm{c}}\right) & =\left(\frac{\operatorname{Re}_{\mathrm{c}}}{2 \times 10^{5}}\right)^{-0.575} \text { for } \operatorname{Re}_{\mathrm{c}}<2 \times 10^{5} \\
& =\left(\frac{\operatorname{Re}_{\mathrm{c}}}{2 \times 10^{5}}\right)^{-0.4} \text { for } \operatorname{Re}_{\mathrm{c}} \geq 2 \times 10^{5}\end{aligned}$ \\
\hline
\end{tabular}

Table 2.1 Differences Between Kacker \& Okapuu and Zhu \& Sjolander Profile Loss Correlations

impulse blade specific reductions, $\mathbf{K}_{\mathrm{in,N}}$ and $\mathrm{K}_{\mathrm{in,l}, \mathrm{l}}$, the predicted losses displayed a better fit with the measured data. Introducing $K_{m}$ to the correlation resulted in a more accurate prediction of the losses for blades with a maximum thickness-to-chord ratio greater than 0.2. The Kacker and Okapuu correlation over predicted the losses for these types of blades. Finally, the Reynolds number correction was modified for the full range of Reynolds numbers.

\subsubsection{Benner, Sjolander \& Moustapha Secondary Loss Update}

The Kacker and Okapuu total pressure loss breakdown scheme assumes that profile losses at any point along the span of the blade are equal to the profile losses at the mean radius. This is physically unrealistic in that the endwall vortical structures that make up 
the secondary flow penetrate spanwise into the blade profile flow. Benner et al. (2005a \& b) argue that losses generated on the portion of the blade surface covered by endwall vortices should not be included in the traditional profile losses. When the traditional breakdown method is used for predicting losses at off-design conditions, especially with positive incidence, the secondary loss coefficient, taken as the difference between the profile and overall loss coefficient, can work out to be negligible or even negative (Benner et al. 2005a). A new loss prediction method was developed by Benner, Sjolander, and Moustapha (Benner et al. 2005a \& b) in an attempt to more accurately capture the secondary losses.

Benner uses straight separation lines to approximate the extent of the spanwise penetration of the endwall vortices on the blade surface, as shown in Figure 2.11. The figure shows the regions of primary and secondary flow on the suction surface of an airfoil. The lengths $Z_{T E}$ are the penetration depths of the secondary vortices from endwalls at the trailing edge.

Benner's correlation for penetration depth is:

$$
\frac{Z_{\mathrm{TE}}}{\mathrm{h}}=\frac{0.10\left(\mathrm{~F}_{1}\right)^{0.79}}{\sqrt{\mathrm{CR}}\left(\frac{\mathrm{h}}{\mathrm{c}}\right)^{0.55}}+32.70\left(\frac{\delta^{*}}{\mathrm{~h}}\right)^{2}
$$

where

$$
F_{1}=2\left(\frac{S}{c_{x}}\right) \cos ^{2} \alpha_{m}\left(\tan \alpha_{1}-\tan \alpha_{2}\right)
$$




$$
\begin{gathered}
\mathrm{CR}=\frac{\cos \alpha_{1}}{\cos \alpha_{2}} \\
\alpha_{\mathrm{m}}=\tan ^{-1}\left[\frac{1}{2}\left(\tan \alpha_{1}-\tan \alpha_{2}\right)\right]
\end{gathered}
$$

and, $\mathrm{c}$ is airfoil chord, $\delta^{*} / \mathrm{h}$ is non-dimensional inlet endwall boundary layer displacement thickness, $h$ is airfoil height, $S$ is airfoil spacing, $c_{x}$ is airfoil axial chord, and $\alpha_{1}$ and $\alpha_{2}$ are the inlet and outlet flow angles.

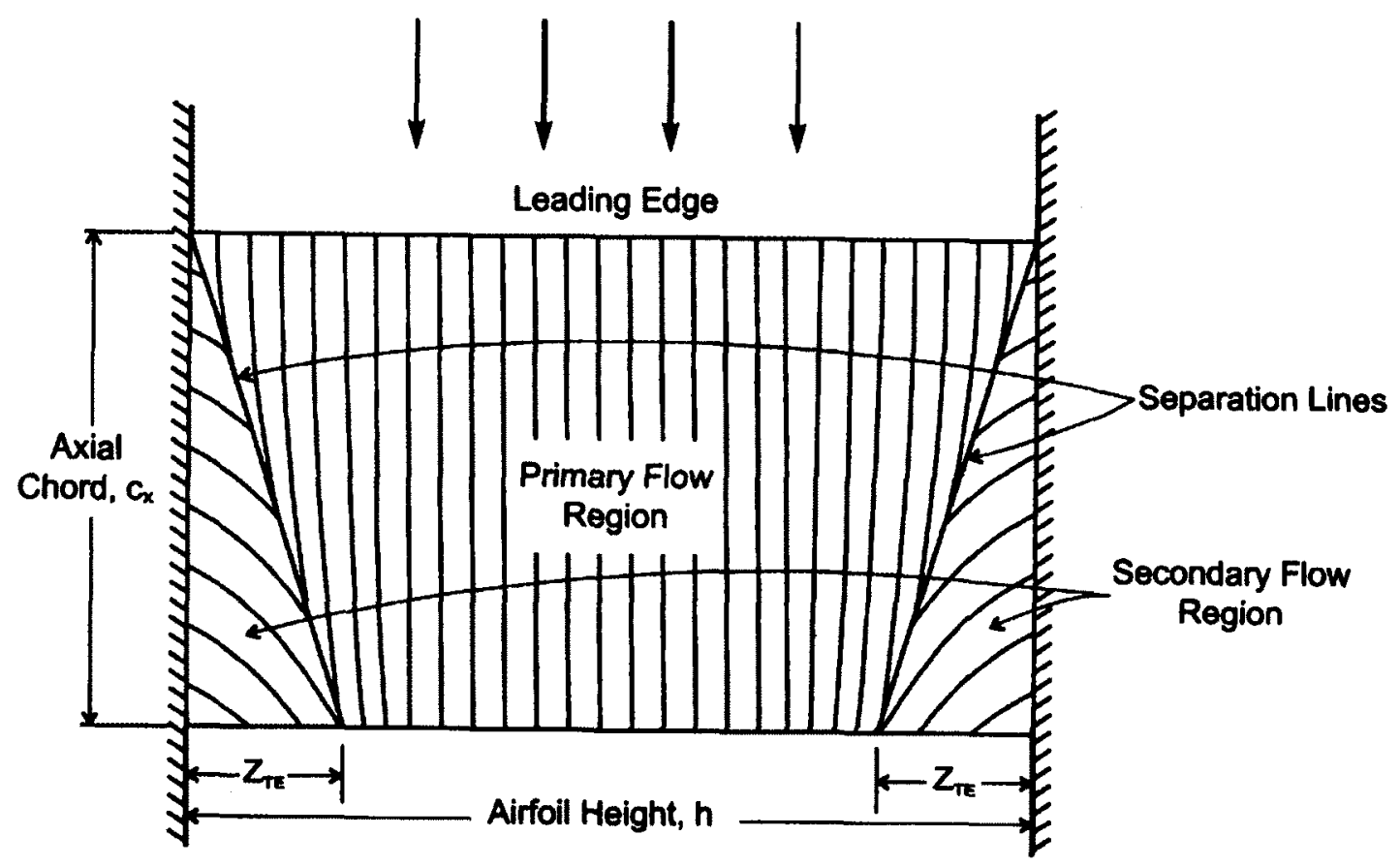

Figure 2.11 Depiction of Penetration Depth on the Suction Surface of an Airfoil (Reproduced from Benner 2003)

To account for the presence of endwall vortices the profile losses are reduced by the fraction of airfoil surface area occupied by the secondary flow. Benner's formula for the total pressure loss is: 


$$
Y_{\text {Towa }}=Y_{P} f\left(\operatorname{Re}_{c}\right)\left(1-\frac{Z_{T E}}{h}\right)+Y_{S}+Y_{T E T}+Y_{T C}
$$

This would replace the loss breakdown given by Equation 2.10. Benner developed a new secondary loss correlation which is intended to work with the penetration depth correlation (Benner 2005b), as follows:

$$
\begin{aligned}
Y_{s, \mathrm{BSM}} & =\frac{0.038+0.41 \tanh \left(1.20 \delta^{*} / \mathrm{h}\right)}{\sqrt{\cos \gamma}(\mathrm{CR})(\mathrm{h} / \mathrm{c})\left(\frac{\mathrm{c} \cdot \cos \alpha_{2}}{\mathrm{c}_{\mathrm{x}}}\right)^{0.55}} \text { for } \mathrm{h} / \mathrm{c} \leq 2.0 \\
& =\frac{0.052+0.56 \tanh \left(1.20 \delta^{\circ} / \mathrm{h}\right)}{\sqrt{\cos \gamma}(\mathrm{CR})(\mathrm{h} / \mathrm{c})\left(\frac{\mathrm{c} \cdot \cos \alpha_{2}}{\mathrm{c}_{\mathrm{x}}}\right)^{0.55}} \text { for } \mathrm{h} / \mathrm{c}>2.0
\end{aligned}
$$

where, $\gamma$ is the stagger angle of the airfoil.

\subsubsection{Yaras \& Sjolander and Kim \& Chung Tip Clearance Loss Updates}

The Yaras and Sjolander (1992) tip clearance loss correlation estimates losses by calculating the kinetic energy of the component of the flow through the tip gap that is orthogonal to the blade chord. The energy method is based on a better understanding of the flow physics through the tip gap than what was available to Ainley and Mathieson (Yaras and Sjolander, 1992). It is assumed that the kinetic energy of the component of the flow through the tip gap which is orthogonal to the blade chord will eventually mix out and is not recoverable. 
The Yaras and Sjolander correlation breaks the tip clearance losses into two components, $Y_{\text {tip }}$ and $Y_{\text {gap }} . Y_{\text {tip }}$ is the loss from the mixing out of the tip clearance vortex and $Y_{\text {gap }}$ is the loss generated inside the tip gap. The correlations are given by:

$$
Y_{\text {tip }}=2 K_{E} \frac{c}{S} \frac{\tau}{h} C_{D} \frac{\cos ^{2}\left(\alpha_{2}\right)}{\cos ^{3}\left(\alpha_{m}\right)} C_{L}^{1.5}
$$

and

$$
Y_{\text {ap }}=K_{\text {emp }} K_{o} \frac{c}{S} \frac{C_{D} C_{L}{ }^{1 / 2}}{\cos \alpha_{m}} \frac{c}{h}
$$

where

$$
\begin{aligned}
K_{E} & =0.566 \text { for a front- or aft-loaded blade } \\
& =0.5 \text { for a mid-loaded blade } \\
K_{G} & =0.943 \text { for a front- or aft-loaded blade } \\
& =1.0 \text { for a mid-loaded blade } \\
K_{\text {emp }} & \cong 0.007 \\
C_{D} & =0.577
\end{aligned}
$$

and, $\tau$ is tip clearance, $C_{D}$ is the discharge coefficient for the tip gap, and $C_{L}$ is lift coefficient. The two components of the tip clearance losses, $Y_{\text {tip }}$ and $Y_{\text {gap }}$, are added together linearly to get the predicted tip clearance loss,

$$
Y_{\mathrm{TC}, \mathrm{YS}}=\mathrm{Y}_{\mathrm{tip}}+\mathrm{Y}_{\mathrm{gap}}
$$

The Yaras and Sjolander correlation was revisited by Kim and Chung (1997). Kim and Chung took the two components of the Yaras and Sjolander correlation and 
combined them. The effect of the separation bubble inside the tip gap is captured by a tip unloading factor, $\lambda$, introduced by Kim and Chung (1997). This factor varies with incidence but at the design point it has a value of about 0.4 . They also suggested that the value of the tip gap discharge coefficient, $C_{D}$, be changed from 0.577 to 0.67 . The $\mathrm{Kim}$ and Chung correlation is given by,

$$
Y_{\mathrm{TC}, \mathrm{KC}}=2 \mathrm{~K}_{\mathrm{E}} \frac{\mathrm{c}}{\mathrm{S}} \frac{\tau}{\mathrm{h}} \mathrm{C}_{\mathrm{D}} \lambda^{1.5} \frac{\cos ^{2}\left(\alpha_{2}\right)}{\cos ^{3}\left(\alpha_{\mathrm{m}}\right)} \mathrm{C}_{\mathrm{L}}^{1.5}
$$

\subsubsection{Benner, Sjolander \& Moustapha Off-Design Profile Loss Correlation}

When calculating off-design profile losses one first calculates the losses as if the flow was approaching the airfoils at the design flow angle. The additional losses, due to incidence, are added to the design point losses. The design flow angle losses can be calculated using the Kacker and Okapuu or Zhu and Sjolander correlations.

Benner et al. (1997) examined the effects of incidence, leading-edge diameter, and leading-edge wedge angle on the profile losses of airfoils. It was found that the size of both the leading-edge wedge angle and diameter had an effect on the discontinuity in the surface curvatures at the blend points where the leading-edge circle meets the splines that make up the rest of the suction and pressure surfaces. The abrupt change in curvature near the leading-edge causes a separation bubble to form. Typically at design incidence the separation bubble is small. At both positive and negative incidence the separation bubble will grow, although it will always reattach. As the separation bubble grows the losses near the leading-edge increase (Benner et al. 1997). 
The correlation from Benner et al. is given by,

$$
\Delta \varphi_{\mathrm{p}}^{2}=\mathrm{a}_{8} \chi^{8}+\mathrm{a}_{7} \chi^{7}+\mathrm{a}_{6} \chi^{6}+\mathrm{a}_{5} \chi^{5}+\mathrm{a}_{4} \chi^{4}+\mathrm{a}_{3} \chi^{3}+\mathrm{a}_{2} \chi^{2}+\mathrm{a}_{1} \chi
$$

where

$$
\chi=\left(\frac{d_{L E}}{S}\right)^{-0.05} W e^{-0.2}\left(\frac{\cos \beta_{1}}{\cos \beta_{2}}\right)^{-1.4}\left[\alpha_{1}-\alpha_{1, \text { design }}\right]
$$

and

$$
\begin{array}{llll}
a_{8}=3.711 \times 10^{-7} & a_{7}=-5.318 \times 10^{-6} & a_{6}=1.106 \times 10^{-5} & a_{5}=9.017 \times 10^{-5} \\
a_{4}=-1.542 \times 10^{-4} & a_{3}=-2.506 \times 10^{-4} & a_{2}=1.327 \times 10^{-3} & a=-6.149 \times 10^{-5}
\end{array}
$$

for $\chi \geq 0$, and

$$
\Delta \varphi_{\mathrm{p}}^{2}=1.358 \times 10^{-4} \chi^{2}-8.720 \times 10^{-4} \chi
$$

for $\chi<0$. We is leading-edge wedge angle, $\chi$ is an incidence parameter, $d_{L E} / S$ is leadingedge diameter-to-spacing ratio, $\alpha$ is flow angle, $\beta$ is the leading-edge metal angle of the airfoil, and $\Delta \varphi_{\mathrm{p}}^{2}$ is the change in kinetic energy loss coefficient for the profile losses.

The Benner et al. correlation uses the changes in kinetic energy rather than the total pressure loss. As mentioned in Section 2.5.3 kinetic energy can be converted into a total pressure loss coefficient using Equation 2.15.

\subsection{Supercritical Fluids}

Figure 2.12 shows the different states of carbon dioxide in terms of a phase diagram. The supercritical region is defined as the region above both the critical temperature and 
critical pressure of a particular fluid (Taylor, 1996). Carbon dioxide has a critical temperature, $T_{c}$, of $304 \mathrm{~K}$ and a critical pressure, $P_{c}$, of 73.9 bar (Moran and Shapiro, 2004). The combination of $T_{c}$ and $P_{c}$ is called the critical point. Within the supercritical region a fluid is neither a liquid nor a gas but has properties of both (Taylor, 1996). For example a supercritical fluid will fill whatever container it is in, like a gas. However, if the temperature and pressure are near their critical values the density of the fluid will be similar to that of a liquid.

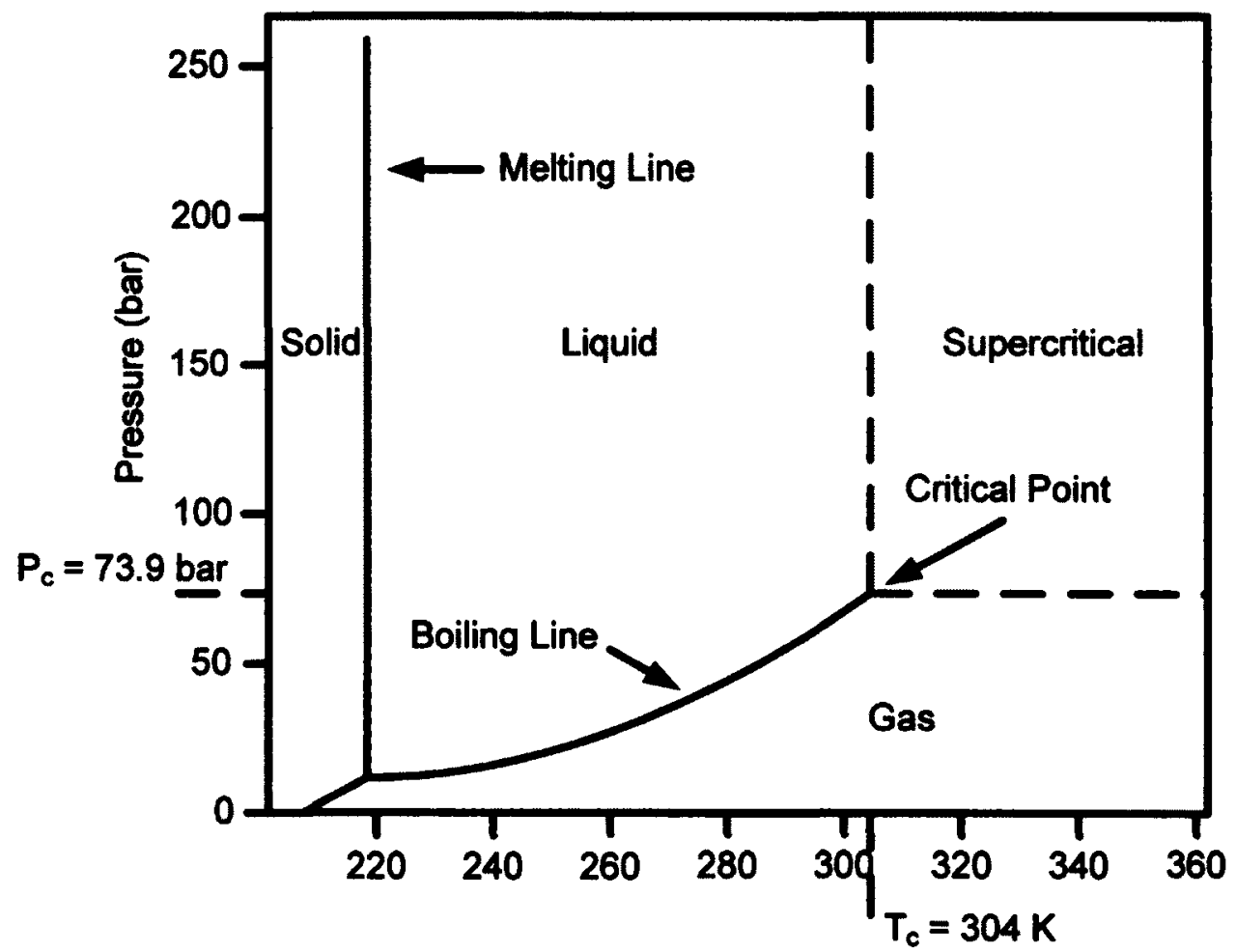

Temperature (K)

Figure 2.12 Carbon Dioxide Phase Diagram (Adapted from Taylor, 1996) 
Near the critical point supercritical fluids exhibit very non-ideal gas behaviour. As the pressure and temperature increase supercritical fluids behave more like ideal gases. The extent to which a fluid behaves like an ideal gas is quantified by the compressibility factor, $Z$, where a value of 1.0 indicates an ideal gas. The variation of $Z$ with temperature and pressure is shown in Figure 2.13, where temperature is expressed in terms of reduced temperature, $T_{R}=T / T_{c}$, and pressure is expressed in terms of reduced pressure, $P_{R}=P / P_{c}$. Figure 2.13 shows the compressor and turbine inlet compressibility factors of the 20082009 Carleton University Fourth-Year Engineering Project Plant from Figure 1.1. The circle represents the compressor inlet and the square represents the turbine inlet.

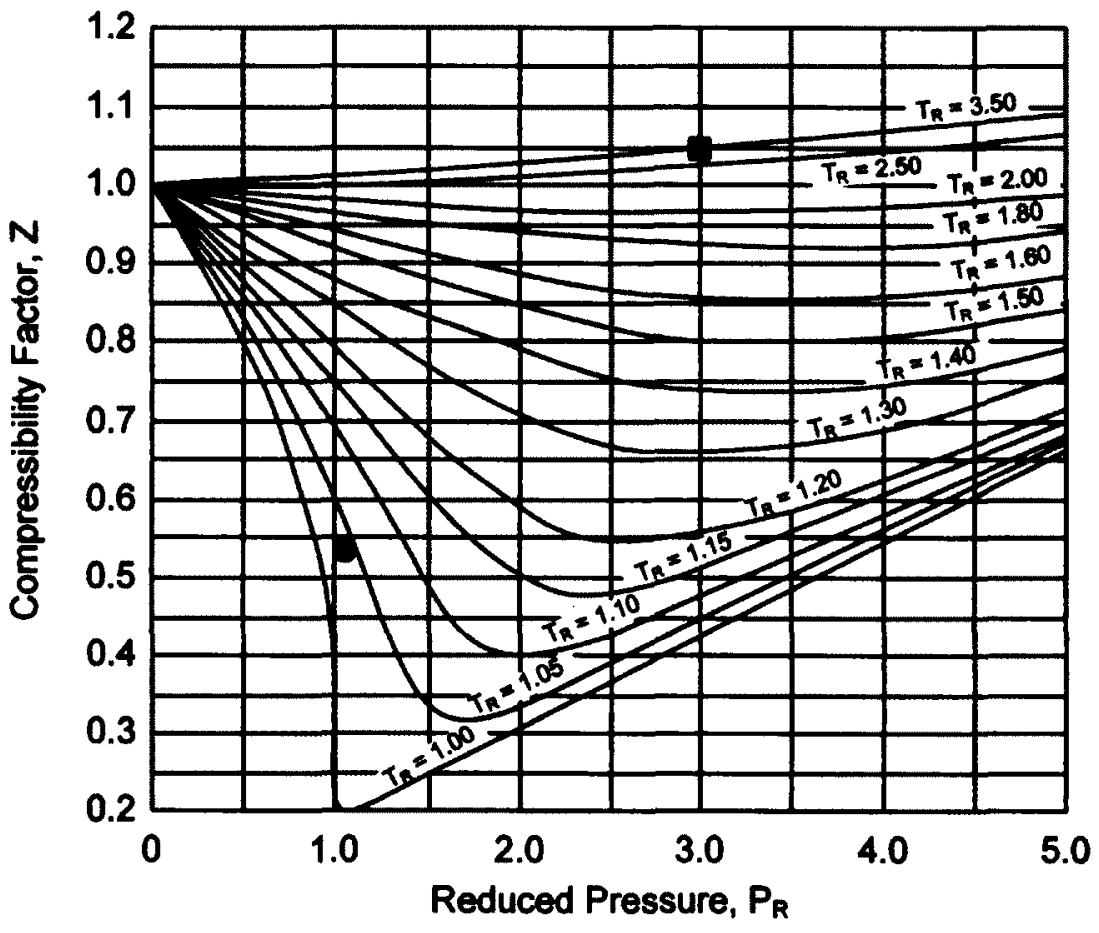

Figure 2.13 Generalized Compressibility Chart (Adapted from Moran and Shapiro, 2004) 
The compressibility factor is sometimes included in the ideal gas equation in an attempt to compensate for non-ideal gas behaviour. While this does increase the accuracy of the density and sonic velocity calculations it does not account for all non-ideal gas behaviour.

\subsection{Designing a Turbomachine with Real Fluid Properties}

Typically when designing an air breathing gas turbine engine the meanline analysis is performed using the ideal gas assumption which states that the enthalpy, internal energy, and entropy of ideal gasses are functions of temperature only (Moran and Shapiro, 2004). Employing this assumption the properties of a working fluid can be estimated using the ideal gas equation, given by:

$$
P=\rho R T
$$

where, $P$ is static pressure, $\rho$ is static density, $R$ is gas constant of the working fluid, and $\mathrm{T}$ is static temperature. There are many applications for turbomachinery where even as an initial assumption treating the working fluid as an ideal gas is not adequate. Below are three approaches employed by Aungier (2000) for dealing with non-ideal fluids when designing centrifugal compressors.

One method is to use a real gas equation of state to calculate modified gas constants (Aungier, 2000). Aungier's modified constants are $\bar{R}, \bar{c}_{p}, \bar{c}_{v}$, and $\bar{\gamma}$, where $\bar{R}$ is the gas constant of the working fluid, $\overline{\mathbf{c}}_{\mathrm{p}}$ is specific heat at constant pressure, $\overline{\mathbf{c}}_{\mathrm{v}}$ is specific heat 
at constant volume, and $\bar{\gamma}$ is an isentropic exponent but not the ratio of the specific heats. To calculate the modified gas constants one must first define the range of the thermodynamic conditions to be approximated. The range must span all of the thermodynamic conditions that will be encountered when using these gas constants. The modified gas constant are calculated using,

$$
\begin{aligned}
& \bar{R}=R\left(Z_{1} Z_{2}\right)^{0.5} \\
& \bar{c}_{p}=\frac{h_{2}-h_{1}}{T_{2}-T_{1}} \\
& \bar{c}_{v}=\frac{u_{2}-u_{1}}{T_{2}-T_{1}} \\
& \bar{\gamma}=\frac{\ln \left(P_{2} / P_{1}\right)}{\ln \left(v_{2} / v_{1}\right)}
\end{aligned}
$$

where, the subscripts 1 and 2 denote the limits of the thermodynamic conditions, $R$ is the gas constant of the working fluid, $\mathrm{Z}$ is compressibility factor, $\mathrm{h}$ is enthalpy, $\mathrm{T}$ is temperature, $u$ is internal energy, $P$ is pressure and $v$ is specific volume. The compressibility factor, enthalpy, internal energy and specific volume are all calculated using a real gas equation of state. The modified constants replace the traditional $R, c_{p}, c_{v}$, and $\gamma$ in any equations derived using the ideal gas assumption. However, the modified gas constants cannot be used to calculate each other, e.g. $\bar{R} \neq \bar{c}_{p}-\bar{c}_{v}$. This method is computational inexpensive but is not very accurate in regions where fluid properties change rapidly. 
The second method involves replacing the ideal gas equation with a different equation of state. Aungier found that a modified version of the two parameter model of Redlich and Kwong (1949) was able to capture the trends of most fluids used in centrifugal compressors. Aungier's modified version is given by,

$$
P=\frac{R T}{v-b+c}-\frac{a}{v(v+b) T_{R}^{n}}
$$

where

$$
\begin{gathered}
\mathrm{n}=0.4986+1.1735 \omega+0.4754 \omega^{2} \\
\omega=-\log _{10}\left(\frac{P_{v}}{P_{c}}\right)-1 \\
a=0.42747 R^{2} \frac{T_{c}^{2}}{P_{c}} \\
b=0.08664 R \frac{T_{c}}{P_{c}}
\end{gathered}
$$

and, $P$ is static pressure, $P_{v}$ is the static pressure on the vapor saturation line, $P_{c}$ is the static pressure at the critical point, $R$ is the gas constant, $T$ is static temperature, $v$ is specific volume, $T_{c}$ is the static temperature at the critical point and $T_{R}$ is the reduced temperature. The constant $\mathrm{c}$ is different for different fluids and is used to capture the rapid changes in fluid properties near the critical point. Equations that use ideal gas assumptions, e.g. static to total conditions relations using the isentropic compressible flow relations, are not valid using this method. In order to perform the static to total conditions relations one must know the velocity of the fluid along with the static or total enthalpy and entropy. The procedure for calculating the enthalpy and entropy as a 
function of temperature and pressure can be found in thermodynamic text books such as Moran and Shapiro (2004).

The third method for dealing with non-ideal fluids involves two steps. First, the enthalpy and entropy are determined at a reference temperature and pressure where the fluid is thermally perfect. Second, a correction, called a departure function, is applied to the enthalpy and entropy to account for the difference in the temperature and pressure from the reference state. The form of the departure functions depends on the equation of state. For example the departure functions derived using the ideal gas equation of state are shown in Equations 2.51, 2.52 and 2.53. The departure functions derived using Aungier's model are shown in Equations 2.54 and 2.55 (Aungier 2000).

$$
\begin{gathered}
A-A^{0}=-I^{\prime}(P-R T / v) d v-R T \ln \left(v / v^{0}\right) \\
s-s^{0}=-\left(\frac{\partial\left(A-A^{0}\right)}{\partial T}\right)_{v} \\
h-h^{0}=\left(A-A^{0}\right)+T\left(s-s^{0}\right)+R T(Z-1) \\
\frac{s-s^{0}}{R}=\ln \left[\frac{v}{v^{0}} \frac{v-b+c}{v}\right]-\frac{n a}{R b T} T_{R}^{-n} \ln \left[\frac{v+b}{v}\right] \\
h-h^{0}=P v-R T-\frac{a}{b}(n+1) T_{R}^{-n} \ln \left[\frac{v+b}{v}\right]
\end{gathered}
$$

where, $A$ is Helmholtz energy, $s$ is entropy, $h$ is enthalpy and the superscript 0 denotes properties at the reference state. 


\subsection{National Institute of Standards and Technology (NIST)}

The National Institute of Standards and Technology (NIST) is a non-regulatory federal agency of the U.S. Department of Commerce whose mission includes "advancing measurement science, standards and technology" (NIST, 2011a). NIST is responsible, among other things, for maintaining a database of thermodynamic and transport properties for various working fluids. The fluid property database is updated regularly, incorporating the most recent available data (NIST, 2011b). The database appears to be the most accurate available source of fluid property data.

Complex equations of state using many coefficients have been developed for the fluids in the NIST fluid property database (Span and Wagner, 1994). The large number of coefficients allows the correlations to capture changes in the fluid properties over a very wide range of temperatures and pressures. NIST states that "These equations are the most accurate equations available world wide" (NIST, 2011c). NIST developed a program entitled REFPROP which uses the equations of state mentioned above. REFPROP will return fluid property data for any of the fluids in its database at state points specified by the user. The state points are typically defined by a set of either temperature and pressure or enthalpy and entropy. The most recent version of the program is REFPROP 8.0 which comes with a FORTRAN source code to allow programmers to integrate it with their own programs. Unfortunately, the REFPROP source codes were not available in time to be implemented into TMLD. 
When real fluid properties were being added to TMLD the correlations that were available were from a program entitled Gas Properties (GASP). GASP was developed in 1975 at NASA's Lewis Research Center, using the NIST fluid property data, "for the engineer user who requires both accuracy and speed in calculating thermodynamic and transport properties." (Hendricks et al., 1975). GASP, similarly to REFPROP, was written in FORTRAN and uses curve fits with many coefficients to capture the changes in the fluid properties in the critical region (Hendricks et al., 1975). However, the authors state "The results are in excellent agreement for most fluids, except for small differences in the critical and dense liquid regions in the specific heats and the velocity of sound." The report also mentions the densities of certain fluids in the critical region may not completely agree with the NIST database (Hendricks et al., 1975).

Table 2.2 shows the differences between REFPROP and GASP in carbon dioxide's critical region. Supercritical carbon dioxide is the working fluid of particular interest in this thesis. As the temperature and pressure move away from the critical point, $304.13 \mathrm{~K}$ and $73.8 \mathrm{bar}$, the outputs from the two programs are in better agreement. The agreement was deemed acceptable for use in the meanline codes for axial turbines, Turbine Meanline Design and Turbine Meanline Off-Design. 


\begin{tabular}{|c|c|c|c|c|c|c|c|}
\hline \multirow[b]{2}{*}{$\begin{array}{c}\text { Temperature } \\
\text { (K) }\end{array}$} & \multirow[b]{2}{*}{$\begin{array}{c}\text { Pressure } \\
\text { (bar) }\end{array}$} & \multicolumn{3}{|c|}{ REFPROP } & \multicolumn{3}{|c|}{ GASP } \\
\hline & & $\begin{array}{l}\text { Density } \\
\left(\frac{\mathrm{kg}}{\mathrm{m}^{3}}\right)\end{array}$ & $\begin{array}{c}c_{p} \\
\left(\frac{k J}{k g K}\right)\end{array}$ & $\begin{array}{c}\text { Sonic } \\
\text { Velocity } \\
\left(\frac{\mathrm{m}}{\mathrm{s}}\right)\end{array}$ & $\begin{array}{l}\text { Density } \\
\left(\frac{\mathrm{kg}}{\mathrm{m}^{3}}\right)\end{array}$ & $\begin{array}{c}c_{\mathrm{p}} \\
\left(\frac{\mathrm{kJ}}{\mathrm{kgK}}\right)\end{array}$ & $\begin{array}{l}\text { Sonic } \\
\text { Velocity } \\
\left(\frac{\mathrm{m}}{\mathrm{s}}\right)\end{array}$ \\
\hline 305 & 74 & 321.1 & 16.33 & 184.2 & 330.5 & 16.99 & 191.4 \\
\hline 310 & 76 & 264.5 & 5.04 & 202.9 & 266.5 & 5.17 & 206.0 \\
\hline 315 & 78 & 244.2 & 3.53 & 212.5 & 245.6 & 3.63 & 214.2 \\
\hline 320 & 80 & 231.9 & 2.87 & 219.8 & 232.7 & 2.94 & 220.6 \\
\hline 325 & 82 & 223.3 & 2.50 & 226.0 & 223.7 & 2.54 & 226.3 \\
\hline
\end{tabular}

Table 2.2 REFPROP vs. GASP Near Carbon Dioxide's Critical Point

\subsection{Turbine Meanline Design (TMLD)}

The Turbine Meanline Design program (TMLD) was developed by Verhiel (1993) under a contract with Rolls Royce Canada. The purpose of TMLD is to aid in the preliminary design and optimization of axial turbine designs. The user must make a number of initial decisions in order to provide certain input data for TMLD, such as the hub and tip radii of the gas path. TMLD incorporates the design-point correlations described in Sections 2.5 and 2.6 and thus also predicts the efficiency of the machine.

TMLD can handle machine sizes of up to 9 stages. The outlet conditions of one stage are taken as the inlet conditions to the following stage. The inlet conditions for the machine are provided by the user through the input data file. The TMLD input data file is a text file composed of the gas path and basic airfoil geometries, i.e. the hub and tip radii, the number of nozzle and rotor blades in each row, the axial chord lengths of the nozzles 
and rotors, the maximum thickness-to-chord ratio and trailing-edge thickness for both the nozzle and rotor blades, the rotor blade tip clearance and the number of seals in the rotor blade shroud if one exists. The input data file also includes the massflow rate, inlet stagnation temperature and pressure, rotational speed, inlet flow angle, number of stages in the machine, either the stage total enthalpy drop or pressure ratio and either the degree of reaction or the exit flow angle for each stage. The input file format for TMLD is given in Appendix A.

The main function of TMLD is to calculate the meanline velocity triangles of a potential design. TMLD also calculates the static and stagnation temperature and pressure along the length of the machine. Cooling flow can be added to both the nozzles and rotors in the forms of film, hub, disk, tip, and trailing edge flows. The additional mass flow is averaged out over the span and added to the inlet massflow rate. In addition to the meanline, the velocity triangles and static pressures are also calculated at four other span wise locations. The Kacker and Okapuu total pressure loss correlations were built into TMLD so that the isentropic efficiency can be calculated.

The topics discussed in this chapter led to many modifications in TMLD which are discussed in the following chapter. In addition to correcting a number of minor bugs, the major changes made to TMLD in the present thesis were the addition of:

- The GASP subroutines to allow TMLD to account for real fluid properties

- The Kacker and Okapuu unshrouded rotor blade tip clearance loss correlation

- The more recent loss correlations outlined in Section 2.6. 


\section{Chapter 3 Meanline Analysis Codes}

\subsection{Introduction}

This chapter describes the modifications made to the existing Turbine Meanline Design (TMLD) code and discusses the development of the Turbine Meanline OffDesign (TMLO) code.

The original TMLD code assumed that the working fluid was an ideal gas. The major modification to TMLD was therefore the incorporation of real fluid properties. This was prompted by the need to design turbines for use with supercritical carbon dioxide at conditions of temperature and pressure at which the behaviour of the working fluid differs significantly from ideal gas behaviour. These modifications were carried over to the TMLO code, which was developed from TMLD to predict the complete turbine characteristics. Section 3.2 therefore describes the changes to the codes needed to account for the real fluid properties.

Section 3.3 describes some additional modifications and improvements made to TMLD. Section 3.4 then gives an overview of the development of TMLO. Since much of the flow analysis is common to TMLD and TMLO, large sections of the code from TMLD are reused in TMLO. Section 3.5 describes the off-design loss correlations that are currently available in TMLO. Finally, Section 3.6 briefly describes the input and 
output data files for the two codes. More detailed specification of the data files are given in Appendices A and B.

\subsection{Modifications to Account for Real Fluid Properties}

The original version of TMLD used an exhaust gas consisting of air and the products of combustion of a standard hydrocarbon fuel as the working fluid. The specific heat at constant pressure and the isentropic exponent of the exhaust gas were determined using a correlation based on temperature and the fuel to air ratio. The ideal gas assumption was required to relate static and total conditions, calculate the machine efficiency, and evaluate the other fluid properties, e.g. density and sonic velocity. One of the objectives for this thesis was to enable TMLD and TMLO to run using real fluid properties which would replace the ideal gas assumption.

The ideal gas assumption allows one to use the ideal gas equation and isentropic relations. The ideal gas equation, shown in Section 2.8, is given by,

$$
P=\rho R T
$$

where, $P$ is static pressure, $\rho$ is static density, $R$ is the gas constant of the working fluid, and $\mathrm{T}$ is static temperature. As discussed in Section 2.7 , the compressibility factor, $\mathrm{Z}$, can be included in the ideal gas equation in an attempt to compensate for non-ideal gas behaviour. However, neither TMLD nor TMLO include the compressibility factor in any 
calculations as this does not completely account for the effects of non-ideal fluids. Real fluid properties are required to completely account for non-ideal behaviour.

The isentropic relations were used in the original version of TMLD to relate the static and total temperatures and pressures. The isentropic relations for temperature and pressure are given by,

$$
T_{0}=T\left(1+\frac{\gamma-1}{2} M^{2}\right)
$$

and

$$
P_{0}=P\left(1+\frac{\gamma-1}{2} M^{2}\right)^{\frac{\gamma}{\gamma-1}}
$$

where, $T_{0}$ is total temperature, $T$ is static temperature, $\gamma$ is isentropic exponent, $M$ is Mach number, $P_{0}$ is total pressure, and $\mathbf{P}$ is static pressure. The ideal gas assumption and isentropic relations were also used to convert the stage total pressure ratio into a drop in total enthalpy and to calculate the isentropic efficiency. Using the ideal gas assumption the sonic velocity can also be estimated from a simple equation given by,

$$
a=\sqrt{\gamma R T}
$$

Subroutines for three fluids namely dry air, nitrogen and carbon dioxide, were added to TMLD from NASA's GASP program, discussed in Section 2.9 (Hendricks et al., 1975). Given a temperature and pressure the subroutines from GASP return twelve fluid properties, including: density, sonic velocity, enthalpy, and entropy. The enthalpy and 
entropy can be used instead of the ideal gas assumption and isentropic relations to relate static and total conditions in the flow.

The relationship between total and static enthalpy is given by,

$$
h_{0}=h+\frac{V^{2}}{2}
$$

where, $h_{0}$ is total enthalpy, $h$ is static enthalpy and $V$ is the velocity of the flow. The relationship between static and total conditions is isentropic. Therefore, the entropy at the total conditions is equal to the entropy at the static conditions.

The procedure used to relate the static to total conditions is as follows. The static temperature and pressure are sent to the GASP subroutines which return the entropy and static enthalpy. Using the velocity of the working fluid and Equation 3.4 the total enthalpy is calculated. Both the temperature and pressure are iterated on to find the temperature and pressure that give the entropy and calculated total enthalpy. These values are the temperature and pressure that correspond to stagnation conditions. An equivalent iteration is performed to relate total to static conditions. This double iteration procedure replaces the two explicit isentropic relations, Equations 3.1 and 3.2. Therefore, the time required for TMLD and TMLO to run their calculations is longer when the real fluid properties are used.

In order to incorporate the real fluid properties all of the original equations for density and sonic velocity had to be replaced with call statements to the GASP subroutines. 
There were also equations which used the specific heat or the isentropic exponent to calculate parameters, e.g. isentropic efficiency, which had to be replaced. Any equation which uses the specific heat, isentropic exponent, and/or the gas constant of the working fluid is associated with the ideal gas assumption and therefore had to be replaced with the real fluid properties. These equations appear hundreds of times throughout TMLD.

Since the GASP subroutines return the specific heat at constant pressure and the isentropic exponent, it is also possible to treat dry air, nitrogen, and carbon dioxide as ideal gases in both TMLD and TMLO. The user can choose to have dry air, nitrogen, and carbon dioxide treated as either an ideal gas or a real fluid. The available working fluid options are listed in Table 3.1.

\begin{tabular}{|l|l|}
\hline Exhaust gas & Ideal gas \\
\hline Dry air & \multirow{2}{*}{ Treated as an ideal gas } \\
\cline { 1 - 1 } Nitrogen & \\
\hline Carbon dioxide & \\
\cline { 1 - 1 } Dry air & \multirow{2}{*}{ Treated as a real fluid } \\
\cline { 1 - 1 } Nitrogen & \\
\cline { 1 - 1 } Carbon dioxide & \\
\hline
\end{tabular}

Table 3.1 Working Fluid Options in Latest Version of TMLD and TMLO

When the working fluid is treated as an ideal gas the specific heat at constant pressure and the isentropic exponent are returned by the GASP subroutines. The ideal gas equation, Equation 2.41 , is then used to estimate the density. The sonic velocity is estimated using Equation 3.3. The degree of reaction and isentropic efficiency are 
calculated using temperatures, specific heats, pressure ratios and isentropic exponents. When the working fluid is a real fluid all of the required fluid properties are returned from the GASP subroutines. The degree of reaction and isentropic efficiency are calculated using enthalpies.

As mentioned above, TMLD and TMLO will take longer to run when the working fluid is treated as a real fluid rather than an ideal gas. This is largely due to the iterations required when relating static and total conditions. However, the time required by TMLO to predict one off-design operating point is much shorter than the corresponding time required in TMLD at the design point. This is because TMLO requires only a single pass through the machine, blade row by blade row, to complete the prediction. By comparison, TMLD requires multiple iterations for each stage to establish the velocity triangles that give the required performance. Therefore, the increase in time required for TMLO to converge is negligible. Section 4.3.2 presents data on the increase in time required for TMLD to reach a converged solution.

\subsection{Additional Modifications to the Turbine Meanline Design Code}

\subsubsection{TMLD Specific Modifications to Account for Real Fluid Properties}

The modifications discussed in Section 3.2 were sufficient to allow TMLO to run using real fluid properties. However, TMLD required additional modifications to address some specific issues. These modifications are discussed below. 
When TMLD is calculating the conditions at the exit of the nozzle blade row the velocity of the working fluid is not known. TMLD therefore guesses a Mach number at the nozzle exit. If the working fluid is being treated as an ideal gas then the static conditions at the nozzle exit can be calculated from the Mach number and the known total conditions using the isentropic relations. The static temperature and pressure are used to calculate the density and velocity. After the calculations for the rest of the stage have been carried out the stage outlet flow angle or the degree of reaction from the input data file is compared to the calculated value from the velocity triangles. If the calculated value is not close enough to the user specified value then the velocity triangles for the entire stage are recalculated using a different Mach number at the nozzle exit. TMLD continues to iterate on the Mach number until the velocity triangles meet the requirements set by the user. This procedure works well for the ideal fluid case. However, to relate the total and static conditions with real fluid properties the absolute velocity of the fluid is required not the Mach number. Therefore, an extra iteration loop is required to calculate the fluid properties and velocities at the nozzle exit.

The additional iteration loop determines the sonic velocity at the exit of the nozzle in order to calculate a velocity from the assumed value of Mach number. The iteration procedure for the sonic velocity is as follows:

1. Call the GASP subroutines with the total temperature and pressure to get an initial estimate of the sonic velocity.

2. Multiply the sonic velocity by the guessed Mach number to get the fluid velocity. 
3. Calculate the static temperature and pressure using the velocity obtained in 2 and the total temperature and pressure.

4. Call the GASP subroutines with the static temperature and pressure to get a new sonic velocity.

5. Compare the new and old sonic velocities. If the sonic velocity has not converged repeat steps 2 through 5 using the updated sonic velocity.

Once the static conditions have been determined the procedure for calculating the velocity triangles can carry on as described above.

When TMLD calculates the velocity components at the exit of the rotor blade row it uses the drop in total enthalpy across the stage to calculate the whirl velocity. This is done employing the Euler equation given by,

$$
\Delta \mathrm{h}_{0}=\mathrm{U}_{2} \mathrm{C}_{\mathrm{w}_{2}}-\mathrm{U}_{1} \mathrm{C}_{\mathrm{w} 1}
$$

where, $\Delta \mathrm{h}_{0}$ is the drop in total enthalpy across the stage, $\mathrm{U}$ is blade speed, and $\mathrm{C}_{\mathrm{W}}$ is whirl velocity. The subscripts 1 and 2 denote the inlet and outlet of the rotor blade row. The user can choose to set the total enthalpy drop or the total pressure ratio in the input data file. If the user chooses to set the total pressure ratio then TMLD must convert it into a drop in total enthalpy. For ideal fluids TMLD estimates the drop in total enthalpy using,

$$
\Delta h_{0}=\eta c_{\text {Pavg }} T_{0, \text { inlet }}\left(1-\left(\frac{1}{P R}\right)^{\frac{\gamma_{\text {ovg }}-1}{\gamma_{\text {vg }}}}\right)
$$


where, $\eta$ is isentropic stage efficiency, $c_{P a v g}$ and $\gamma_{\text {avg }}$ are specific heat at constant pressure and isentropic exponent averaged across the rotor blade row respectively, $T_{0 \text {,inlet }}$ is the stage inlet total temperature and PR is the total pressure ratio of the stage.

In the first iteration a default value of efficiency and the inlet values of specific heat and isentropic exponent are used. TMLD calculates the velocity triangles using the estimated drop in total enthalpy. Once the velocity triangles have been calculated TMLD compares the user specified total pressure ratio to the calculated stage total pressure ratio. If the calculated pressure ratio is close enough to the user specified pressure ratio then TMLD moves on to the next stage. If not then the efficiency, average specific heat and average isentropic exponent are updated from the values calculated in the most recent iteration and the velocity triangles are recalculated.

For real fluids Equation 3.6 is replaced with a three step procedure. First, the GASP subroutines are called using the inlet total temperature and pressure and they return the inlet entropy and total enthalpy. Second, the total pressure at the exit of the stage is calculated from the user specified total pressure ratio and the inlet total pressure. Finally, the total enthalpy at the exit of the stage is determined as if the expansion through the stage is isentropic. This is done by calling GASP with the calculated stage exit total pressure and a guess of the total temperature. TMLD iterates on the total temperature until the exit entropy matches the inlet entropy. At this total temperature and pressure GASP will return the total enthalpy that corresponds to isentropic expansion with the user defined pressure ratio. The drop in total enthalpy that TMLD uses is given by, 


$$
\Delta h_{0}=\eta\left(h_{0, \text { inet }}-h_{0, \text { exit }}\right)
$$

where, $h_{0, \text { inlet }}$ and $h_{0, \text { exit }}$ are the stage inlet and exit total enthalpies, and $\eta$ is the isentropic efficiency of the stage. As in the ideal gas case a default value of efficiency is used in the first iteration. The subsequent iterations use the calculated value of efficiency from the previous iteration. Once the drop in total enthalpy has been calculated TMLD can calculate the velocity triangles in the normal fashion.

\subsubsection{Kacker \& Okapuu Unshrouded Blade Tip Clearance Total Pressure Loss Correlation}

The original version of TMLD used the Kacker and Okapuu (1982) correlations to estimate the total pressure losses. As described in Section 2.5.5, Kacker and Okapuu provided different correlations for shrouded and unshrouded rotor blades. It was found that the original TMLD code included only the correlation for shrouded blades. Therefore, the correlation for unshrouded blades was added to TMLD.

Kacker and Okapuu express the tip clearance losses for unshrouded rotor blades as a change in efficiency:

$$
\frac{\Delta \eta}{\eta_{0}}=0.93 \frac{\tau}{h \cos \alpha_{2}} \frac{r_{t}}{r_{m}}
$$

where $\eta_{0}$ is the stage efficiency with zero tip clearance losses, $\Delta \eta$ is the change in the efficiency due to the tip clearance, $\tau$ is tip gap height, $h$ is blade height, $\alpha_{2}$ is the flow angle at the exit of the blade row, $r_{t}$ is tip radius, and $r_{m}$ is mean radius. This introduces 
an additional iteration loop. The stage performance is first calculated neglecting tip leakage losses. The efficiency loss due to tip leakage, $\Delta \eta$, is subtracted from the zero tip clearance efficiency, $\eta_{0}$, to get the final stage efficiency. A tip leakage loss coefficient, $Y_{T C}$, is then estimated from $\Delta \eta$. The estimated $Y_{T C}$ is added to the other loss coefficients for the rotor passage flow and the stage performance is reanalysed. The value of $\mathrm{Y}_{\mathrm{TC}}$ is iterated on until the stage efficiency from the latest run is consistent with the efficiency calculated from $\eta_{0}$ and $\Delta \eta$. The additional iterations significantly increase the run time for stages with unshrouded rotor blades.

Interestingly, for some test cases it was found that the tip clearance total pressure loss coefficient for an unshrouded blade row was less than the loss coefficient for the same blade row but shrouded with one seal. As the amount of fluid leakage through the tip gap decreases the tip clearance total pressure loss coefficient should also decrease. Therefore, one would expect that the total pressure loss coefficient for a stage with unshrouded blades will always be greater than the total pressure loss coefficient for a shrouded version with the same clearance. The Kacker and Okapuu shrouded blade tip leakage correlation is given by,

$$
\mathrm{Y}_{\mathrm{TC}}=0.37 \frac{\mathrm{c}}{\mathrm{h}}\left(\frac{\tau^{\prime}}{\mathrm{c}}\right)^{0.78}\left(\frac{\mathrm{C}_{\mathrm{L}}}{\mathrm{S} / \mathrm{c}}\right)^{2} \frac{\cos ^{2} \alpha_{2}}{\cos ^{3} \alpha_{\mathrm{m}}}
$$

where,

$$
\frac{C_{L}}{S / c}=2\left(\tan \alpha_{1}+\tan \alpha_{2}\right) \cos \alpha_{m}
$$




$$
\begin{gathered}
\alpha_{\mathrm{m}}=\tan ^{-1}\left[\frac{1}{2}\left(\tan \alpha_{1}-\tan \alpha_{2}\right)\right] \\
\tau^{\prime}=\frac{\tau}{\operatorname{seals}^{0.42}}
\end{gathered}
$$

where $\mathrm{h}$ is blade height, $\mathrm{c}$ is blade chord, $\alpha_{1}$ is the flow angle at the inlet of the blade row, $\tau$ is tip gap height and "seals" represents the number of knife edges on the shroud.

Comparing Equation 2.23 to Equation 2.25 one can see that the loss correlation for shrouded blade tips includes more blade parameters than the unshrouded correlation. As the aspect ratio, $\mathrm{h} / \mathrm{c}$, of the blades decreases the tip clearance losses for shrouded blades increases, while the losses for unshrouded blades would remain the same. Therefore, low aspect ratio shrouded blades with one seal could end up with a higher predicted tip clearance total pressure loss coefficient than an unshrouded version of the same blades.

At off-design conditions the total pressure loss coefficients generally differ from the design point values. The differences can be caused by changes in the flow angles, Mach numbers or Reynolds numbers. However, the Kacker and Okapuu shrouded tip clearance loss coefficient is a function of the machine geometry only. Therefore, the predicted tip clearance total pressure loss coefficient will not change at off-design conditions.

As discussed in Section 2.5.5, the unshrouded tip clearance correlation is a function of the blade and gas path geometries and the zero tip clearance stage efficiency. This correlation was based on well designed machine geometries. At many off-design points a machine will not be operating like a well designed machine. This raises doubts about how 
accurate the Kacker and Okapuu unshrouded blade tip clearance loss correlation will be for many off-design points. For this reason, and because the shrouded tip clearance loss coefficient remains unchanged at off-design conditions, it was decided that the loss coefficient should remain unchanged for the unshrouded blade case also. Therefore, TMLD simply passes the tip clearance loss coefficient to TMLO. The other design point loss coefficients are recalculated in TMLO to account for the change in flow angles and the Mach and Reynolds numbers effects.

\subsubsection{Design Point Total Pressure Loss Correlations}

As mentioned above the original version of TMLD only had the Kacker and Okapuu (1982) total pressure loss correlations built in. A later version of TMLD also had the Zhu and Sjolander (2005) profile loss correlation, from Section 2.6.2, and the Benner et al. (2005 a \& b) secondary loss correlation, from Section 2.6.3, built into the code. However, the more recent correlations were not fully tested. These correlations have been tested and are included in the current version of TMLD along with the Yaras and Sjolander (1992) and the Kim and Chung (1997) tip clearance loss correlations from Section 2.6.4. The user specifies in the TMLD input data file which loss correlations are to be used. The format of the TMLD input file can be found in Appendix A.

As discussed in Section 2.5.2, the Ainley and Mathieson profile loss correlation uses a weighted average of the losses for an axial inflow nozzle and an impulse blade. The averaging method assumes that the blade shape falls between the impulse and axial inflow nozzle shapes. However, in some cases this does not happen. For example, if the 
working fluid flows from a volute into the turbine there will already be some swirl in the flow. The designer could then choose to have the first stage nozzle add to the swirl that is already present in the flow. As a result, the nozzle shape would not fall between an axial inflow nozzle and an impulse blade as shown in Figure 3:1. This blade shape will be referred to as low turning since the flow turning tends to be low for these particular blade designs.

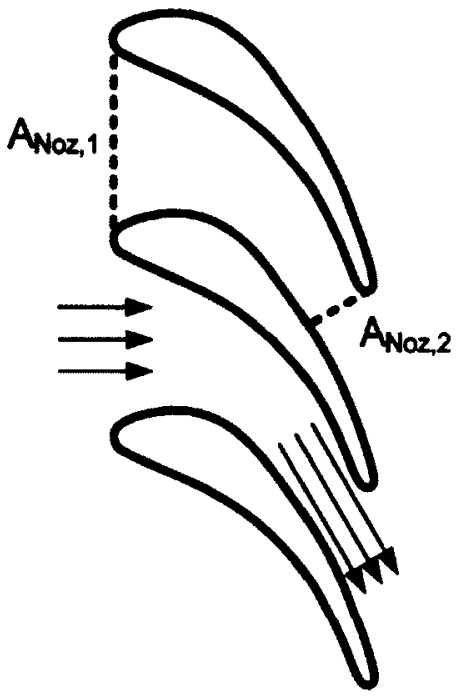

Nozzle

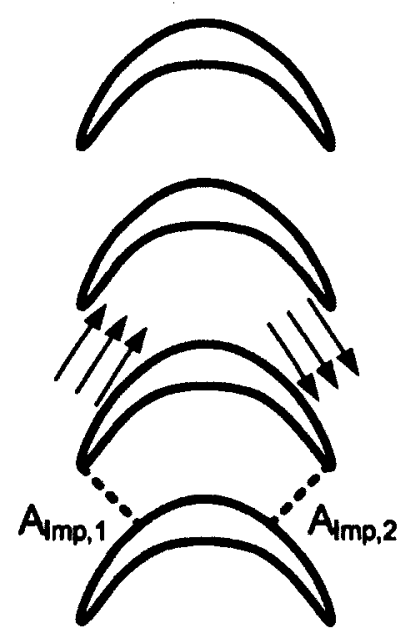

Impulse

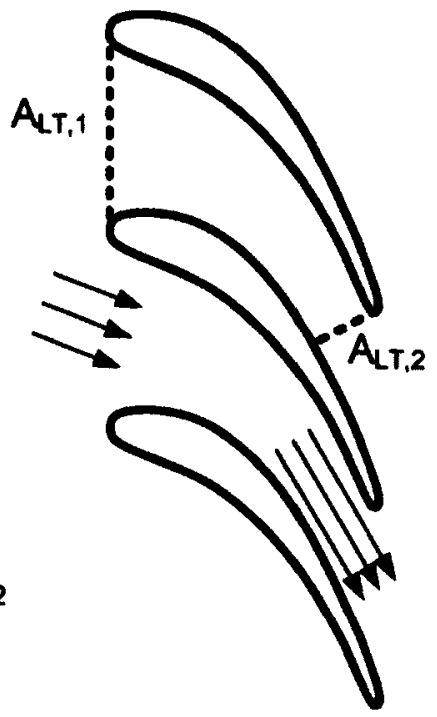

Low Turning

Figure 3.1 Example Axial Inflow Nozzle, Impulse and Low Turning Blade Geometries

In Figure $3.1 \mathrm{~A}$ is cross-sectional flow area and the subscripts 1 and 2 denote the inlet and outlet of the blade row. In the absence of better information, TMLD treats low turning blades as axial inflow nozzles with the same exit angle. This will likely somewhat over predict the losses for the low turning blade rows. 
Figure 2.8, indicates that the Ainley and Mathieson profile loss correlation is only available for exit angles greater than $40^{\circ}$ and less than $70^{\circ}$ for impulse blades and less than $80^{\circ}$ for nozzle blades. Therefore, if a blade has an exit angle of less than $40^{\circ}$ TMLD uses an exit angle of $40^{\circ}$ in the correlation. This typically leads to an over prediction of the profile losses. If a blade has an exit angle between $70^{\circ}$ and $80^{\circ}$ the nozzle correlation will use the correct exit angle and the impulse correlation will use $70^{\circ}$ as the exit angle. If a blade has an exit angle greater than $80^{\circ}$ the impulse blade correlation will use $70^{\circ}$ and the nozzle blade correlations will use $80^{\circ}$. When the exit flow angle is greater than Ainley and Mathieson's maximums the correlations are likely under predicting the profile losses. If any of the angles are outside of the Ainley and Mathieson range, including the low turning blade case, a warning is printed in the TMLD output file in the form of parentheses around the value of the profile total pressure loss coefficient for that blade. An example of this is shown in Figure 3.2.

\begin{tabular}{|rrrrrr|}
\hline \multirow{2}{*}{ LOSSES } & & Nozzle & \multicolumn{3}{c|}{ Rotor } \\
& Rec: & $2.74 \mathrm{E}+05$ & $\mathrm{~K}$ & $3.19 \mathrm{E}+05$ & $\mathrm{~K}$ \\
& Yprofile: & 0.01539 & 1.0 & $(0.01767)$ & 1.0 \\
Ysecondary: & 0.05280 & 1.0 & 0.04417 & 1.0 \\
Ytet: & 0.00757 & 1.0 & 0.00932 & 1.0 \\
Ytc: & & 1.0 & 0.05279 & 1.0 \\
Ytotal: & 0.07576 & & 0.12395 & \\
\hline
\end{tabular}

Figure 3.2 Excerpt from TMLD Output File with Warning on Profile Loss Coefficient Indicating the Flow Angles are out of Correlation Range 


\subsection{Development of the Turbine Meanline Off-Design (TMLO) Code}

The Turbine Meanline Off-Design (TMLO) code was developed to predict the offdesign performance of a turbine that has been designed using TMLD. TMLO employs the gas path and blade row geometries determined using TMLD to predict the performance at specified values of off-design massflow and rotational speed. Once a sufficient number of off-design points have been calculated, the turbine characteristic can be plotted.

Generating the turbine characteristic typically occurs after the through flow analysis has been conducted on the machine design. Through flow analysis is the step which occurs after meanline analysis in the design phase. Through flow analysis is a two dimensional approximation of the flow through the machine, where meanline analysis is only one dimensional. Therefore, where meanline analysis is restricted to the mean radius through flow analysis tracks the streamlines in the spanwise direction also. Upstream and downstream effects are also considered. Therefore the streamlines and fluid properties change smoothly through the machine compared to meanline analysis where analysis points are computed independent of one another. Unfortunately, a through flow analysis code was not available and time did not permit the development of one. Meanline offdesign analysis is not as accurate as through flow analysis however it is the best that could be accomplished.

In some respects, the analysis performed by TMLO is simpler than that in TMLD. TMLD must iterate on the full velocity triangles for each stage to arrive at a design that matches the specified performance. Having arrived at the velocity triangles, TMLD 
applies a deviation correlation to predict the corresponding metal angles needed for the airfoils. Both the velocity triangles and the airfoil geometries are written to an output data file for TMLO. With specified inlet pressure and temperature, massflow rate, and rotational speed TMLO then calculates the development of the flow through the machine, blade row by blade row. Once the outlet of the machine is reached the resulting overall performance parameters, i.e. pressure ratio, efficiency and power output, are calculated.

Large portions of the flow analysis are similar between TMLD and TMLO. Therefore, some of the TMLD code was reused in TMLO. Likewise, all modifications to TMLD that account for real fluid properties, as described in Section 3.2, have been incorporated into TMLO. The main differences between TMLO and TMLD are the iteration procedures used to determine the velocities and fluid properties at each axial station and the incorporation of the off-design loss correlations. Section 3.5 describes these loss correlations.

Following the model provided by TMLD, an effort has been made to make the TMLO code easy to follow and therefore modify in the future. Extensive comments are included in the core and the names of variables are made as descriptive as possible.

\subsection{Off-Design Total Pressure Loss Correlations Used in TMLO}

The Benner et al. (1997) off-design total pressure loss correlation, discussed in Section 2.6.5, is used in TMLO to calculate the profile losses due to incidence. This additional loss is added to the design point profile loss coefficient. Currently, this is the 
only loss correlation in TMLO that is directly expressed as a function of the incidence. The incidence parameter used in Benner et al. (1997) is given by,

$$
\chi=\left(\frac{d_{L E}}{S}\right)^{-0.05} W^{-0.2}\left(\frac{\cos \beta_{1}}{\cos \beta_{2}}\right)^{-1.4}\left[\alpha_{1}-\alpha_{1, \text { desige }}\right]
$$

where, $d_{L E}$ is the leading-edge diameter, $S$ is the spacing between the blades (pitch), We is the leading-edge wedge angle, $\beta$ is the metal angle, $\alpha$ is the flow angle, and the subscripts 1 and 2 denote the inlet and outlet of the blade row. In Benner et al. (1997) $\chi$ is plotted from values of -18 to 6 . If the calculated value of $\chi$ exceeds these limits, TMLO will extrapolate using the curve fit for additional loss as a function of $\chi$ but a warning message is printed in the TMLO output file. Figure 3.3 shows an example of the warning message.

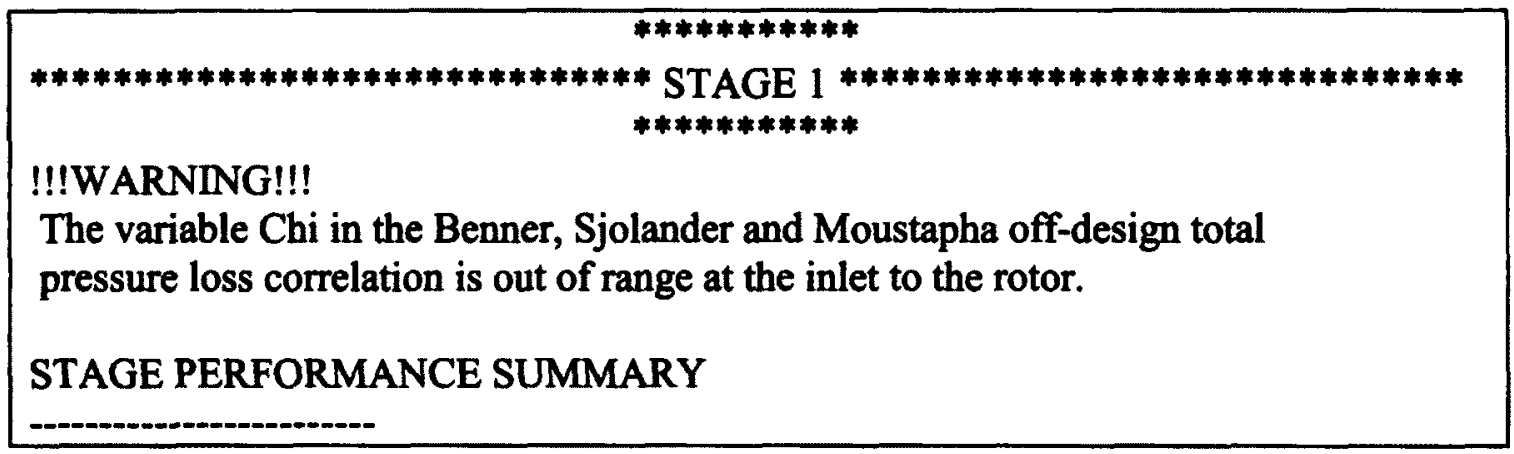

Figure 3.3 Excerpt from TMLO Output File with $\chi$ Out of Range Warning

The increase in kinetic energy loss coefficient due to incidence, calculated from $\chi_{0}$ is then converted to an incremental total pressure loss coefficient using, 


$$
Y=\frac{\left[1-\frac{\gamma-1}{2} M_{2}^{2}\left(\frac{1}{1-\Delta \varphi^{2}}-1\right)\right]^{\frac{\gamma}{\gamma-1}}-1}{1-\left(1+\frac{\gamma-1}{2} M_{2}^{2}\right)^{-\frac{\gamma}{\gamma-1}}}
$$

where, $\mathbf{M}_{2}$ is the Mach number at the blade row exit and $\gamma$ is the isentropic exponent. The incremental loss coefficient is then added to the design-incidence total pressure loss coefficient to obtain the overall profile loss coefficient. The same Mach number and Reynolds number corrections used with the design-point correlations are then applied to obtain the final profile loss coefficient that is used in TMLO.

As discussed in Section 2.5.4, the secondary loss coefficient is expressed in terms of the lift coefficient for the blade row, as follows

$$
\mathrm{Y}_{\mathrm{s}, \mathrm{Ko}}=1.2\left(0.0334 \frac{1}{\mathrm{~h} / \mathrm{c}}\left(\frac{\cos \alpha_{2}}{\cos \beta_{1}}\right)\left(\frac{\mathrm{C}_{\mathrm{L}}}{\mathrm{S} / \mathrm{c}}\right)^{2} \frac{\cos ^{2} \alpha_{2}}{\cos ^{3} \alpha_{\mathrm{m}}}\right) \mathrm{K}_{\mathrm{S}}
$$

where, $\mathrm{K}_{\mathbf{S}}$ captures the compressibility effects. Substituting for the definition of the lift coefficient, this can be written

$$
Y_{8, K O}=1.2\left(0.0334 \frac{1}{h / c}\left(\frac{\cos \alpha_{2}}{\cos \beta_{1}}\right)\left(2\left(\tan \alpha_{1}+\tan \alpha_{2}\right) \cos \alpha_{m}\right)^{2} \frac{\cos ^{2} \alpha_{2}}{\cos ^{3} \alpha_{m}}\right) K_{S}
$$

where,

$$
\alpha_{m}=\tan ^{-1}\left[\frac{1}{2}\left(\tan \alpha_{1}-\tan \alpha_{2}\right)\right]
$$


and the loss coefficient is a function of the blade aspect ratio and the inlet and outlet flow angles only. At off-design incidence, the inlet flow angle can be written as $\alpha_{1}=\alpha_{1 \text { des }}+i$. Substituting into Equation 3.8,

$$
\mathrm{Y}_{\mathrm{s}, \mathrm{KO}}=1.2\left(0.0334 \frac{1}{\mathrm{~h} / \mathrm{c}}\left(\frac{\cos \alpha_{2}}{\cos \beta_{1}}\right)\left(2\left(\tan \left(\alpha_{1 \mathrm{des}}+\mathrm{i}\right)+\tan \alpha_{2}\right) \cos \alpha_{\mathrm{m}}\right)^{2} \frac{\cos ^{2} \alpha_{2}}{\cos ^{3} \alpha_{\mathrm{m}}}\right) \mathrm{K}_{\mathrm{s}}
$$

and the secondary loss coefficient then becomes a function of incidence. Equation 3.9 is therefore used in TMLO to estimate the off-design secondary losses.

\subsection{Overview of TMLD and TMLO Data Files}

This section discusses how the TMLD input and output files were modified to reflect the modifications to the code. The current TMLD input file format is given in Appendix A. This section also describes the formats of the TMLO input and output files.

The first line of the TMLD input data file consists of integer flags that designate the amount of information displayed in the output file, whether the input data is in SI or imperial units, how the meanline radius is defined, and how many machine geometries are in the input file. The working fluid selection flag was added at the end of this line. Table 3.2 shows the working fluid options and the integer used to select them in TMLD's input data file. 


\begin{tabular}{|c|c|c|}
\hline Integer flag & Working Fluid & Ideal Gas or Real Fluid \\
\hline 1 & Exhaust gas & Ideal Gas \\
\hline 2 & Dry air & \multirow{2}{*}{ Treated as an ideal gas } \\
\hline 3 & Nitrogen & \\
\hline 4 & Carbon dioxide & \\
\hline 5 & Dry air & \multirow{1}{*}{ Treated as a real fluid } \\
\hline 6 & Nitrogen & \\
\hline 7 & Carbon dioxide & \\
\hline
\end{tabular}

Table 3.2 Working Fluid Options in TMLD's Input Data File

A second line of integer flags was added to indicate which total pressure loss correlations are to be used. Table 3.3 shows which integers correspond to the different loss correlations. The Kacker and Okapuu (1982) design point loss system is selected by setting all of the loss correlation integer flags to 1. The Yaras and Sjolander (1992) and Kim and Chung (1997) tip clearance loss correlations were developed for unshrouded blade rows only. Therefore, the Kacker and Okapuu loss correlation is automatically used for shrouded rotor blade rows.

The sonic velocity, density and compressibility factor of the working fluid were added to the TMLD output file. While the density has always been calculated it was not displayed in the original output file. If TMLD is running with exhaust gas as the working fluid the compressibility factor is set to 1.0 . When the working fluid is either dry air, nitrogen or carbon dioxide the compressibility factor is obtained from the GASP subroutines and displayed in the output file but is not used in any of the calculations. The design inlet flow angles and the trailing edge metal angles are also displayed in the latest 


\begin{tabular}{|c|c|c|c|}
\hline \multirow{2}{*}{$\begin{array}{c}\text { Total Pressure } \\
\text { Loss Coefficient }\end{array}$} & \multicolumn{3}{|c|}{ Integer Flag Used to Select Loss Correlation } \\
\cline { 2 - 4 } & $\mathbf{1}$ & $\mathbf{2}$ & $\mathbf{3}$ \\
\hline Profile & $\begin{array}{c}\text { Kacker and } \\
\text { Okapuu }\end{array}$ & $\begin{array}{c}\text { Zhu and } \\
\text { Sjolander }\end{array}$ & N/A \\
\hline Secondary & $\begin{array}{c}\text { Kacker and } \\
\text { Okapuu }\end{array}$ & $\begin{array}{c}\text { Benner, } \\
\text { Sjolander and } \\
\text { Moustapha }\end{array}$ & N/A \\
\hline Trailing Edge & $\begin{array}{c}\text { Kacker and } \\
\text { Okapuu }\end{array}$ & N/A & N/A \\
\hline Tip Clearance & $\begin{array}{c}\text { Kacker and } \\
\text { Okapuu }\end{array}$ & $\begin{array}{c}\text { Yaras and } \\
\text { Sjolander }\end{array}$ & Kim and Chung \\
\hline
\end{tabular}

Table 3.3 Total Pressure Loss Correlation Options in TMLD's Input Data File

version of the output file. The design inlet flow angles are equal to the inlet flow angles from the design-point velocity triangles. The trailing edge metal angles are estimated using the exit flow angles from the velocity triangles and the Islam and Sjolander deviation correlation (Islam and Sjolander, 1999).

Under most circumstances the iteration procedure used by TMLD to determine the absolute velocity at each axial station will converge within 10 iterations. Occasionally the iteration procedure will diverge and the code will crash. The divergence is normally caused by incorrect input data from the user. However, divergence might also occur if the flow becomes supersonic during one of the iterations. Under certain circumstances the iteration procedure can reach 100 iterations without meeting the convergence criterion. If the $101^{\text {st }}$ iteration is reached TMLD moves on to the next axial station with the calculated data from the last iteration as if it had met the criterion. The iteration loop ends to ensure that the program does not get caught in an infinite loop. 
It is possible for TMLD to reach convergence in the major iteration loops, i.e. iterating on stage total enthalpy drop and degree of reaction, without reaching the absolute velocity convergence criterion at each axial station. This is only possible when the absolute velocity iterations nearly reach the convergence criterion. Therefore, a warning message is written to the TMLD output file if the absolute velocity iteration procedure at any axial station does not reach the convergence criterion by the time the major iteration loops are completed. Figure 3.4 shows an example of the warning message in TMLD's output file.

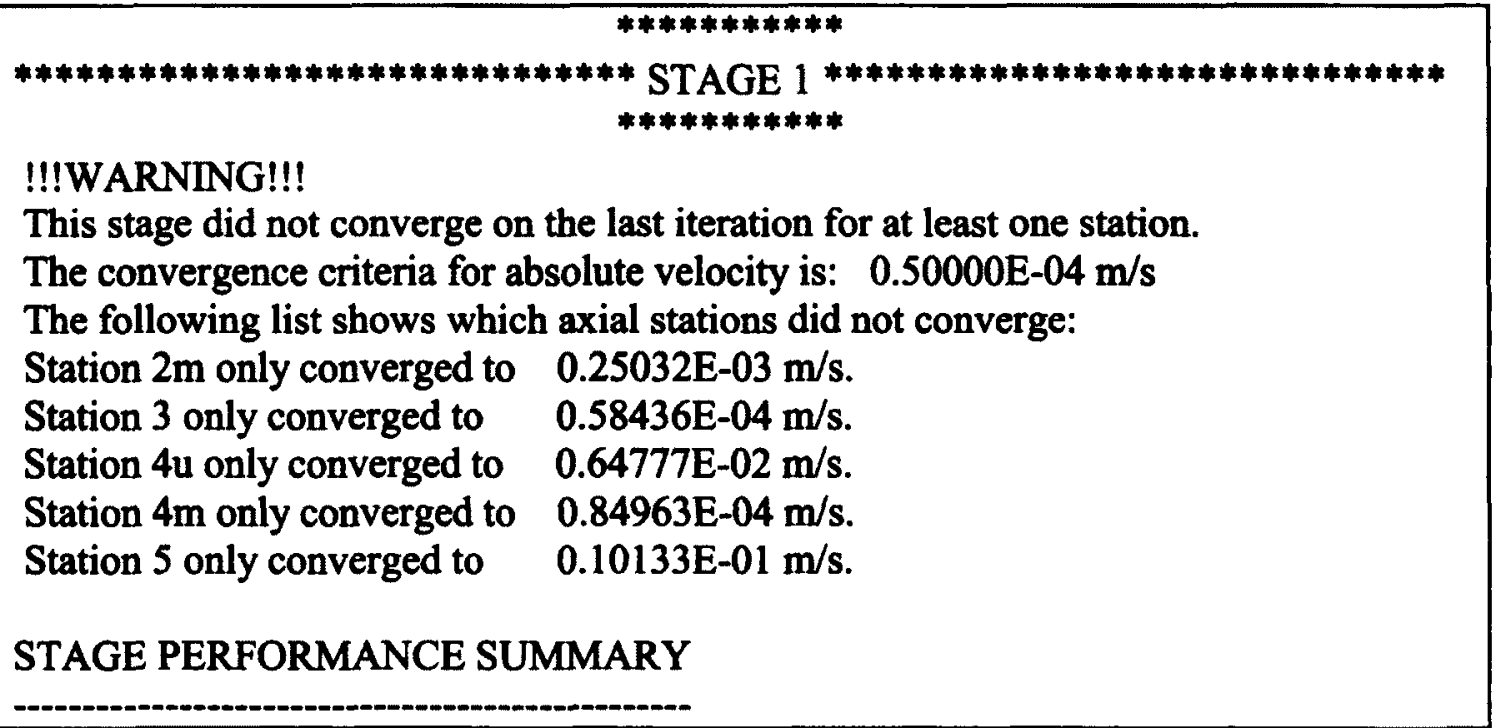

Figure 3.4 Excerpt from TMLD Output File with Failed Convergence Warning

TMLO has one mandatory input data file which is produced by TMLD. TMLO also has an optional input file which contains the leading-edge wedge angles and leading-edge diameter-to-spacing ratios for all of the blade rows. If the user chooses not to use the blade geometry input data file then default values of the wedge angle and leading-edge diameter-to-spacing ratio are applied to each blade row. Appendix B shows the format of 
the TMLO blade geometry input data file and the default values of leading-edge wedge angle and leading-edge diameter-to-spacing ratio. The user can choose to input some values into the data file without providing all of them. If a value of 0.0 is entered for any of the wedge angles or diameter-to-spacing ratios the default values will be automatically applied to replace it. Section 4.4.4 discusses how the default values were obtained.

The mandatory TMLO input file is composed of the information from the TMLD input file, the flow velocities and angles from the design point velocity triangles, the fluid properties at every axial station and the blade geometries calculated by TMLD. The blade geometry data includes the leading-edge design flow angles and the trailing-edge metal angles. The stagger angles, throat-to-spacing ratios and spacing-to-chord ratios are also included. TMLO only requires the user to input the names of the input and output files and the values of the massflow rate and rotational speed of the off-design point to be calculated. Currently TMLO can only handle one set of input data, i.e. massflow rate and rotational speed, at a time.

The TMLO output file has a similar format to the TMLD output file and contains largely the same information. See Appendix C for an example of a TMLD output file. Two values have been added that are specific to TMLO. First, the change in machine isentropic efficiency from the design point value has been added at the top of the output file where the machine performance parameters are listed. Second, a line containing the incidence on both the nozzle and rotor blades has been added under the lines for the inlet design flow and exit metal angles. If TMLD is asked to print out the spanwise results in the output file TMLO will automatically print out the results also. 


\section{Chapter 4 Results and Discussion}

\subsection{Introduction}

This chapter presents turbine performance predictions obtained with manual calculations and using the Turbine Meanline Design (TMLD) and Turbine Meanline OffDesign (TMLO) programs.

The manual calculations, performed using MathCAD, involved single stage machines designed assuming isentropic expansion and ideal gas behaviour. The performance of the same machines was then analysed using real fluid properties. The objective was to obtain preliminary estimates of how real fluid properties affect the performance of a machine that was designed assuming ideal gas. These initial calculations were then followed by related but more accurate predictions using the meanline codes.

TMLD was used to design four single stage machines for both ideal and real working fluids. Both an ideal and a real working fluid machine were designed for two different turbine inlet conditions. The resulting differences in the machine design geometries are discussed. TMLO was then employed to predict the off-design performance of machines designed for ideal working fluids using real fluid properties. The objective was to examine how including the effects of the varying losses influences the off-design performance of the machines. 
Section 4.2 presents the manual calculations. Section 4.3 discusses the results from the TMLD calculations. This section also documents the effect on the code run time when real working fluids are selected by the user. Section 4.4 discusses the off-design results obtained with TMLO. The off-design calculations require additional blade geometry information to be specified. In particular, the correlation for the off-design

profile losses requires the blade leading-edge wedge angle and leading-edge diameter. Section 4.4 therefore also includes a discussion of how these parameters are handled when values are not provided by the user.

\subsection{Manual Calculations for Single Stage Turbines}

\subsubsection{Meanline Design of Axial Turbines}

As mentioned, the manual calculations consisted of developing four meanline designs for single stage turbines. For simplicity, these machines were designed assuming isentropic expansion and that the working fluid was an ideal gas. The performance of each machine was then analysed with real fluid properties. The working fluid was supercritical carbon dioxide $\left(\mathrm{S}-\mathrm{CO}_{2}\right)$.

The four machines were designed to have the same velocity triangles. Using the Smith Chart, Figure 2.4, a moderate value of the work coefficient, $\psi$, of 1.8 was selected. Again using the Smith Chart, a value of 0.75 was then selected for the flow coefficient, $\varphi$, as a value that would give good efficiency for an actual machine. Thus, the machines 
have velocity triangles that are representative of a moderately loaded stage. The work and flow coefficients were defined in Section 2.4.1 as:

$$
\begin{gathered}
\psi=\frac{\Delta \mathrm{h}_{0}}{\mathrm{U}^{2}} \\
\varphi=\frac{\mathrm{C}_{\mathrm{a}}}{\mathrm{U}}
\end{gathered}
$$

where, $\Delta \mathrm{h}_{0}$ is total enthalpy drop across the stage, $\mathrm{U}$ is blade speed, and $\mathrm{C}_{\mathrm{a}}$ is axial velocity. Finally, to fully specify the velocity triangles the four machines were designed with a stage exit-flow angle of $0^{\circ}$.

To give quantitative values for the Mach numbers and other flow variables, the machines were also designed for a rotational speed of 3600 RPM and constant mean radius of 0.3 meters. The mean radius is representative of the turbine designed in the Carleton University $4^{\text {th }}$ year engineering project from 2008-2009. The resulting velocity triangles at the meanline of the four designs are shown in Figure 4.1: $U$ is blade speed, $C$ is absolute velocity, $\mathrm{W}$ is relative velocity. The subscripts 1 and 2 denote the nozzle and rotor outlets respectively.

While the four machines share the same velocity triangles they were designed for different sets of inlet total temperature and pressure. The inlet conditions were selected to result in varying values of compressibility factor, $\mathrm{Z}$, for $\mathrm{S}-\mathrm{CO}_{2}$, as shown in Table 4.1. The turbine designed in the Carleton University $4^{\text {th }}$ year engineering project from 20082009 has an inlet compressibility factor of 1.05 . Therefore a range of $Z$ values near 1.0 


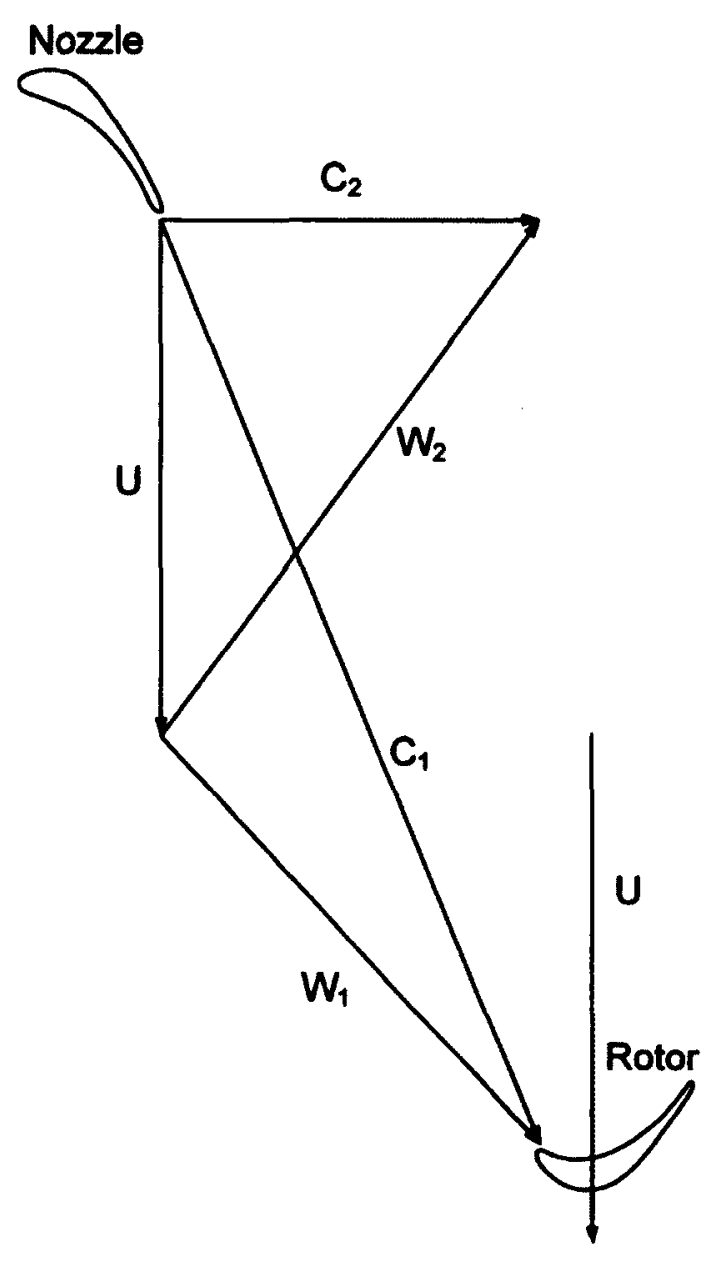

Figure 4.1 Design Velocity Triangles from Hand Calculations

was selected for this investigation. The values of $\mathrm{Z}$ from 0.90 to 1.10 allowed the effect on the performance to be examined for a range of deviations from ideal gas behaviour. Each machine was designed assuming that the fluid behaves as an ideal gas, i.e. with $Z=$ 1.0. The performance of the resulting designs was then recalculated taking into account the real fluid properties.

Because each machine has a different set of inlet conditions they have different massflow rates and hub and tip radii. These values were selected based on having a hub 


\begin{tabular}{|c|c|c|}
\hline $\begin{array}{c}\text { Total } \\
\text { Temperature } \\
\text { (K) }\end{array}$ & $\begin{array}{c}\text { Total } \\
\text { Pressure } \\
\text { (bar) }\end{array}$ & $\begin{array}{c}\text { Inlet } \\
\text { Compressibility } \\
\text { Factor } \\
\text { (Real Fluid } \\
\text { Cases Only) }\end{array}$ \\
\hline 470 & 115 & 0.90 \\
\hline 535 & 115 & 0.95 \\
\hline 1500 & 215 & 1.05 \\
\hline 1500 & 420 & 1.10 \\
\hline
\end{tabular}

Table 4.1 Inlet Conditions of the Four Machines

to tip ratio of 0.75 at the rotor inlet and maintaining a constant axial velocity. The mean radius was held constant throughout the machines.

The real fluid properties were obtained using REFPROP 8.0, as discussed in Section 2.9. The real fluid cases were calculated for the design point inlet conditions and blade speed. Therefore, any differences in the velocity triangles were due to the differences in the fluid properties.

\subsubsection{Effects of Real Fluid Properties on Turbines Designed for Ideal Working Fluids Assuming Isentropic Expansion}

Since the four machine designs have the same work coefficient, flow coefficient, stage exit absolute flow angle and blade speed the velocity triangles for the ideal gas cases are identical. The performance of the four machines was recalculated employing the real fluid properties. The resulting velocity triangles are shown in Figure 4.2, where 
$\Delta \mathrm{C}_{\mathrm{W}}$ is change in absolute whirl, or tangential, velocity, i.e. $\mathrm{C}_{\mathrm{W}_{2}}-\mathrm{C}_{\mathrm{W}_{1}}, \alpha$ is absolute flow angle, and $\omega$ is relative flow angle.

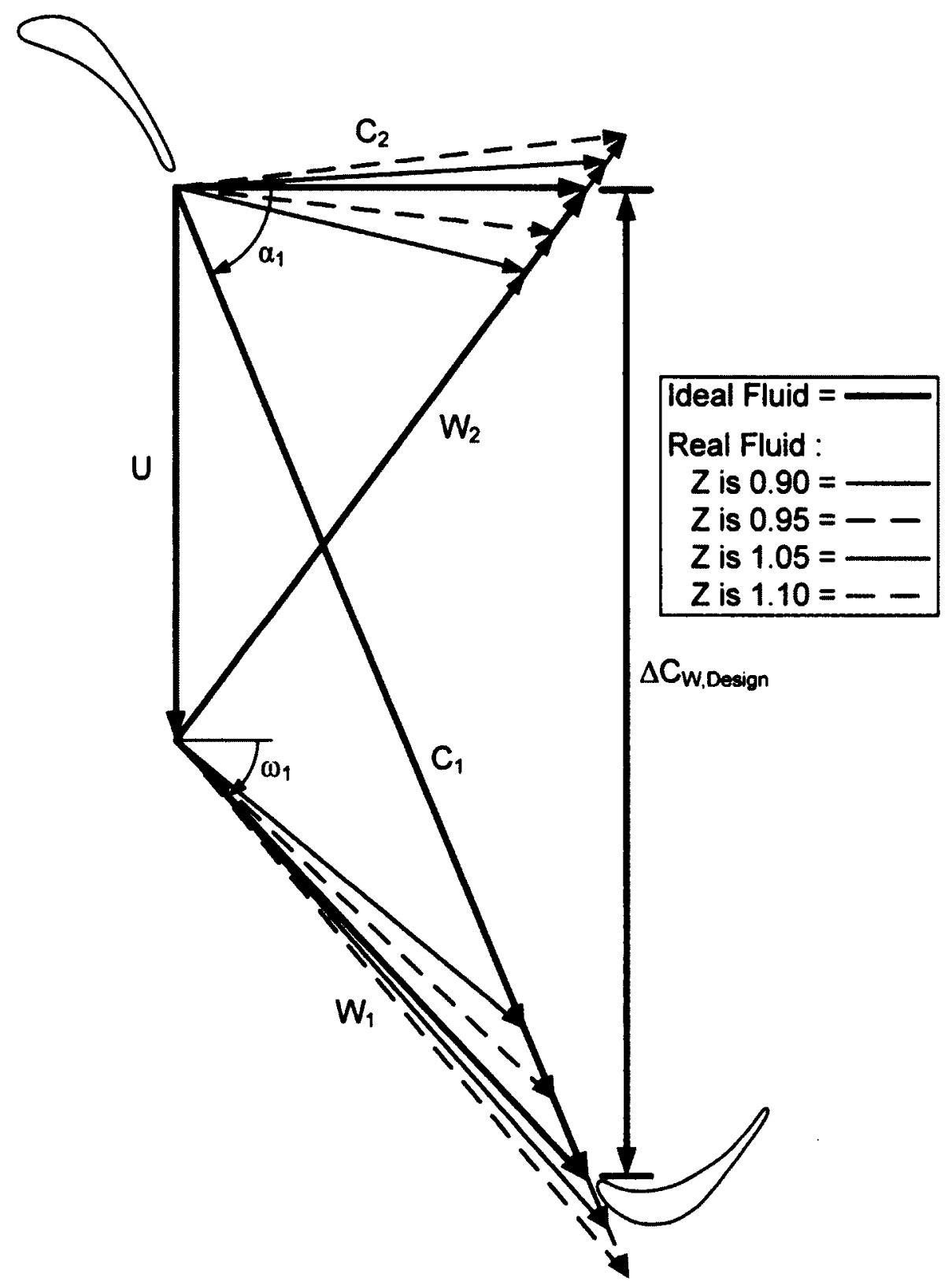

Figure 4.2 Velocity Triangles from Hand Calculations

Figure 4.2 shows that the velocities in the real fluid cases increase as the compressibility factor increases. This increase in velocity leads to an increase in the 
change in whirl velocity, $\Delta \mathrm{C}_{\mathrm{W}}$. Increasing $\Delta \mathrm{C}_{\mathrm{W}}$ leads to an increase in the total enthalpy drop across the stage, from Euler's equation,

$$
\Delta \mathrm{h}_{0}=\mathrm{U}_{2} \mathrm{C}_{\mathrm{w}_{2}}-\mathrm{U}_{1} \mathrm{C}_{\mathrm{w}_{1}}
$$

In Figure $4.2 U_{1}$ is equal to $U_{2}$ since the mean radius is constant. Therefore,

$$
\Delta \mathrm{h}_{0}=\mathrm{U} \Delta \mathrm{C}_{\mathrm{W}}
$$

Figure 4.3 shows how $\Delta h_{0}$ varies with the inlet $Z$. As discussed above, $\Delta h_{0}$ does increase with increasing $Z$. However, the effect of the real fluid properties is stronger for $\mathrm{Z}$ factors less than 1.0. Figure 4.3 shows that $\Delta \mathrm{h}_{0}$ decreased by $23.8 \%$ when $\mathrm{Z}$ had a value of 0.90 and $\Delta h_{0}$ only increased by $15.1 \%$ when $Z$ was equal to 1.10 . Increasing the total enthalpy drop leads to an increase in the power output of the turbine since,

$$
\dot{\mathrm{W}}=\dot{\mathrm{m}} \Delta \mathbf{h}_{\mathbf{0}}
$$

where, $\dot{\mathrm{W}}$ is the power output and $\dot{\mathrm{m}}$ is the massflow rate. Therefore, a machine designed using the ideal gas assumption with an inlet compressibility factor greater than 1.0 would actually produce more power than was originally intended.

Figure 4.2 shows that in the real fluid cases $\alpha_{2}$ and $\omega_{1}$ are altered. Therefore, if the compressibility factor is different from 1.0 the rotor blade will be at some value of incidence angle to the oncoming flow. If the designs had a following stage the next stage nozzle would also be at some off-design incidence angle due to the change in $\alpha_{2}$. The 


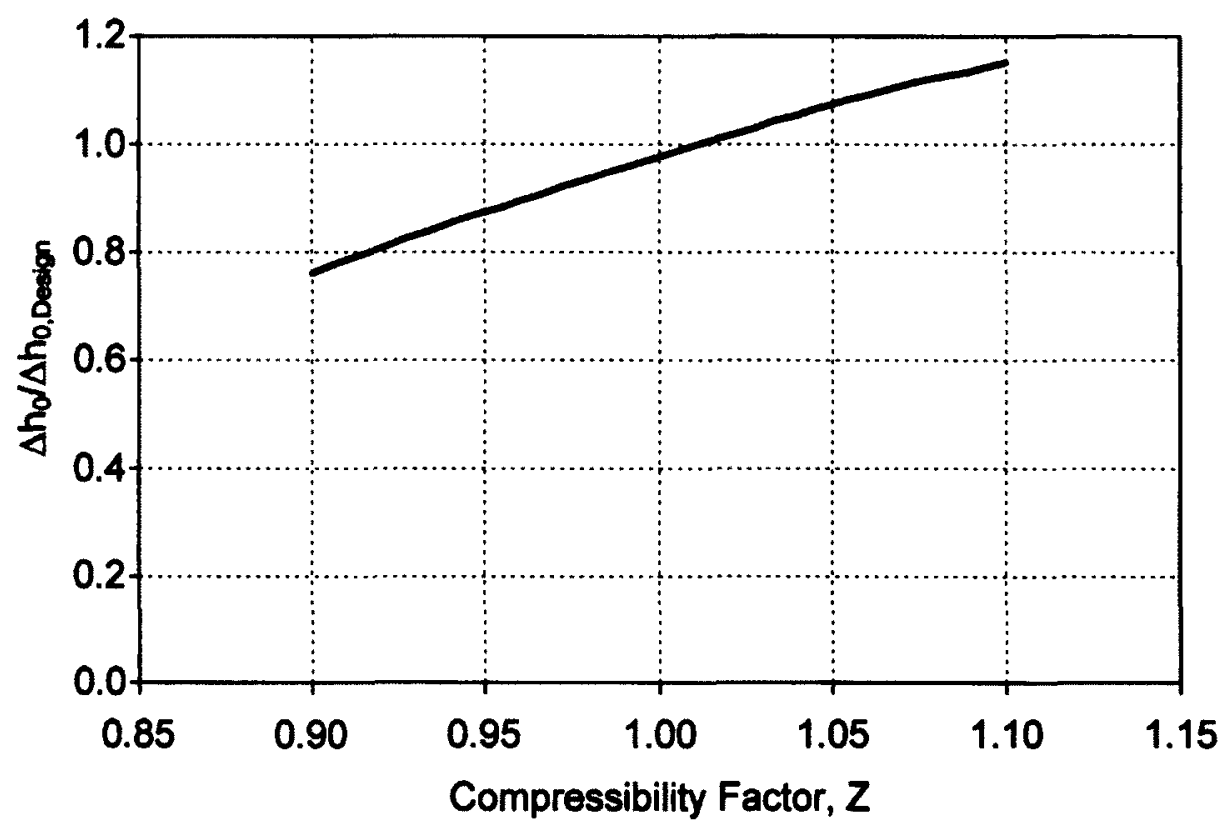

Figure 4.3 Total Enthalpy Drop Variation with Compressibility Factor

variation in the incidence angles with change in the compressibility factor is shown in Figure 4.4. The presence of incidence will cause additional losses.

Figure 4.5 shows the effect of varying compressibility factor on the Mach numbers. The Mach numbers from the real fluid cases normalized on the values from the ideal cases are shown for three locations: the stage inlet, nozzle outlet and rotor outlet. For compressibility factors greater than 1.0 the sonic velocities in the real fluid properties cases were greater than those in the ideal gas cases. Therefore, even though the velocities are larger in the real fluid cases the Mach numbers are almost equal to the design values. For compressibility factors less than 1.0 the sonic velocities of the two working fluids are similar. Therefore, due to the lower velocities in the real fluid cases the Mach numbers are smaller than the design values. The result is that the real fluid properties have a much stronger effect on the Mach numbers when the compressibility factor is less than 1.0. 


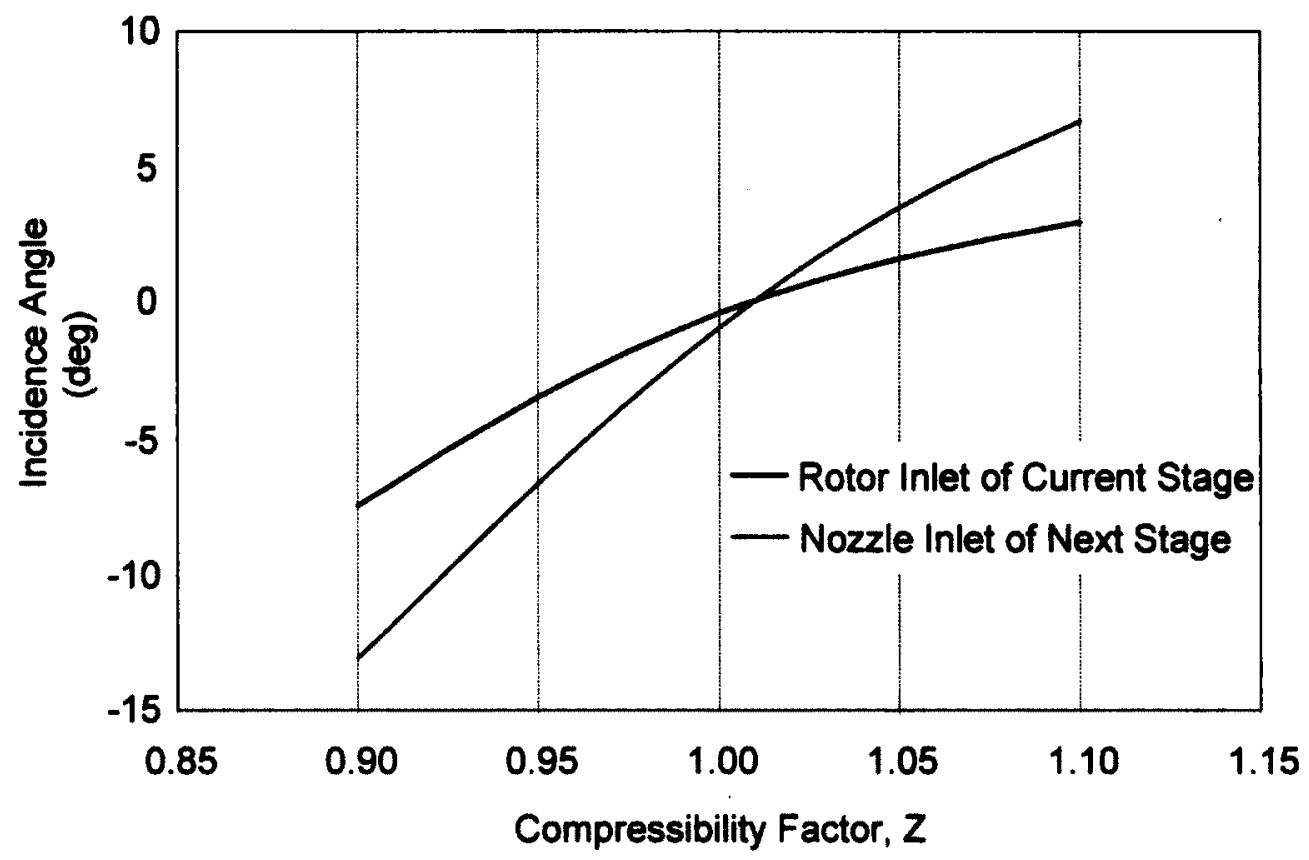

Figure 4.4 Incidence Angle Variation with Compressibility Factor

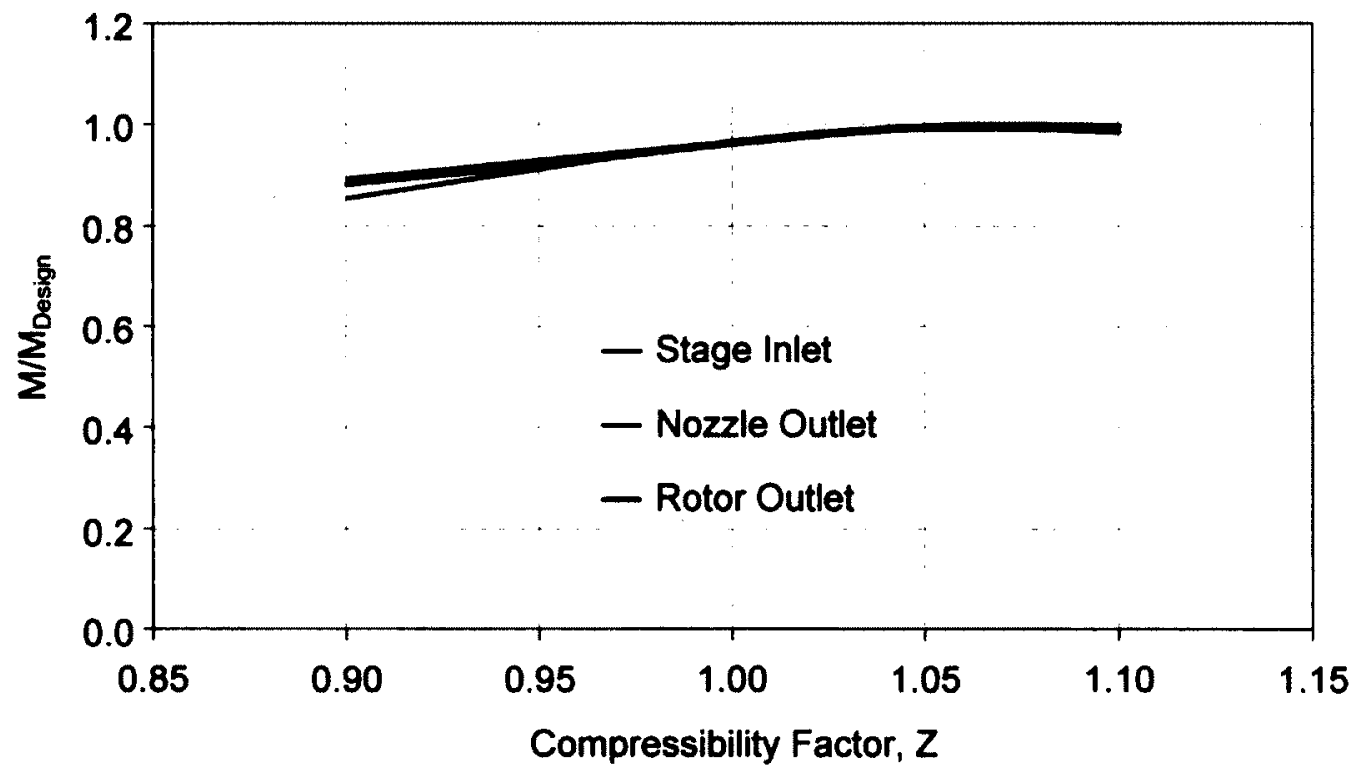

Figure 4.5 Mach Number Variation with Compressibility Factor

As mentioned, the total enthalpy drop across the stage, $\Delta \mathrm{h}_{0}$, increases as the compressibility factor increases. Therefore, the work coefficient, $\psi=\Delta h_{0} / U^{2}$, also 
increases with the compressibility factor. An increase in the work coefficient indicates an increase in the stage loading. Higher stage loading will result in higher blade loading as there are a fixed number of blades in each row. Therefore, the tangential force coefficient, the Zweifel coefficient, will increase with increasing compressibility factor. As blade loading increases there is a risk of separation on the suction side of the blade. Since the axial component of velocity increases with increasing compressibility factor as seen in Figure 4.2, the flow coefficient, $\varphi=C_{a} / U$, also increases.

The degree of reaction is a measure of how the pressure drop is split between the rotor and nozzle blade rows and is defined as:

$$
\Lambda=\frac{h_{2}-h_{1}}{h_{02}-h_{01}}=\frac{\frac{1}{2}\left[\left(U_{2}^{2}-U_{1}^{2}\right)+\left(W_{1}^{2}-W_{2}^{2}\right)\right]}{\Delta h_{0}}
$$

Changing the compressibility factor will affect both the relative velocities and the total enthalpy drop. The total enthalpy drop will behave as described above, i.e. it will increase as the compressibility factor increases. The change in $\left(W_{1}^{2}-W_{2}^{2}\right)$ will depend on the flow angles at the exit of the nozzle and rotor blade rows. If the relative velocity at the nozzle exit, $W_{1}$, increases faster than the relative velocity at the rotor exit, $W_{2}$, then the difference between them will increase as the compressibility factor increases. Depending on the shape of the velocity triangles the difference in the relative velocities could also decrease as the compressibility factor increases. For the machines discussed in this thesis the difference in the relative velocities increased as the compressibility factor increased. 
However, the total enthalpy drop increased at a faster rate. Therefore, the degree of reaction decreases with increasing compressibility factor, as shown in Figure 4.6.

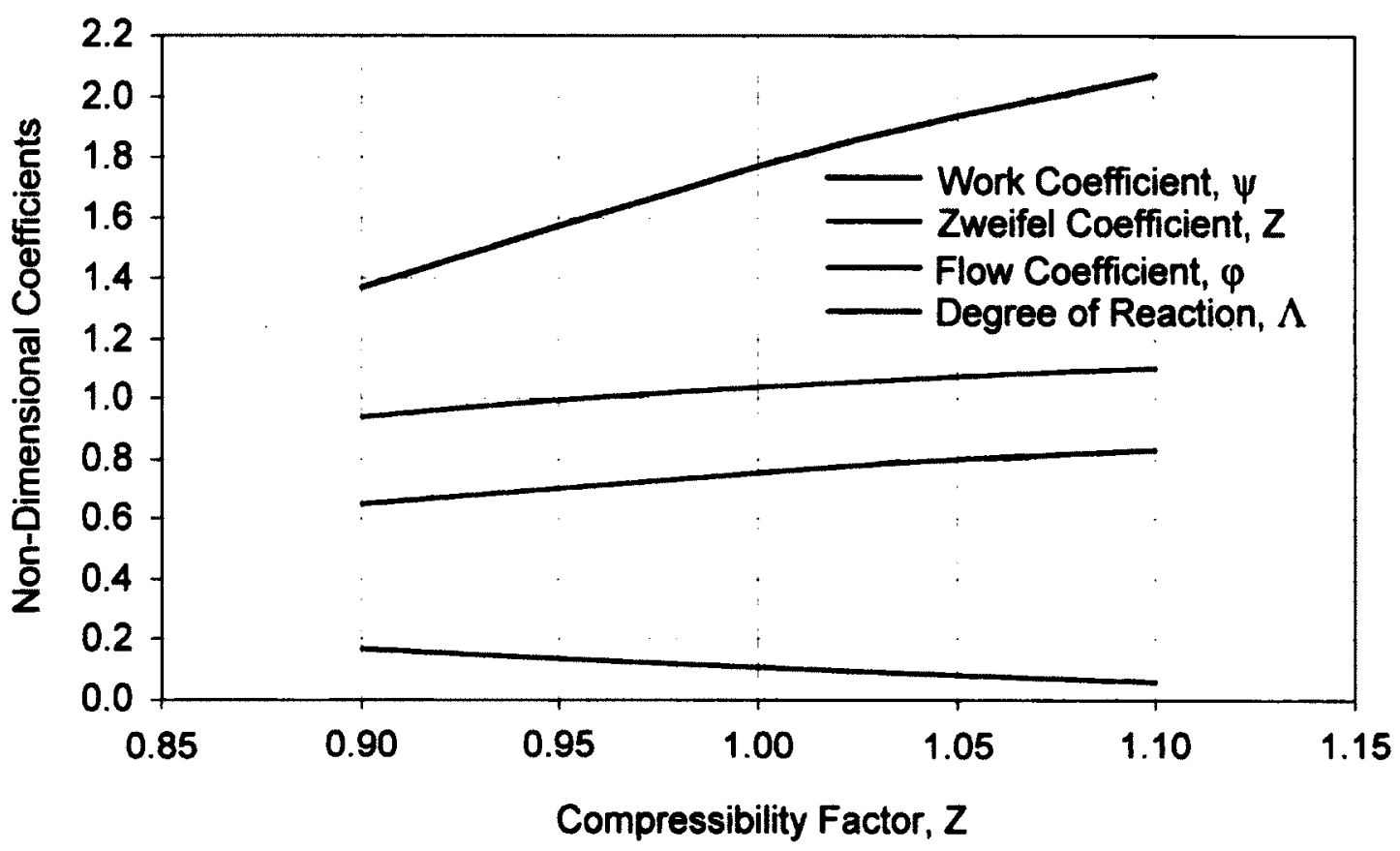

Figure 4.6 Non-Dimensional Coefficients Variation with Compressibility Factor

Figure 4.6 also shows how the work, flow, and Zweifel coefficients vary with the inlet compressibility factor. The values at $\mathrm{Z}=1.0$ indicate the ideal gas value of each coefficient.

The manual calculations indicate that there are substantial effects on the aerodynamic performance of a machine that has been designed using the ideal gas assumption and is then operated with a working fluid that differs considerably from ideal behaviour. However, the manual calculations assumed isentropic expansion and therefore do not account for the effects of the losses that will be present in an actual turbine. These effects are examined in the following sections. 


\subsection{Effects of Real Fluid Properties on Results from TMLD}

\subsubsection{Effects of Real Working Fluids on Turbine Geometries}

As described in Section 2.10, TMLD is a code developed for the meanline design of axial turbines. It also predicts the design-point efficiency of the machine based on empirical loss correlations. The original code assumed ideal gas behaviour for the working fluid, but it has been modified in the present work to account fully for real fluid properties.

TMLD was employed to design four single stage machines: two for ideal gas working fluids and two for real working fluids. One ideal and one real machine were designed for inlet conditions corresponding to an inlet compressibility factor, $Z$, of 0.90 and the other two machines for $Z=1.10$. For convenience, these machines will be referred to as 190 , I1 10, R90, and R110 where I and R refer to "ideal gas" and "real fluid" and the number indicates the value of $\mathrm{Z} \times 100$. The inlet conditions of the four machines are shown in Table 4.2.

\begin{tabular}{|c|c|c|c|c|}
\hline $\begin{array}{c}\text { Machine } \\
\text { Names }\end{array}$ & $\begin{array}{c}\text { Total } \\
\text { Temperature } \\
\text { (K) }\end{array}$ & $\begin{array}{c}\text { Total } \\
\text { Pressure } \\
\text { (bar) }\end{array}$ & $\begin{array}{c}\text { Massflow } \\
\text { Rate } \\
\text { (kg/s) }\end{array}$ & $\begin{array}{c}\text { Inlet } \\
\text { Compressibility } \\
\text { Factor } \\
\text { (Real Fluid } \\
\text { Cases Only) }\end{array}$ \\
\hline 190, R90 & 470 & 115 & 1500 & 0.90 \\
\hline I110, R110 & 1500 & 420 & 1900 & 1.10 \\
\hline
\end{tabular}

Table 4.2 Inlet Conditions of the Four TMLD Machines 
As with the manually-designed turbines, the four machines were designed to have a work coefficient of 1.8 , a flow coefficient of 0.75 and an absolute stage exit flow angle of $0^{\circ}$. They would therefore again be regarded as moderately-loaded stages. All four machines again also have a constant mean radius of 0.3 meters and a rotational speed of $3600 \mathrm{RPM}$. The differences in geometry and performance between the 190 and R90 machines are primarily due to the difference in the fluid properties as both machines have the same inlet conditions and velocity triangles. The same can be said for the I1 10 and R110 machines.

In the ideal gas cases the density of the working fluid is calculated from the ideal gas equation:

$$
\rho=\frac{P}{R T}
$$

where, $P$ is static pressure, $R$ is the gas constant of the working fluid, and $T$ is static temperature. When the compressibility factor is included the ideal gas equation becomes,

$$
\rho=\frac{P}{Z R T}
$$

where, $\mathrm{Z}$ is compressibility factor. From Equation 4.3 one can see that as the compressibility factor decreases the density increases. Therefore, the cross-sectional areas of the 190 machine are greater than those for the R90 machine and the areas for the I1 10 machine are less than those for the R110 machine. Figure 4.7 compares the crosssectional areas of the $Z=0.90$ machines and Figure 4.8 compares the $Z=1.10$ machines. 


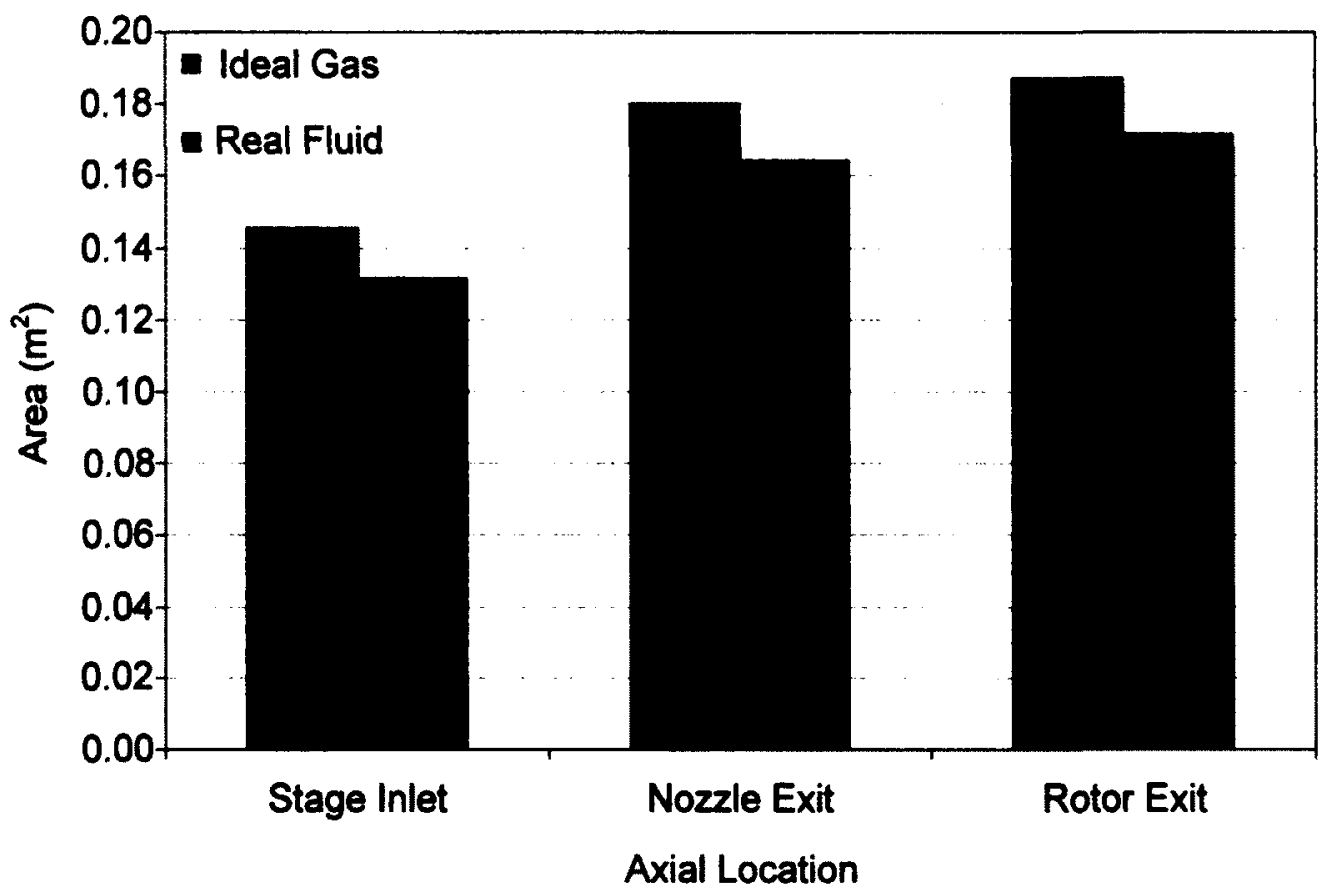

Figure 4.7 Cross-Sectional Areas of the 0.90 Inlet Compressibility Factor Machines

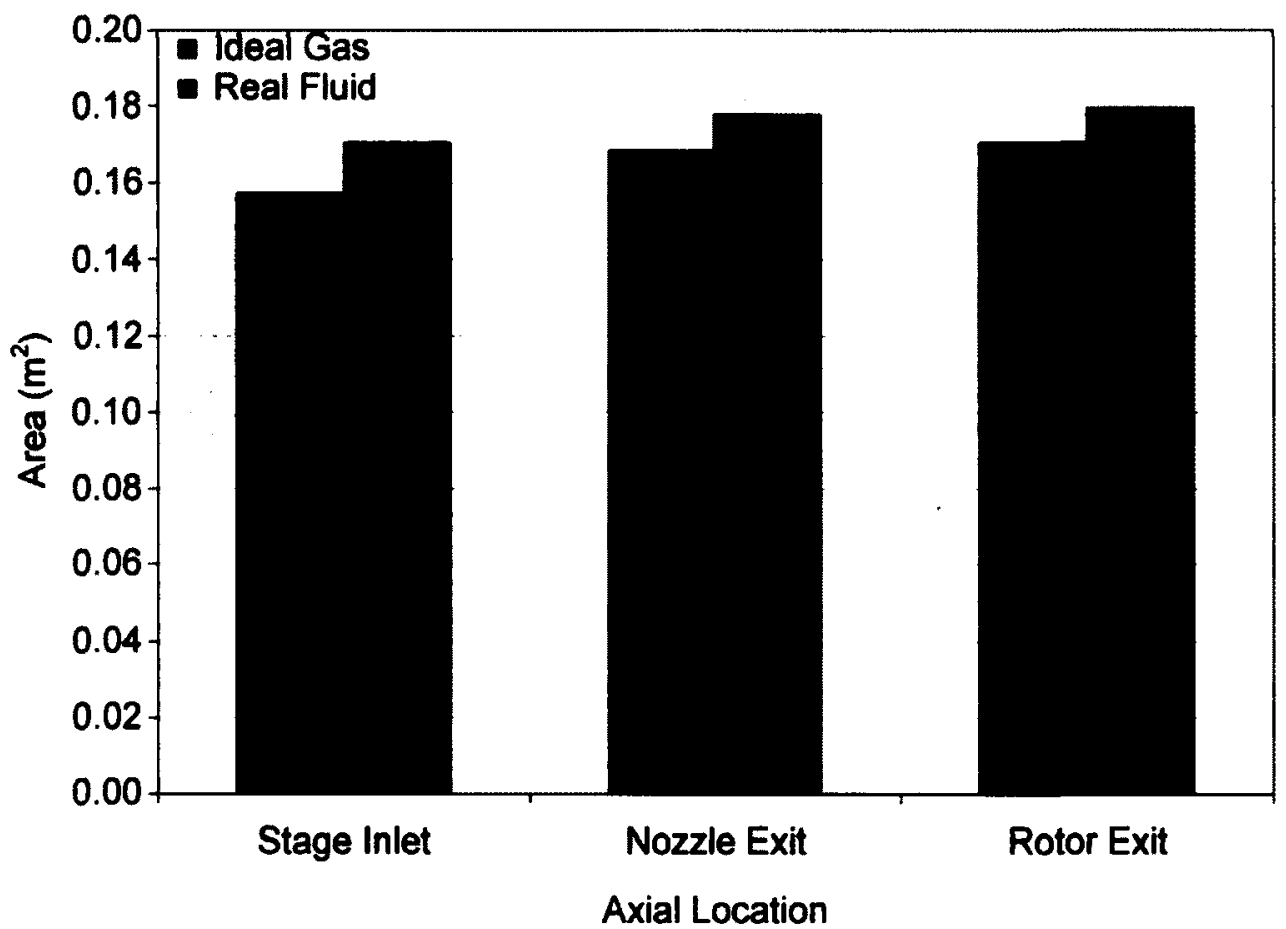

Figure 4.8 Cross-Sectional Areas of the 1.10 Inlet Compressibility Factor Machines 
Figure 4.9 shows to scale the gas path geometries of the four machines.

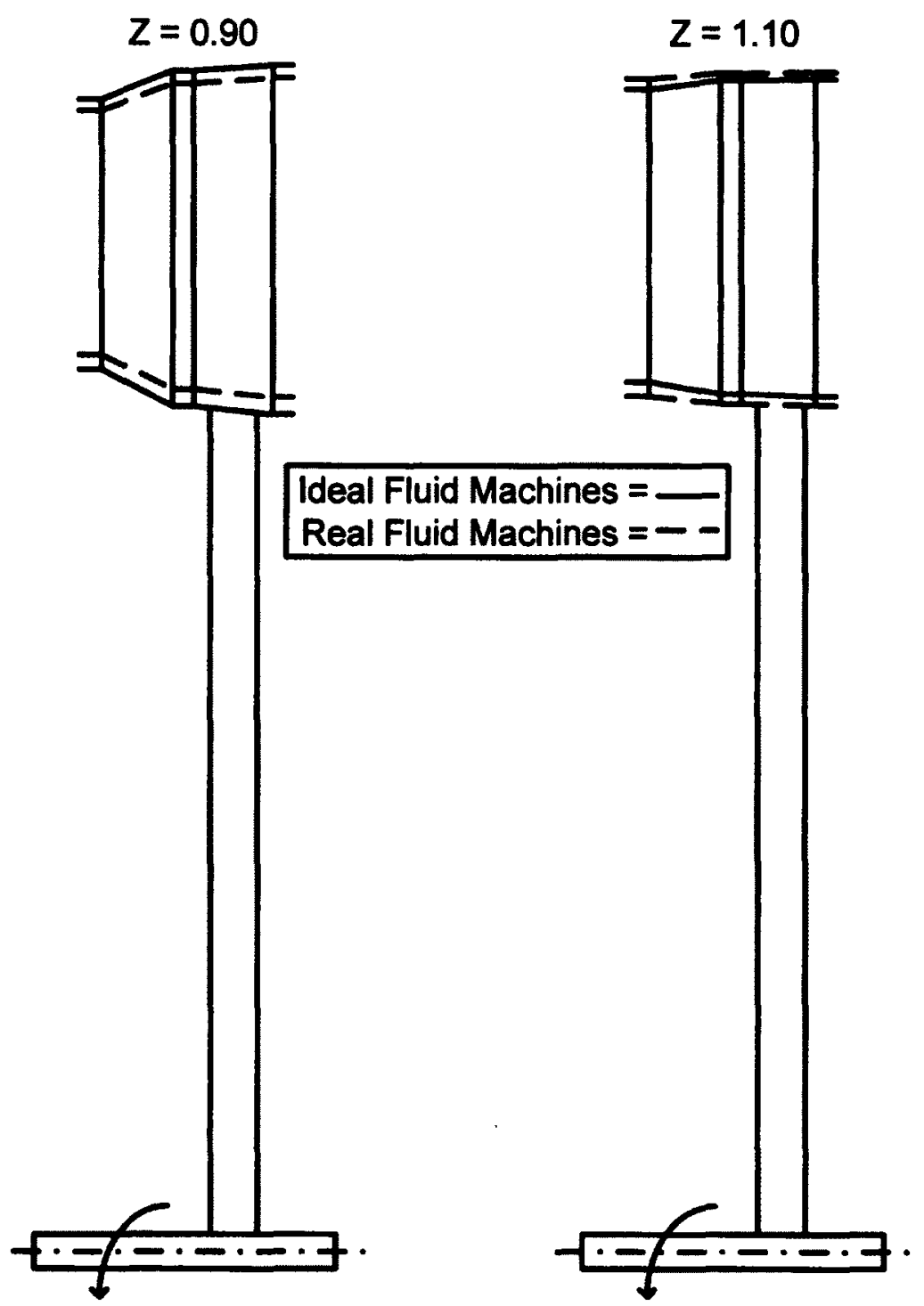

Figure 4.9 Cross-Sectional Areas of the Four TMLD Designed Machines

The performance predictions obtained using TMLD at the design point are presented next. Figure 4.10 shows the Mach number values calculated using TMLD for the $Z=$ 0.90 turbines and Figure 4.11 those for the $Z=1.10$ turbines. 


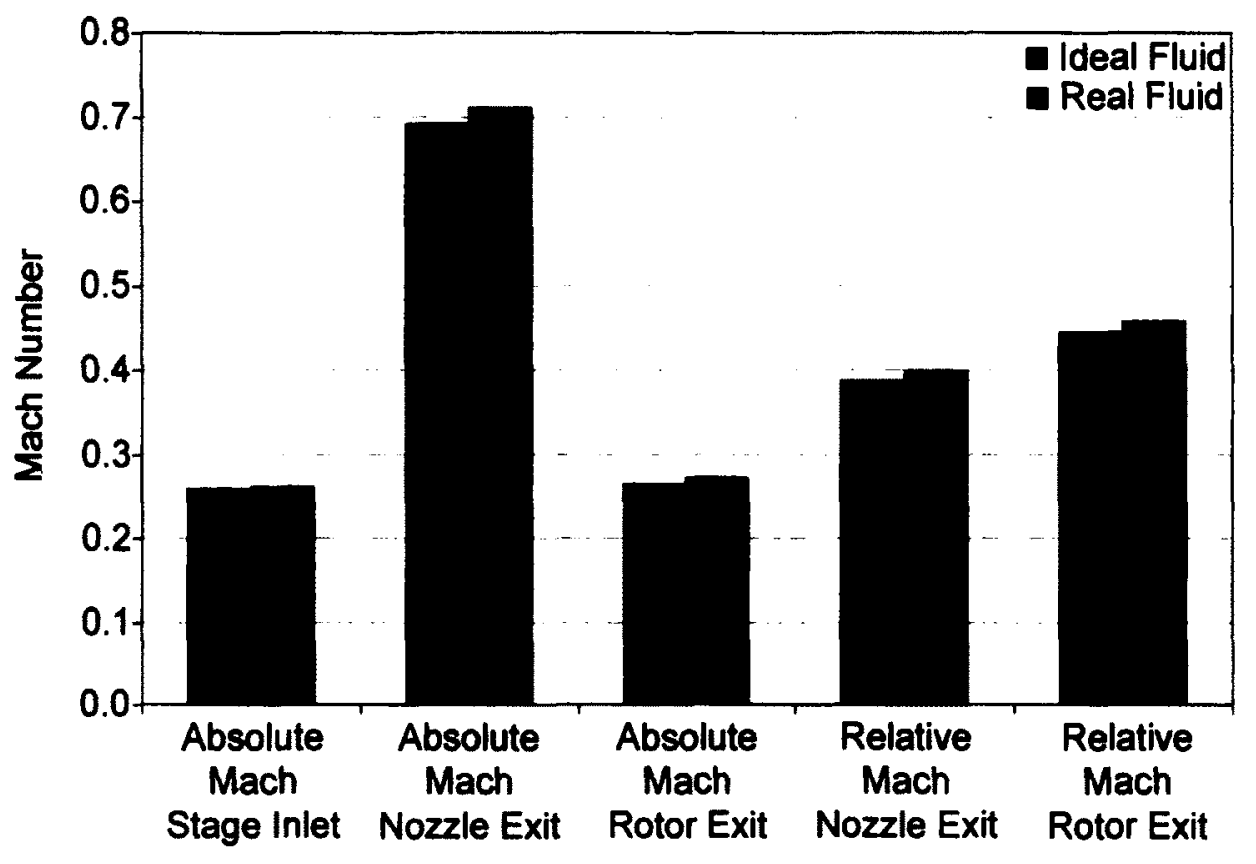

Figure 4.10 Mach Number Values for the $Z=0.90$ Turbines

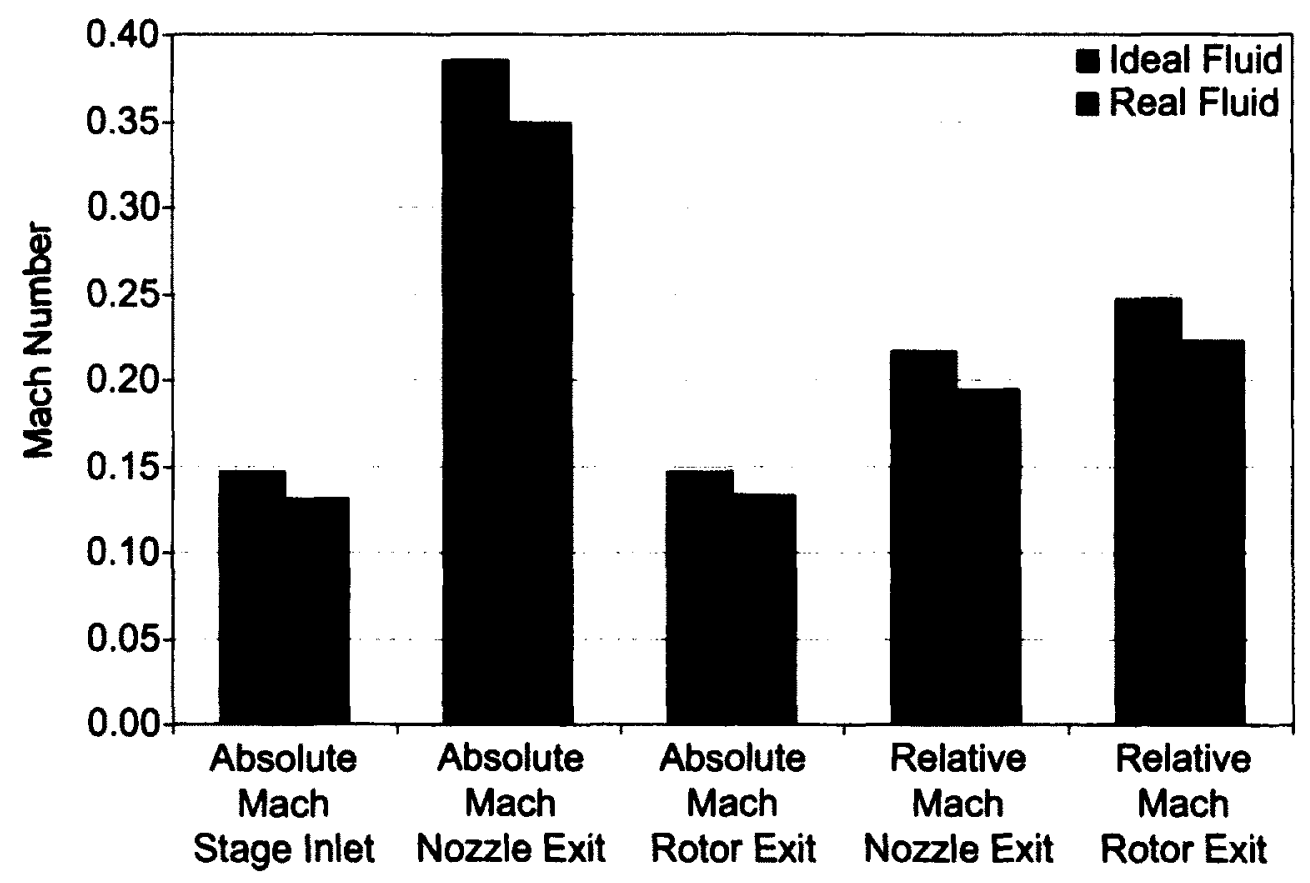

Figure 4.11 Mach Number Values for the $Z=1.10$ Turbines 
The velocities in all four machines are identical. Therefore, the differences in the Mach numbers are a result of the sonic velocity estimations. The equation for sonic velocity including the compressibility factor is given by,

$$
a=\sqrt{Z \gamma R T}
$$

where $\gamma$ is the isentropic exponent. For compressibility factors less than 1.0 the sonic velocity decreases compared with the ideal gas value at the same pressure and temperature. Therefore, neglecting the real fluid effects causes the Mach numbers to be under predicted for compressibility factors less than 1.0 and over predicted for values greater than 1.0.

Figure 4.12 shows the predictions from TMLD of the total pressure ratios and isentropic efficiencies of the four machine designs. The total pressure ratio across the 190 machine is less than that of the $\mathrm{R} 90$ machine, whereas the total pressure ratio of the $\mathrm{II} 10$ machine is greater than that of the R110 machine. Thus, for inlet compressibility factors less than 1.0 the ideal gas assumptions under estimate the total pressure ratio required to achieve the specified total enthalpy drop, whereas it is over estimated when the compressibility factor is greater than 1.0. The isentropic efficiencies are similar in all four cases because the four sets of velocity triangles are identical. However, the efficiencies are not identical due to the differences in the Mach numbers, shown in Figure 4.10 and Figure 4.11. 


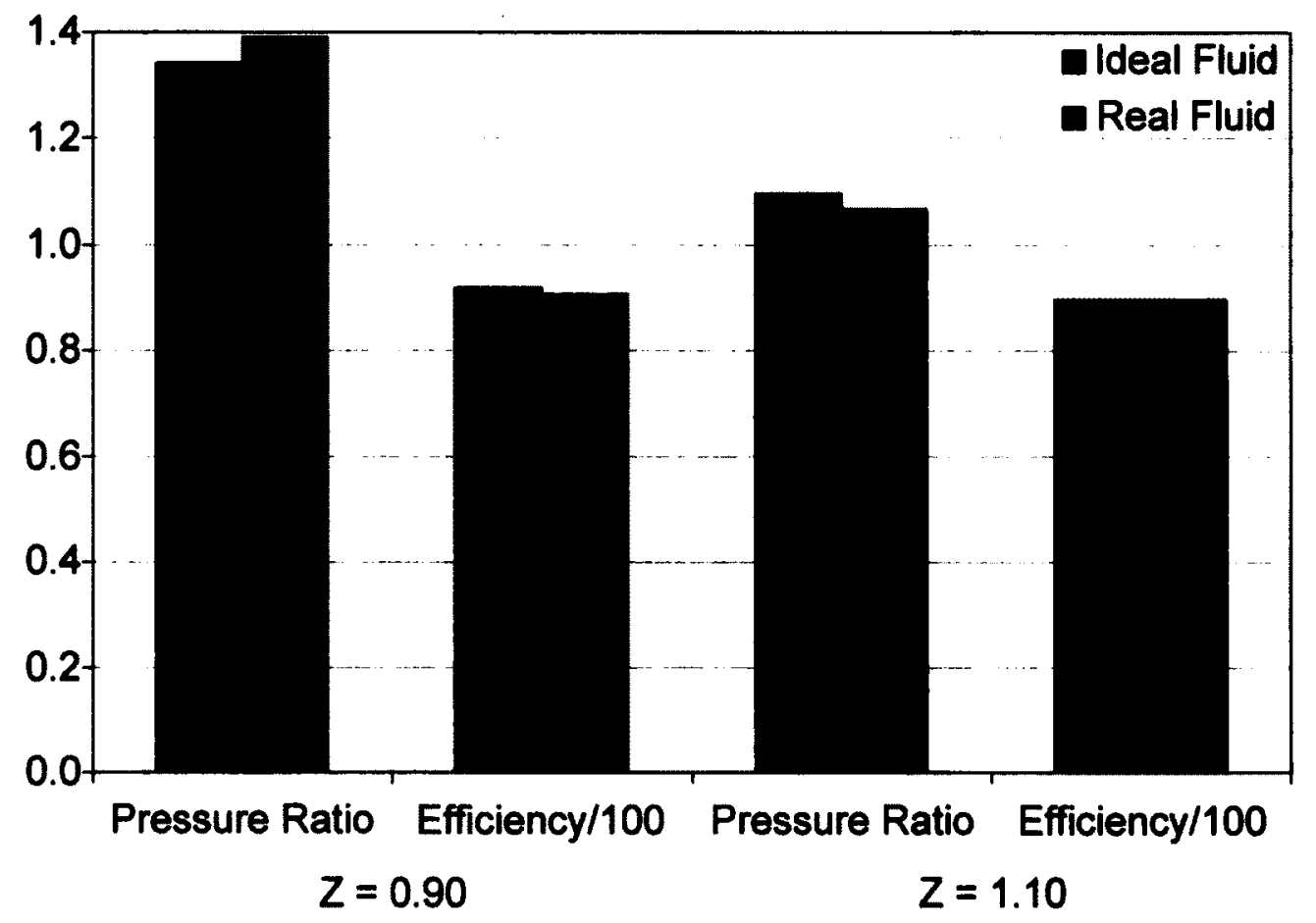

Figure 4.12 Performance Parameters of the Four TMLD Designed Machines

\subsubsection{Convergence Times for Ideal and Real Working Fluids}

The time required for TMLD to reach a converged solution depends on whether the working fluid is treated as an ideal gas or real fluid. When the working fluid is an ideal gas the relationships between static and total conditions are obtained using the isentropic relations, which are explicit. When the working fluid is treated as a real fluid the thermodynamic properties become a function of pressure and temperature. Relating the static and total conditions requires an additional level of iteration as described in Section 3.2. As a result, the convergence time for real working fluids is significantly longer than for ideal working fluids. 
There is a small difference in the convergence time between the exhaust gas working fluid and the dry air, nitrogen and carbon dioxide working fluids when they are treated as ideal gases. This difference is due to how the specific heat and isentropic exponent are estimated. The exhaust gas working fluid employs a simple correlation to estimate the specific heat and isentropic exponent. When the working fluid is dry air, nitrogen or carbon dioxide and is treated as an ideal gas the specific heat and isentropic exponent are determined using the NASA developed GASP program subroutines (Hendricks et al., 1975). The convergence time for these fluids is similar to the exhaust gas working fluid but not as fast.

As mentioned in Section 3.3.2, in order to incorporate the Kacker and Okapuu unshrouded rotor blade tip clearance total pressure loss correlation an iteration loop was added to the calculation of the velocity triangles for any stage with unshrouded blades. This additional iteration loop also increases the time required for TMLD to converge.

The convergence time also depends on what two conditions are selected to specify the target performance. These can be chosen from the total enthalpy drop, total pressure ratio, degree of reaction or stage exit absolute flow angle. However, TMLD was designed to use inputs of total enthalpy drop across a stage and the degree of reaction. If the total enthalpy drop is replaced with the total pressure ratio, then TMLD must use an additional iteration loop to arrive at the stage velocity triangles that give the specified the total enthalpy drop. The same applies if the stage exit absolute flow angle is specified rather than the degree of reaction. 
Table 4.3 shows the results for typical, relative TMLD convergence times obtained on a particular computer. Each fluid was run for the best and worst case scenarios in terms of the type of input data provided and whether the rotor blades were shrouded or not. The best case scenario corresponds to shrouded rotor blades and the total enthalpy drop and degree of reaction being specified. The worst case scenario corresponds to unshrouded rotor blades and the total pressure ratio and stage exit absolute flow angle being specified.

\begin{tabular}{|l|c|}
\hline \multicolumn{1}{|c|}{ Type of Fluid and Case } & Approximate Convergence Time \\
\hline Exhaust Gas, Best Case & $<0.5$ seconds per stage \\
\hline Exhaust Gas, Worst Case & 1 second per stage \\
\hline Other Fluids Treated as Ideal, Best Case & $<1$ seconds per stage \\
\hline Other Fluids Treated as Ideal, Worst Case & 50 seconds per stage \\
\hline Other Fluids Treated as Real, Best Case & 5 seconds per stage \\
\hline Other Fluids Treated as Real, Worst Case & 15 minutes per stage \\
\hline
\end{tabular}

Table 4.3 TMLD Convergence Time for Three Fluid Types

\subsection{Off-Design Calculations Using TMLO}

\subsubsection{Introduction}

The investigations conducted with TMLO consisted of two parts. First, the performance of the two ideal gas turbines designed using TMLD were reanalysed using the real fluid properties of the working fluid. Second, the full turbine characteristic for 
one of the real fluid turbines designed using TMLD was generated. Sections 4.4.2 and 4.4.3 discuss the results from these investigations.

\subsubsection{Effects of Real Working Fluids on Ideal Gas Machine Performance}

In Section 4.2.2 manual calculations were performed to determine the effects of real fluid properties on the velocity triangles and performance parameters of turbines that were designed for ideal gases. In these calculations it was assumed that the expansion of the working fluid through the turbines was isentropic. This section revisits the investigation of the effects of real fluid properties on the performance of turbines designed employing the ideal gas assumptions. However, this section also discusses the interaction of the losses and the real fluid properties. The I90 and 1110 machine geometries designed using TMLD were run with TMLO using real fluid properties. The massflow rate and blade speed were set to the design point values. Therefore, any differences between the TMLD and TMLO predictions of the velocity triangles and performance parameters were due to the properties of the working fluid.

As mentioned in Section 4.3.1 the ideal gas machines, I90 and I110, were designed to have the same velocity triangles. Figure 4.13 shows these design velocity triangles along with the velocity triangles resulting from the real fluid properties cases.

While the trends shown in Figure 4.13 are similar to those from the manual calculations, Figure 4.2, the real fluid properties did not affect the 1110 machine as much 


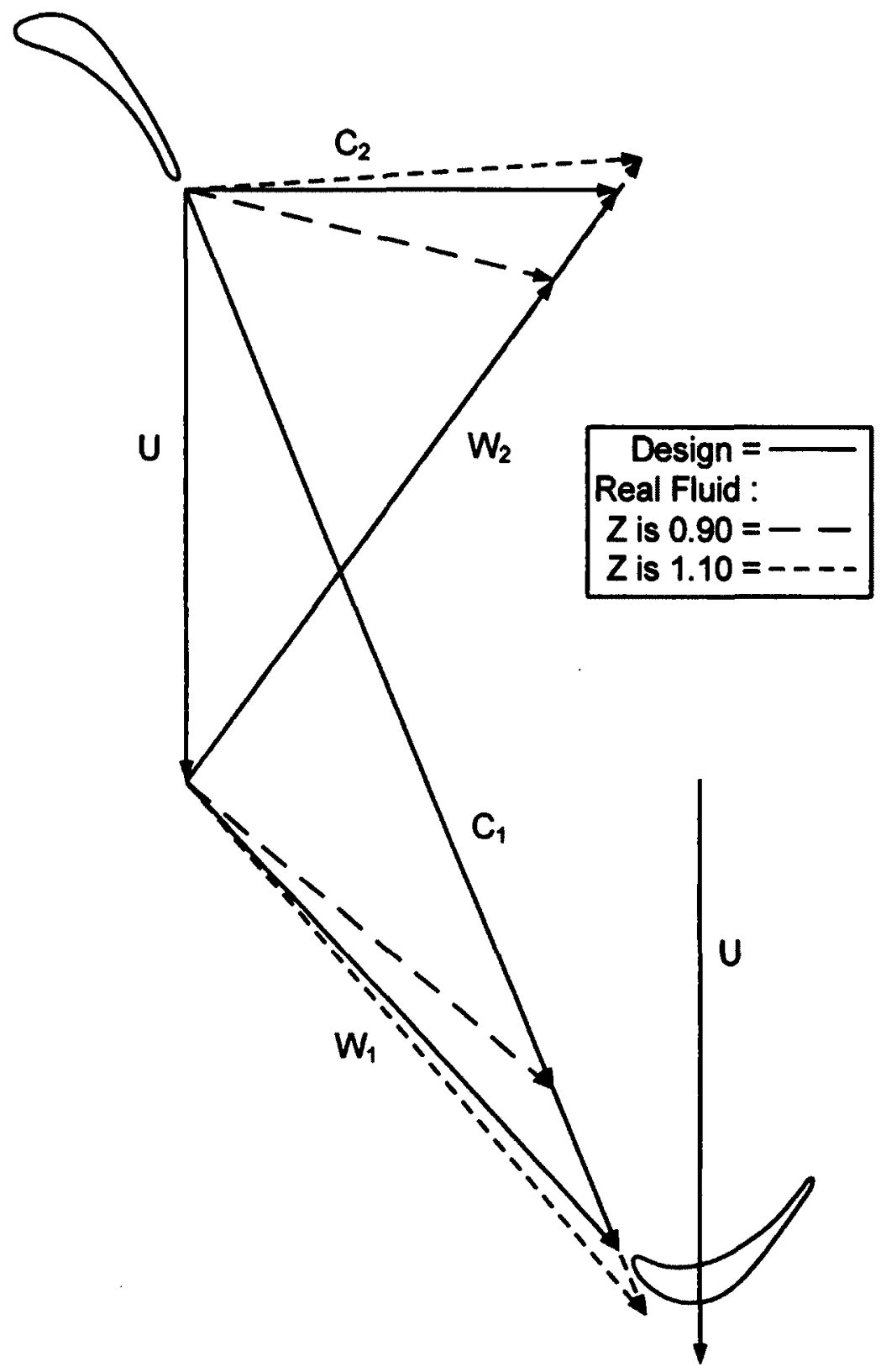

Figure 4.13 Design and Real Fluid Velocity Triangles for the I90 and I1 10 Machines

as they did in the manual calculations. This result indicates that accounting for the losses reduces the effects of the real fluid properties.

Figure 4.13 shows the change in incidence caused by the change in the fluid properties. Changes in incidence were also observed in the manual calculations, Section 
4.2.2. Table 4.4 shows the differences between the results from the manual calculations and TMLO.

\begin{tabular}{|c|c|c|c|c|}
\cline { 2 - 5 } \multicolumn{1}{c|}{} & $\begin{array}{c}\text { Manual } \\
\text { Calculations } \\
\mathbf{Z}=0.90\end{array}$ & $\begin{array}{c}\text { TMLO } \\
\mathbf{Z}=0.90\end{array}$ & $\begin{array}{c}\text { Manual } \\
\text { Calculations } \\
\mathbf{Z}=1.10\end{array}$ & $\begin{array}{c}\text { TMLO } \\
\mathbf{Z}=1.10\end{array}$ \\
\cline { 2 - 5 } & \multicolumn{4}{c|}{ Difference from design flow angle (deg) } \\
\hline Rotor Inlet & -7.4 & -7.3 & 3.0 & 2.0 \\
\hline Rotor Outlet & 13.3 & 12.8 & -6.6 & -3.9 \\
\hline
\end{tabular}

Table 4.4 Differences in Flow Angles Between Manual Calculations and TMLO Results

Table 4.4 shows that accounting for losses influences the flow angles in both the $\mathrm{Z}=$ 0.90 and $\mathrm{Z}=1.10$ cases. However, the interaction of losses and real fluid properties is stronger in the $Z=1.10$ case.

Figure 4.14 shows the values of the work coefficient, $\psi$, flow coefficient, $\varphi$, and total enthalpy drop, $\Delta \mathrm{h}_{0}$, from the TMLO and manual calculations real fluid properties cases normalized on the design values. The design values of $\psi, \varphi$, and $\Delta h_{0}$ were the same in the manual calculations and TMLD designed turbines. Thus, the design values are represented by the bars labeled "Design".

Figure 4.14 shows that the $Z=0.90$ results are very similar in the two cases, although TMLO predicted a slightly smaller effect from the real fluid properties, i.e. the TMLO values are slightly closer to the design values. The $Z=1.10$ cases show a much more noticeable difference between the TMLO and manual calculations results. The TMLO predicted results are significantly closer to the design values, thus were not as affected by 


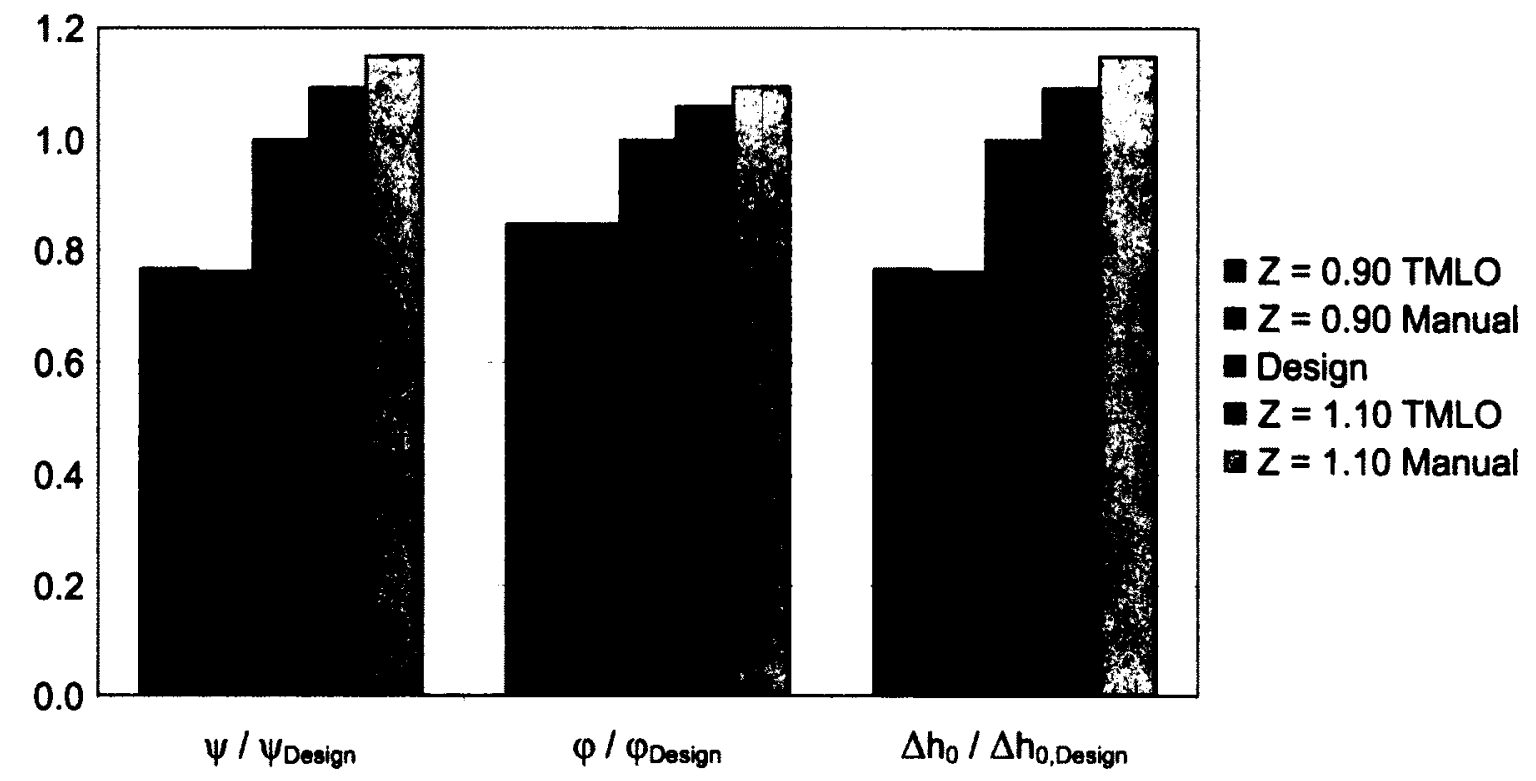

Figure 4.14 TMLO and Manual Calculations Predicted Performance Parameters Normalized on Design Values

the real fluid properties as the manual calculations case. Therefore, accounting for the losses in TMLO lessened the effects of the real fluid properties, especially in the 1.10 compressibility factor results.

The results from the TMLO cases show that when losses are included the real fluid properties have a stronger influence on the velocity triangles and performance parameters of turbines with $Z<1.0$ compared to turbines with $Z>1.0$. Therefore, turbines with an inlet $Z>1.0$ and were designed using the ideal gas assumption will run closer to the design performance than a turbine with an inlet $Z<1.0$. This is important as the turbine design from the Carleton University $4^{\text {th }}$ year engineering project from 2008-2009 has an inlet $\mathrm{Z}$ of 1.05 . 


\subsubsection{Single Stage Turbine Characteristic}

Turbine characteristics are representations of how a turbine will perform over its full operating range. The turbine characteristics are usually presented as plots of isentropic efficiency and massflow rate against the total pressure ratio, for a range of rotational speeds. TMLO can be used to calculate such off-design characteristics.

The R90 turbine, discussed in Section 4.3.1, was analysed with TMLO over a range of off-design points to produce a characteristic. This analysis was conducted to show the range of off-design conditions over which TMLO can successfully operate. Other turbine designs were analysed and showed similar results, therefore only the R90 results will be presented here.

Figure 4.15 shows how the isentropic efficiency of the R90 machine changes with respect to the total pressure ratio and rotational speed, $\mathrm{N}$. The solid black diamond indicates the design point value of the isentropic efficiency, estimated with TMLD. The design point value of efficiency falls on the design rotational speed curve at the design total pressure ratio. Therefore, the TMLO and TMLD results are in very close agreement. Figure 4.15 shows that TMLO can predicted efficiencies which form smooth and easily discernable curves. This shows that TMLO is stable even at conditions that are significantly different from the design-point.

Figure 4.16 shows the massflow rate versus total pressure ratio for the R90 turbine. The traditional expression for normalizing massflow rate, shown in Figure 2.6, cannot be 


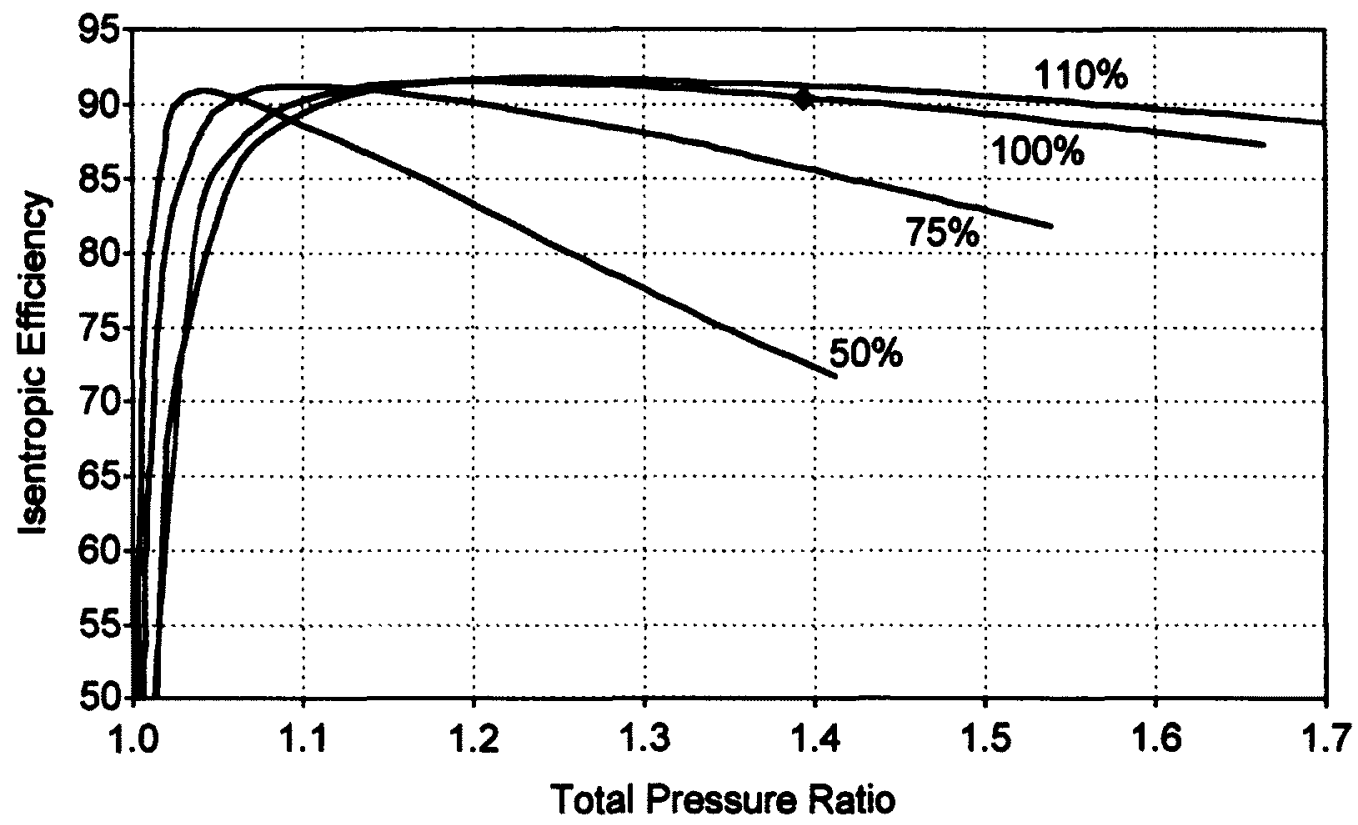

Figure 4.15 Isentropic Efficiency Component of the R90 Machine Turbine Characteristic used in this case as it was arrived at using the ideal gas assumptions. Therefore, the massflow rate was non-dimensionalized on the design value. As in Figure 4.15, the black diamond represents the design point. Again, the design point values from TMLD are in very close agreement with the TMLO predicted values. Figure 4.16 also shows that TMLO predicts that the machine chokes at a massflow rate of approximately $107 \%$ of the design value with increasing total pressure ratio as indicated by the asymptotic behaviour of the massflow rate.

To produce Figure 4.16 TMLO had to converge at off-design points where the exit of the nozzle was at nearly choked conditions. If the value of the massflow rate provided by the user was larger than what the turbine could pass then TMLO crashed. Therefore the massflow rate was increased in small increments from the design-point value in order to approach the choking conditions without crashing the program. The warning message 


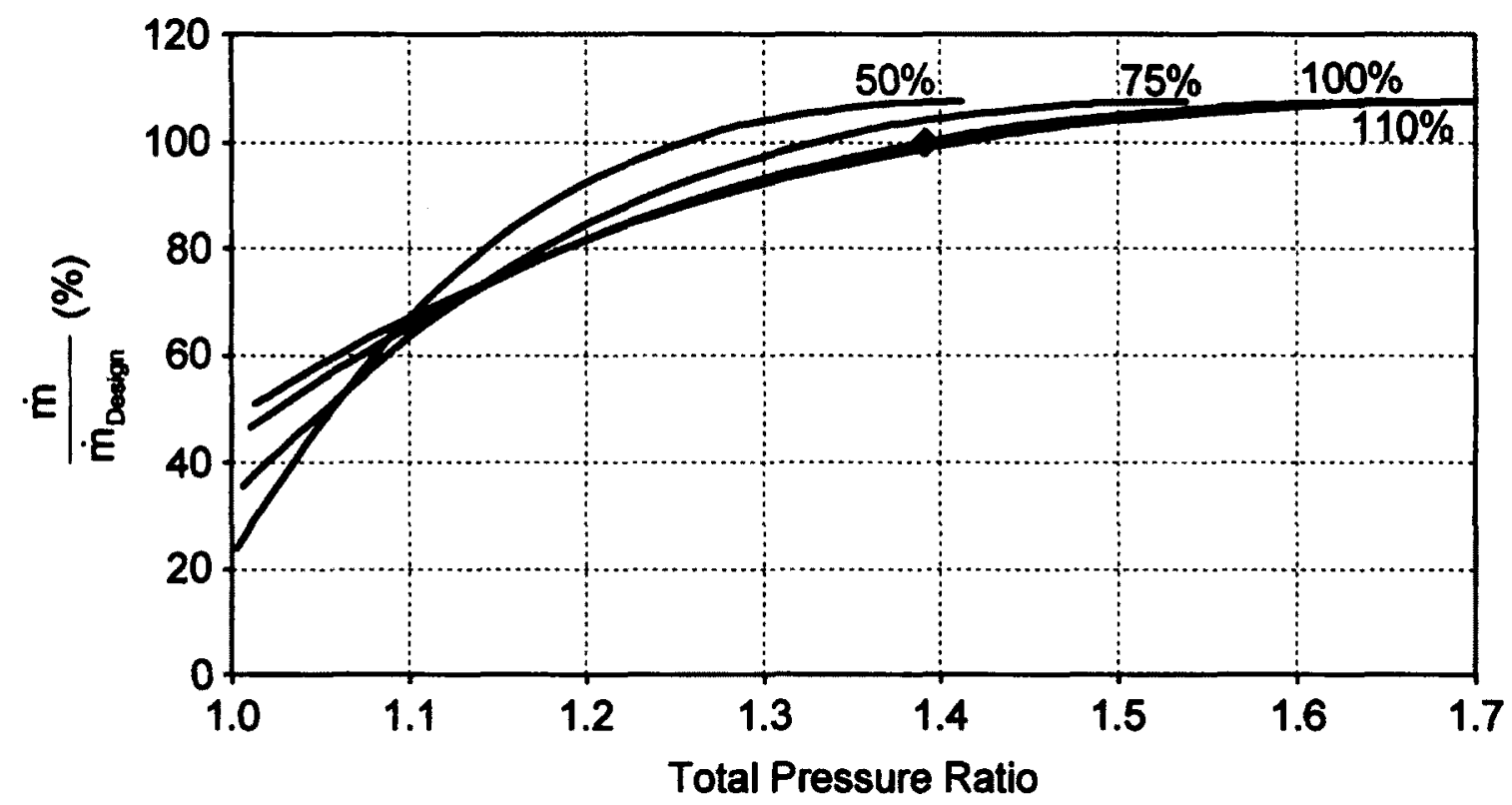

Figure 4.16 Massflow Rate Component of the R90 Machine Turbine Characteristic

shown in Section 3.6, Figure 3.4, appeared in the TMLO output file stating that the absolute velocity at the nozzle exit failed to reach the convergence criterion as the value of the massflow rate neared the value required to choke the turbine. This was used as an indicator to stop increasing the massflow rate.

In Figure 4.16 the shape and order of the constant speed curves matches Figure 2.6 when the massflow rate is above approximately $85 \%$ of the design value. However, below a massflow rate of $85 \%$ of the design value the curves begin to cross and the order of the curves eventually reverses. It was found that the order of the curves depends on the work coefficient of the machine at a given operating point.

Figure 4.17 shows how two sets of velocity triangles with initial work coefficients very different from 1.0 change when the blade speed is changed. The set of velocity 
triangles on the left has an initial work coefficient of 2.0 and a flow coefficient of 0.8 . The set on the right has an initial work coefficient of 0.5 and a flow coefficient of 0.4 . The flow coefficients were selected using the Smith Chart, Figure 2.4, in order to have realistic velocity triangles for the given initial work coefficients. It was assumed that the axial velocity at the rotor inlet and outlet were equal and would be unaffected by the changing blade speed when making Figure 4.17.

In both cases the change in whirl velocity, $\Delta \mathrm{C}_{\mathrm{W}}$, increases as the blade speed, $\mathrm{U}$, decreases. However, as shown in Table 4.5 the total enthalpy drop, $\Delta \mathrm{h}_{0}=\mathrm{U} \Delta \mathrm{C}_{\mathrm{W}}$, can increase or decrease as the blade speed increases depending on the magnitude of the work coefficient. In Table 4.5 the blade speed and change in whirl velocity were normalized on the initial blade speed. The total enthalpy drop was normalized on the initial blade speed squared. The table shows that increasing the blade speed in machines with an initial work coefficient greater than 1.0 will increase the total enthalpy drop. However, increasing the blade speed in a machine with an initial work coefficient less than 1.0 will result in a lower total enthalpy drop. This argument can also be made by manipulation of the Euler equation, shown in Appendix D.

The design point work coefficient for the R90 turbine is 1.8. In Figure 4.16 the work coefficient of any point above a massflow rate of approximately $85 \%$ of the design value is greater 1.0. Therefore, for a constant massflow rate the total enthalpy drop increases with increasing blade speed. At the design blade speed and a massflow rate of approximately $80 \%$ of the design value the work coefficient of the machine is 1.0 . Therefore, for massflow rates below $80 \%$ of the design value the work coefficient drops 


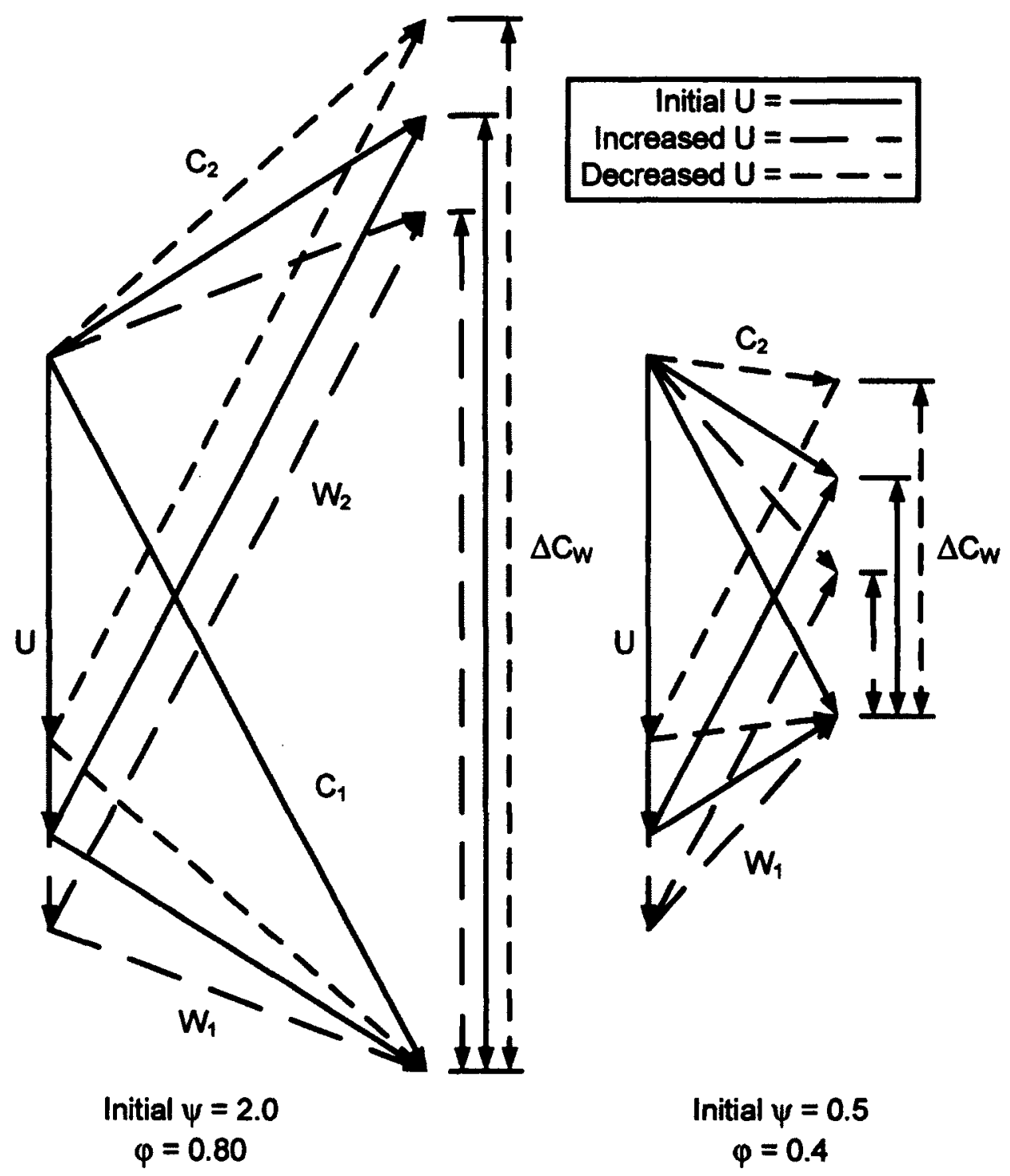

Figure 4.17 Change in $\Delta C_{W}$ with Blade Speed

below 1.0 and increasing the blade speed results in decreasing total enthalpy drop. If the isentropic efficiency remained constant at all off-design points then the total pressure ratio would increase and decrease with the total enthalpy drop. Therefore, the constant speed curves would cross at a single point, which is not the case in Figure 4.16. 


\begin{tabular}{|c|c|c|c|c|}
\cline { 2 - 5 } \multicolumn{1}{c|}{} & $\mathbf{U} / \mathbf{U}_{\text {Inttinl }}$ & $\Delta \mathbf{C}_{\mathbf{W}} / \mathbf{U}_{\text {Inttal }}$ & $\Delta \mathbf{h}_{\mathbf{0}} / \mathbf{U}_{\text {Inttal }}{ }^{2}$ \\
\hline \multirow{3}{*}{ Initial $\psi=2.0$} & Increased U & 1.10 & 1.90 & 2.09 \\
\cline { 2 - 5 } & Initial U & 1.00 & 2.00 & 2.00 \\
\cline { 2 - 5 } & Decreased U & 0.90 & 2.10 & 1.89 \\
\hline \multirow{3}{*}{ Initial $\psi=0.5$} & Increased U & 1.10 & 0.40 & 0.44 \\
\cline { 2 - 5 } & Initial U & 1.00 & 0.50 & 0.50 \\
\cline { 2 - 5 } & Decreased U & 0.90 & 0.60 & 0.54 \\
\hline
\end{tabular}

Table 4.5 Change in $\Delta \mathrm{h}_{0}$ with Blade Speed

Figure 4.15 shows that the isentropic efficiency changes significantly over the range of total pressure ratio from 1.05-1.2, which is where the constant speed curves cross over in Figure 4.16. Therefore, the value of the work coefficient causes the curves of constant rotational speed to cross over each other but the value of total pressure ratio where this occurs is a function of both work coefficient and efficiency.

\subsubsection{Leading-Edge Wedge Angle and Diameter-to-Spacing Ratio}

As shown in Section 2.6.5 the Benner et al. (1997) correlation for off-design profile losses requires the values of the leading-edge wedge angle, We, and the leading-edge diameter-to-spacing ratio, $d_{L E} / s$, for each blade row. These values are typically not determined until the detailed blade profile is defined, after the meanline analysis has been completed. Therefore, an investigation was conducted to determine reasonable estimates of these two parameters for use in TMLO. 
Figure 4.18 shows the relationship found between the We and the $d_{\mathrm{LE}} / \mathrm{s}$. The blade geometry data used to plot Figure 4.18 was obtained from several open source papers. The values of We and $d_{L E} / s$ of each data point along with corresponding references can be found in Appendix E.

Figure 4.18 shows that an approximate correlation exists between $W e$ and $d_{L E} / s$. Therefore, if either the We or $d_{L E} / s$ could be determined, e.g. from a correlation with other known geometry parameters, then Figure 4.18 could be used to determine the other variable. Several potential correlating parameters were considered for both We and $d_{L E} / s$. However, it was concluded that a correlation with geometric parameters only was unlikely since We and $d_{L E} / s$ are affected by other factors: for example, the choice of leading-edge diameter is influenced by whether the blade has film cooling. The decision was therefore taken to provide reasonable default values of $W e$ and $d_{\mathrm{LE}} / \mathrm{s}$ that are representative of modern blade designs, while also allowing the user to provide specified values that will over ride the defaults.

The Benner et al. (1997) profile loss correlation is a modified version of an early correlation by Tremblay et al. (1990). Tremblay et al. correlated the additional losses due to incidence with an incidence parameter $\chi$, defined as

$$
\chi^{\prime}=\left(\frac{d_{L E}}{S}\right)^{-1.6}\left(\frac{\cos \beta_{1}}{\cos \beta_{2}}\right)^{-2}\left[\alpha_{1}-\alpha_{1, \text { desiget }}\right]
$$

where $\beta$ is the metal angle of the blade and $\alpha$ is the flow angle and subscripts 1 and 2 denote the inlet and outlet of the blade row. 


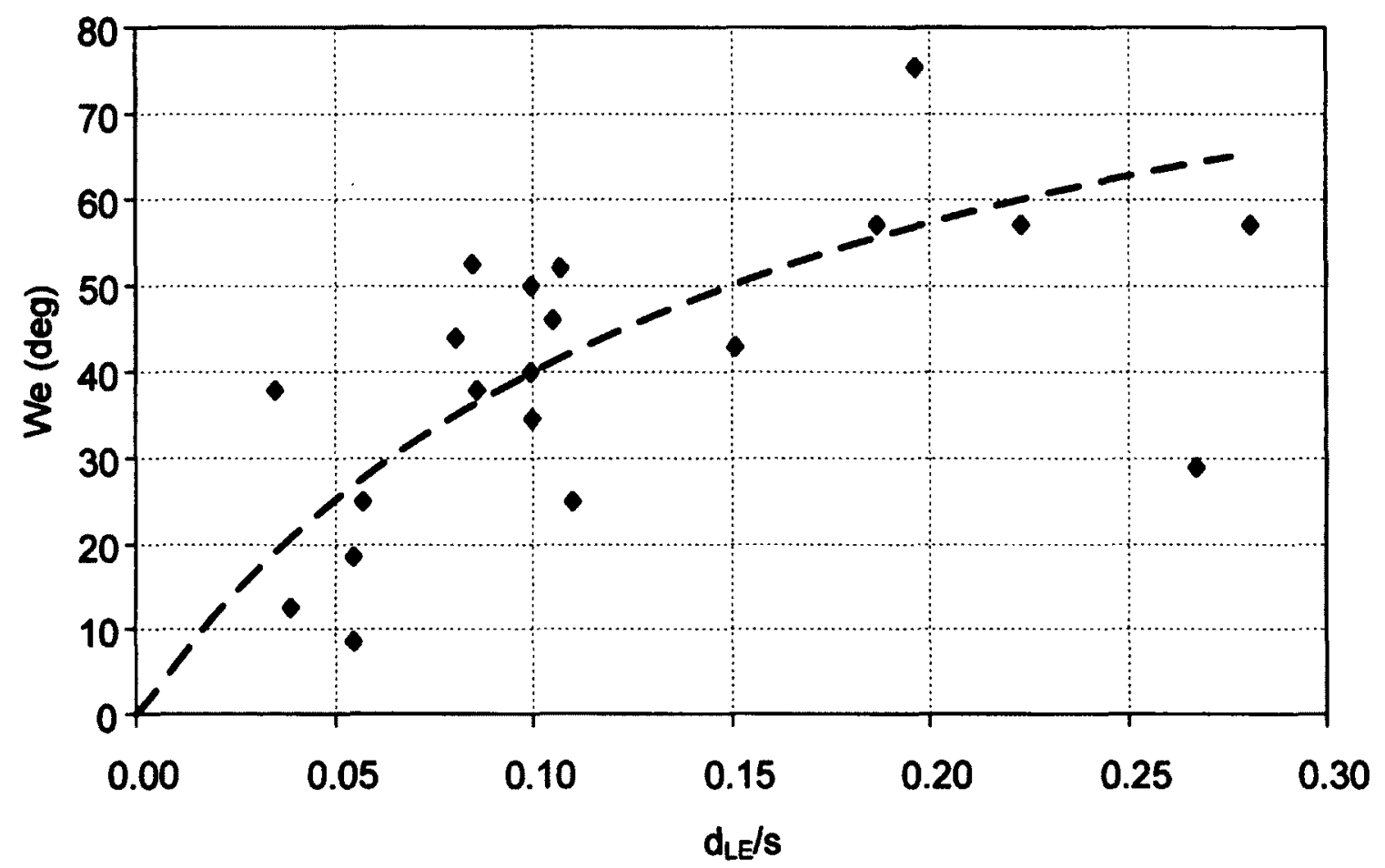

Figure 4.18 Leading-Edge Wedge Angle versus Leading-Edge Diameter-to-Spacing Ratio

The resulting correlation was somewhat scattered with particularly poor correlation for some blade geometries. This suggested that the correlation was missing at least one correlating parameter. Benner et al. proposed an alternative expression for $\chi$ in the form

$$
\chi=\left(\frac{\mathrm{d}_{\mathrm{LE}}}{\mathrm{S}}\right)^{-0.05} \mathrm{We}^{-0.2}\left(\frac{\cos \beta_{1}}{\cos \beta_{2}}\right)^{-1.4}\left[\alpha_{1}-\alpha_{1, \text { desige }}\right]
$$

The leading-edge wedge angle was added as an indirect measure of the discontinuity in curvature at the locations where the pressure and suction side splines meet the leadingedge circle. These locations are known as the blend points. Benner (2003) discusses how discontinuities in curvature at the blend points can lead to separation bubbles forming 
when the inlet flow is at incidence angle relative to the blade. The addition of We in the incidence parameter $\chi$ greatly reduced the scatter in the loss correlation. Many modern blades are designed using leading-edge ellipses or other definitions of leading-edge geometry that reduce or eliminate curvature discontinuities at the blend points. Therefore, for use in the correlation the value of We that will best represent modern blade designs would be one that results in a small discontinuity in curvature and therefore lower offdesign profile losses, for given values of $d_{L E} / s$ and incidence.

Calculations were performed using the Benner et al. (1997) correlation to identify the influence of We on the profile losses. The off-design total pressure loss coefficient was calculated over a range of We and $d_{\mathrm{LE}} / \mathrm{s}$ with $10^{\circ}$ of incidence. Figure 4.19 shows the results of the calculations. Figure 4.19 shows that as the We increases the total pressure loss coefficient decreases. Therefore, higher values of We are expected to be representative of modern blade designs. Based on Figure 4.18, a value of We of $40^{\circ}$ was selected as the default. Then, using Figure 4.18 a corresponding default value of 0.10 was selected for $d_{L E} / s$.

Based on the relationship between We and $d_{L E} / s$, shown in Figure 4.18, the Benner et al. (1997) correlation could be revisited. The expression for $\chi$ could be modified to be based on either We or $d_{L E} / s$ instead of requiring both. However, it is unclear what parameters should be used in a correlation for either We or $d_{L E} / s$. 


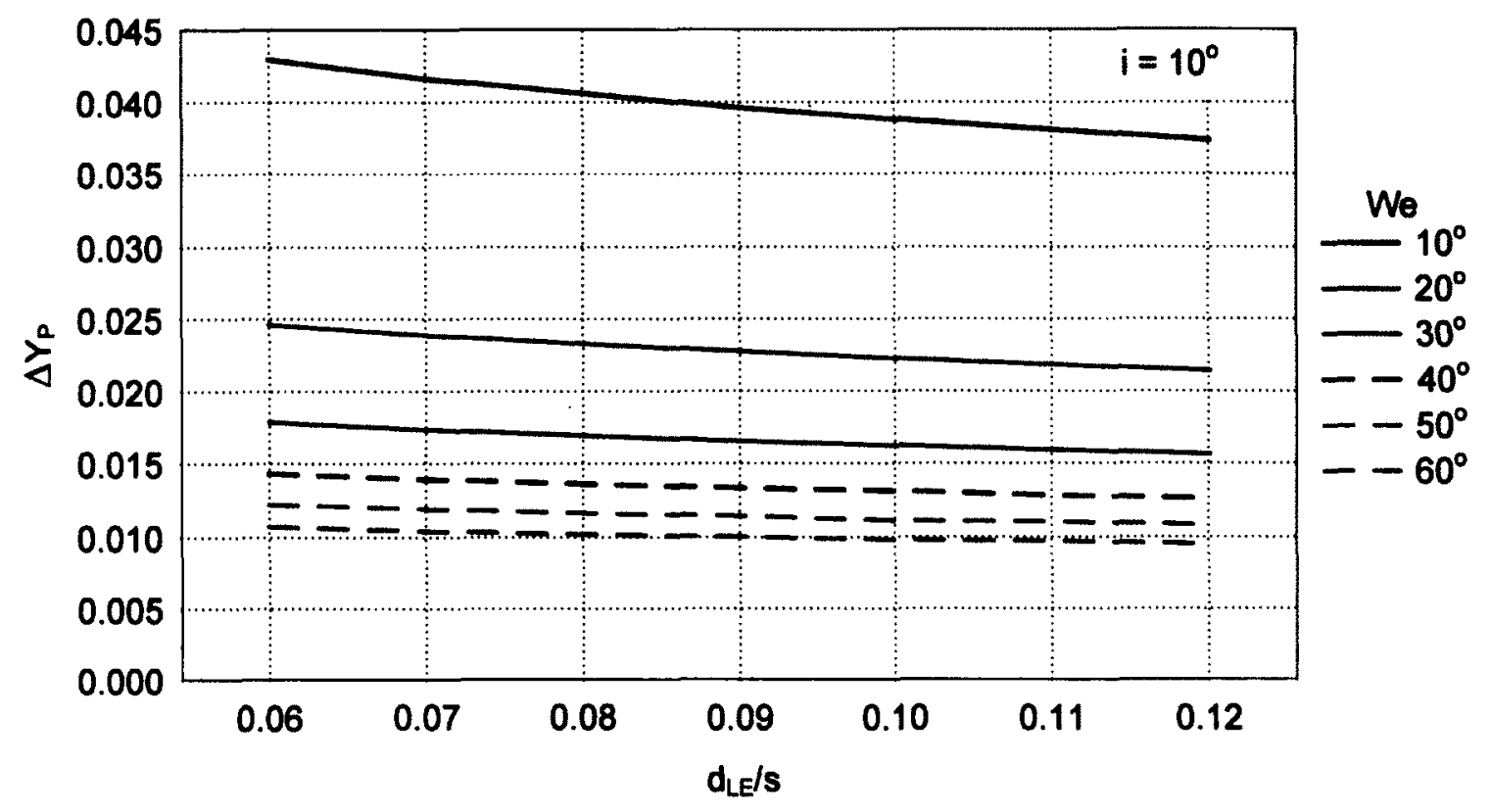

Figure 4.19 Sensitivity of We and $\mathrm{d}_{\mathrm{LE}} / \mathrm{s}$ on Off-Design Total Pressure Loss Coefficient 


\section{Chapter 5 Conclusions and Recommendations}

\subsection{Conclusions}

The focus of the thesis was to investigate of the effects of real fluid properties on axial turbine meanline design and off-design analysis. This investigation was conducted through the use of manual calculations and the Turbine Meanline Design (TMLD) and Turbine Meanline Off-Design (TMLO) codes. The working fluid of interest was supercritical carbon dioxide $\left(\mathrm{S}-\mathrm{CO}_{2}\right)$.

Several machines were designed for both ideal and real working fluids in order to determine the effects of real fluid properties on meanline design. These machines were designed over a range of inlet conditions where $\mathrm{S}-\mathrm{CO}_{2}$ exhibits non-ideal gas behaviour. The ideal gas and real fluid machine designs and performances were compared. The same ideal gas machines were then reanalysed with real fluid properties to see how machines designed with ideal gases perform with real fluids. The manual calculations were performed assuming that the expansion through the turbines was isentropic. Both TMLD and TMLO account for losses; therefore, the interaction of losses with the effects of real fluid properties was also examined. Finally, TMLO was employed to generate the full turbine characteristics of one of the real fluid machines. 
In comparing the machines designed with ideal and real working fluids it was found that the relative sizes of the gas path areas, total pressure ratios and Mach numbers depend on the turbine inlet conditions. For inlet conditions where the compressibility factor, $Z$, was less than 1.0 the gas path area of the ideal gas machine was larger than that of the real fluid machine. However, the total pressure ratio and the Mach numbers were lower in the ideal gas machine. When the inlet $\mathrm{Z}$ was greater than 1.0 the effect was reversed with the real fluid machine being larger than the ideal gas machine. Likewise, the total pressure ratio and Mach numbers of the real fluid machine were lower than those of the ideal gas machine.

The investigation showed that real fluid properties have a significant effect on the performance of machines designed using the ideal gas assumption. However, the performance was affected in different ways depending on whether the inlet $Z$ was less than or greater than 1.0 . For $Z=0.90$ the power output dropped by nearly $24 \%$, the relative flow angle at the nozzle exit, $\omega_{1}$, decreased by almost $13^{\circ}$, and the absolute flow angle at the rotor exit, $\alpha_{2}$, increased by about $7^{\circ}$. Where, for $Z=1.10$ the power output increased by about $15 \%, \omega_{1}$ increased by $2^{\circ}$ and $\alpha_{2}$ decreased by nearly $4^{\circ}$. Although the performance of all the machines was significantly affected by the real fluid properties the effects were stronger in the cases where $Z$ was less than 1.0. It was found that accounting for losses reduces the effects of the real fluid properties. This was especially true for turbines with an inlet $\mathrm{Z}$ greater than 1.0.

It was found that TMLO was able to predict successfully the turbine characteristics for a wide range of conditions. For a given rotational speed, converged solutions were 
obtained from essentially choked massflow to less than $50 \%$ of the choking value. Similarly, the characteristics were successfully predicted from $50 \%$ of design speed. Interestingly, it was found that the constant speed curves could cross as the massflow rate decreased. This behaviour was found to be associated with the changes in the work coefficient as the operating point changes. TMLO was also able to predict the off-design efficiency at conditions significantly different from the design point.

The present work was motivated by the requirement to design the axial turbines for a closed-cycle gas turbine engine using $\mathrm{S}-\mathrm{CO}_{2}$ as the working fluid. At the time, a meanline code was available for the design point analysis of such turbines. However, that code

assumed that the working fluid is an ideal gas. The present study has demonstrated that if the turbine had been designed using the available code, the resulting performance with the actual turbine would have been significantly different. For example for the inlet conditions of $\mathrm{Z}=1.05$ in the $\mathrm{S}-\mathrm{CO}_{2}$ plant, the resulting power output of a single stage turbine would have been greater than the design intended by about $7 \%$. Similarly, the efficiency would have been lower than the predicted value by about 0.5 percentage points. A multistage machine would experience a much larger drop in efficiency.

\subsection{Recommendations for Future Work}

The investigations discussed in this thesis have examined the effects of real fluid properties on turbine meanline analysis. However, the investigations were only conducted for single stage turbines. Multistage machines will follow the same trends as the single 
stage machines; however the extent of the effects of the real fluid properties on each successive stage is unknown. An investigation could be conducted to examine the extent to which the effects of the real fluid properties compound with each additional stage.

As mentioned, TMLO requires the leading-edge wedge angle and leading-edge diameter-to-spacing ratio in order to employ the off-design profile loss correlation. It would be beneficial for TMLO to be able to estimate appropriate values of this geometric data if it is not already provided by the user. The current default values would then be replaced with a correlation based on geometry data from TMLD. However, developing such a correlation will present substantial challenges.

The compressor and turbine blades designed for the $\mathrm{S}-\mathrm{CO}_{2}$ plant in the current Carleton University fourth-year engineering project are subjected to much higher bending stresses than what are typically found in air-breathing gas turbine engines. This is due to the high density of the working fluid. Therefore, the blades being designed are distinctive in that they have higher maximum thickness-to-chord ratios, abnormal leading-edge geometries, and thick trailing-edges compared with the airfoils for conventional gas turbines. It is recommended that an investigation be conducted which would determine whether current loss correlations accurately capture the total pressure losses of these blade designs. This could be done by measuring the total pressure losses through linear cascades of the blades in question. However, it is possible that the non-ideal fluid properties of S- $-\mathrm{CO}_{2}$ could also affect the losses. Developing an apparatus that could accurately measure the total pressure losses across linear cascades with $\mathrm{S}-\mathrm{CO}_{2}$ as the working fluid would be very expensive and difficult. 
One could develop an apparatus which uses $\mathrm{S}-\mathrm{CO}_{2}$ as the working fluid and could measure the total pressure losses through other test sections that are representative of typical loss mechanisms, e.g. straight pipes, sudden expansions, and curved pipes. If the measured losses through these test sections are different from the expected values found in many fluid dynamics text books, e.g. White (2003), then new loss correlations should be developed to account for the effects of non-ideal fluid properties.

One potential approach to developing the loss correlations would be to produce many computational fluid dynamic (CFD) models of various blade designs using $\mathrm{S}-\mathrm{CO}_{2}$ as the working fluid. The new correlations would be based on the results from these models. However, one would have to validate the results through experimental means. Therefore, CFD models would be generated of the same test sections mentioned above and the results could be compared. If the experimental measurements match the CFD results then one would have some confidence in generating loss correlations for non-ideal fluids using CFD.

Finally, a similar investigation to the one discussed in this thesis should be completed for compressors using the compressor inlet conditions found in the fourth-year project design. As mentioned, some of this work has already been started by Simon Stor (Stor, 2010). Stor completed the compressor meanline design and off-design codes but an investigation of the real fluid properties effects has not been conducted. 


\section{References}

Ainley, D. G. and Mathieson, G.C.R., 1951, “A Method of Performance Estimation for Axial-Flow Turbines," British ARC, R\&M, 2974.

Aronov, B. M., Bogatyrev, A. G., Epifanov, V. M., Mamaev, B.I., and Shkurikhin, I. B., 1975, "Experimental Study of Blade Inlet Angle Influence on Profile Cascade Effectiveness," Soviet Aeronautics, Vol. 18, No. 3, pp 82-86.

Aungier, R. H., 2000, “Centrifugal Compressors: A Strategy for Aerodynamic Design and Analysis," The American Society of Mechanical Engineers Press.

Benner, M. W., 2003, "The Influence of Leading-Edge Geometry on Profile and Secondary Losses in Turbine Cascades," Ph.D. Thesis, Carleton University, Ottawa, Canada.

Benner, M. W., Sjolander, S. A. and Moustapha, S. H., 1997, "Influence of Leading-Edge Geometry on Profile Losses in Turbines at Off-Design Incidence: Experimental Results and an Improved Correlation," ASME, Vol. 119, pp 193-200.

Benner, M. W., Sjolander, S. A. and Moustapha, S. H., 2005a, “An Empirical Prediction Method for Secondary Losses in Turbines: Part I - A New Loss Breakdown 
Scheme and Penetration Depth Correlation," ASME Paper No. GT-2005-68637, Reno, USA.

Benner, M. W., Sjolander, S. A. and Moustapha, S. H., 2005b, “An Empirical Prediction Method for Secondary Losses in Turbines: PART II - A New Secondary Loss Correlation," ASME Paper No. GT-2005-68639, Reno, USA.

Corriveau, D., 2005, "Influence of Loading Distribution on the Performance of High Pressure Turbine Blades," Ph.D. Thesis, Carleton University, Ottawa, Canada.

Dunham, J. and Came, P., 1970, "Improvements to the Ainley-Mathieson Method of Turbine Performance Prediction," Journal of Engineering for Power, pp. 252-256.

Hendricks, R. C., Baron, A. K. and Peller, C., 1975, “GASP - A Computer Code for Calculating the Thermodynamic and Transport Properties of Ten Fluids:

Parahydrogen, Helium, Neon, Methane, Nitrogen, Carbon Monoxide, Oxygen, Fluorine, Argon, and Carbon Dioxide," NASA Technical Note TN D-7808.

Hodson, H. P. and Dominy, R. G., 1987, "The Off-Design Performance of a LowPressure Turbine Cascade," Journal of Turbomachinery, Vol. 109, pp. 201-209.

Islam, A. M. T. and Sjolander, S. A., 1999, "Deviation in Axial Turbines at Subsonic Conditions," ASME Paper No. 99-GT26. 
Jeffries, M. S., 2000, "Initial Investigations of Transonic Turbine Aerodynamics Using the Carleton University High-Speed Wind Tunnel," Ph.D. Thesis, Carleton University, Ottawa, Canada.

Jouini, D. B. M., 2000, “Experimental Investigation of Two Transonic Linear Turbine Cascades at Off-Design Conditions," Ph.D. Thesis, Carleton University, Ottawa, Canada.

Kacker, S. C. and Okapuu, U., 1982, “A Mean Line Prediction Method for Axial Flow Turbine Efficiency," Journal of Engineering for Power, Vol. 104, pp. 111-119.

Kim, B. N. and Chung, M. K., 1997, "Improvements of Tip Leakage Loss Model for Axial Turbines," Journal of Turbomachinery, Vol. 119, pp. 339-401.

Moran, M. J. and Shapiro, H. N., 2004, "Fundamentals of Engineering Thermodynamics $5^{\text {th }}$ Edition," John Wiley \& Sons, Inc.

NIST, 2011a, "NIST General Information," http://www.nist.gov/public_affairs /general_information.cfm, accessed April 6, 2011.

NIST, 2011b, "NIST Chemistry WebBook, The Proper Citation of the NIST WebBook," http://webbook.nist.gov/cgi/cbook.cgi?Contrib=, accessed April 4, 2011.

NIST, 2011 c, "NIST Chemistry WebBook, Version History," http://webbook.nist.gov/chemistry/history.html, accessed April 4, 2011. 
Perdichizzi, A. and Dossena, V., 1993, "Incidence Angle and Pitch-Chord Effects on Secondary Flows Downstream of a Turbine Cascade," Journal of Turbomachinery, Vol. 115, pp. 383-391.

Redlich, O. and Kwong, J. N. S., 1949, "On the Thermodynamics of Solutions. V. An Equation of State. Fugacities of Gaseous Solutions," Chemical Review, Vol. 44, pp. 233-244.

Smith, S. F., 1965, “A Simple Correlation of Turbine Efficiency,” Journal of the Royal Aeronautical Society, Vol 49, pp. 467-470.

Span, R. and Wagner, W., 1994, “A New Equation of State for Carbon Dioxide Covering the Fluid Region from the Triple-Point Temperature to $1100 \mathrm{~K}$ at Pressures up to $800 \mathrm{MPa}$," The Journal of Physical Chemistry, Vol. 25, No. 6.

Stor, S., 2010, "Meanline Analysis of an Axial Compressor, Operating with Supercritical Carbon Dioxide as the Working Fluid," Diploma Thesis, Technical University of Munich.

Taylor, L. T., 1996, “Supercritical Fluid Extraction," John Wiley \& Sons, Inc.

Tremblay, B., Sjolander, S. A., and Moustapha, S. H., 1990, “Off-Design Performance of a Linear Cascade of Turbine Blades," ASME Paper No. 90-GT314. 
Taremi, F., Sjolander, S. A., and Praisner, T. J., 2010a, "Measurements of Endwall Flows in Transonic Linear Turbine Cascades: Part I - Low Flow Turning," ASME Paper No. GT2010-22759.

Taremi, F., Sjolander, S. A., and Praisner, T. J., 2010b, "Measurements of Endwall Flows in Transonic Linear Turbine Cascades: Part II - High Flow Turning," ASME Paper No. GT2010-22760.

Taremi, F., 2010, Private Communication, Carleton University, Ottawa, Canada.

Verhiel, J., 1993, “GTE-TMLD: A Program for the Meanline Aerodynamic Design of Axial Turbines - User's Guide".

Vijayaraghavan, S. B. and Kavanagh, P., 1988, "Effect of Free-Stream Turbulence, Reynolds Number, and Incidence on Axial Turbine Cascade Performance," ASME Paper No. 88-GT-152.

White, F. M., 2003, “Fluid Mechanics $5^{\text {th }}$ Edition," McGraw-Hill Companies Inc.

Yamamoto, A. and Nouse, H., 1988, "Effects of Incidence on Three-Dimensional Flows in a Linear Turbine Cascade," Journal of Turbomachinery, Vol. 110, pp. 486-496.

Yaras, M. I. and Sjolander, S. A., 1992, "Prediction of Tip-Leakage Losses in Axial Turbines," Journal of Turbomachinery, Vol. 114, pp. 204-210. 
Zhu, J. and Sjolander, S. A., 2005, "Improved Profile Loss and Deviation Correlations for Axial-Turbine Blade Rows," ASME Paper No. GT-2005-69077, Reno, USA. 


\section{Appendix A}

\section{TMLD Input File Format}

\begin{tabular}{|c|c|c|c|c|c|c|c|c|}
\hline \multicolumn{2}{|c|}{$\begin{array}{c}\text { Line } \\
\text { Number }\end{array}$} & \multicolumn{5}{|c|}{ Input Data } & $\begin{array}{c}\text { Type/ } \\
\text { Format }\end{array}$ & Comments \\
\hline 1 & 1 & $\begin{array}{l}\text { Number of } \\
\text { Cases }\end{array}$ & Units & $\begin{array}{l}\text { Meanline } \\
\text { Option }\end{array}$ & $\begin{array}{l}\text { Output } \\
\text { Option }\end{array}$ & Fluid Option & INTEGER & $\begin{array}{l}\text { (i) Number of cases (NOC) contained in data } \\
\text { file. } \\
\text { If NOC = 1, the data are used as the starting } \\
\text { point for a parametric study (either } \\
\text { interactive or stand-alone) } \\
\text { If NOC }>1 \text {, the cases specified in the file are } \\
\text { analysed in turn with no further prompting. } \\
\text { (ii) Units for the input and output data. } \\
1=\text { Modified Imperial } \\
2=\text { S.I. } \\
\text { (iii) Definition of meanline. } \\
1=\text { Meanline divides annulus area in half } \\
2 \text { = Meanline divides annulus height in half } \\
\text { (iv) Output of approximate spanwise results. } \\
\text { Determines whether spanwise results are } \\
\text { written to the printable output file. The } \\
\text { results will always be calculated and are } \\
\text { included in the compact data file. } \\
1=\text { Spanwise results are included }\end{array}$ \\
\hline
\end{tabular}




\begin{tabular}{|c|c|c|c|c|c|c|c|}
\hline & & & & & & & $\begin{array}{l}2 \text { = Spanwise results are omitted } \\
\text { (v) Working fluid selection. } \\
\text { See following table for details. }\end{array}$ \\
\hline 2 & 2 & $\begin{array}{l}\text { Profile Loss } \\
\text { Option }\end{array}$ & $\begin{array}{l}\text { Secondary } \\
\text { Loss } \\
\text { Option }\end{array}$ & $\begin{array}{l}\text { Trailing } \\
\text { Edge Loss } \\
\text { Option }\end{array}$ & $\begin{array}{l}\text { Tip Clearance } \\
\text { Loss Option }\end{array}$ & INTEGER & $\begin{array}{l}\text { This row allows the user to specify which } \\
\text { loss correlations are employed by TMLD. } \\
\text { (i) Profile loss option } \\
\text { = Kacker and Okapuu } \\
2 \text { = Zhu and Sjolander (2005) } \\
\text { (ii) Secondary loss option } \\
1=\text { Kacker and Okapuu } \\
2 \text { = Benner et al. (2005) } \\
\text { (iii) Trailing edge loss option must be set to } \\
\text { 1. Only Kacker and Okapuu correlation is } \\
\text { available at this time. } \\
\text { (iv) Tip clearance loss option } \\
1=\text { Kacker and Okapuu } \\
2=\text { Yaras and Sjolander (1992) } \\
3=\text { Kim and Chung (1997) }\end{array}$ \\
\hline 4 & 2 & \multicolumn{4}{|c|}{ Description } & $\begin{array}{l}\text { CHARACTER } \\
\text { (40) }\end{array}$ & $\begin{array}{l}\text { Description of the case. Will also be written } \\
\text { to all output data files. If the user chooses to } \\
\text { create a series of stand-alone parametric } \\
\text { studies from within TMLD, he/she will be } \\
\text { prompted for a new description for each } \\
\text { series. The new description will supersede } \\
\text { the one read from the data file. The } \\
\text { description may be left blank. } \\
\text { N.B. Text string must be enclosed in single } \\
\text { quotes ( ' })\end{array}$ \\
\hline
\end{tabular}




\begin{tabular}{|c|c|c|c|c|c|c|c|c|c|}
\hline 5 & 3 & $\begin{array}{l}\text { Mass Flow } \\
(\mathrm{kg} / \mathrm{s}, \mathrm{lbm} / \mathrm{s})\end{array}$ & $\begin{array}{l}\text { To (Inlet) } \\
\text { (K, K) }\end{array}$ & $\begin{array}{l}\text { Po (Inlet) } \\
(\mathbf{k P a}, \text { psia) }\end{array}$ & Fuel-air Ratio & $\begin{array}{c}\text { Speed } \\
\text { (rev/s, RPM) }\end{array}$ & $\begin{array}{l}\text { Alpha (Inlet) } \\
\left(\mathrm{deg}_{\mathrm{g}} \mathrm{deg}\right) \\
\end{array}$ & $\begin{array}{l}\text { FLOATING } \\
\text { POINT }\end{array}$ & $\begin{array}{l}\text { Conditions at inlet to stage } 1 \text {. The inlet mass } \\
\text { flow is used as the reference for specifying } \\
\text { the cooling flows for all stages. }\end{array}$ \\
\hline 6 & 4 & $\begin{array}{c}\text { Number of } \\
\text { Stages }\end{array}$ & & & & & & INTEGER & $\begin{array}{l}\text { Total number of stages in the machine to be } \\
\text { analysed. }\end{array}$ \\
\hline & & & & & & & & & REPEAT FOR EACH STAGE \\
\hline 7 & 1 & $\begin{array}{l}\text { Current } \\
\text { Stage }\end{array}$ & & & & & & INTEGER & $\begin{array}{l}\text { The number of the stage for which data } \\
\text { follows. }\end{array}$ \\
\hline 8 & 2 & $\begin{array}{l}\text { RH (1) } \\
\text { (mm, in.) }\end{array}$ & $\begin{array}{c}\text { RT (1) } \\
\text { (mm, in.) }\end{array}$ & $\begin{array}{c}\text { Open Area } \\
\text { Fraction (1) }\end{array}$ & & & & $\begin{array}{l}\text { FLOATING } \\
\text { PONT }\end{array}$ & $\begin{array}{l}\text { Hub and tip radii at axial station } 1 \text { (nozzle } \\
\text { inlet). Annulus boundary layer blockage, } \\
\text { expressed as an open area fraction. Thus for } \\
\text { no boundary layer blockage set Open Area } \\
\text { Fraction to } 1.0 \text {. }\end{array}$ \\
\hline 9 & 3 & RH (2) & RT (2) & $\begin{array}{c}\text { Open Area } \\
\text { Fraction (2) }\end{array}$ & & & & $\begin{array}{l}\text { FLOATING } \\
\text { POINT }\end{array}$ & $\begin{array}{l}\text { Radii and blockage at axial station } 2 \\
\text { (nozzle outlet) }\end{array}$ \\
\hline 10 & 4 & RH (3) & RT (3) & $\begin{array}{l}\text { Open Area } \\
\text { Fraction (3) }\end{array}$ & & & & $\begin{array}{l}\text { FLOATING } \\
\text { POINT } \\
\end{array}$ & $\begin{array}{l}\text { Radii and blockage at axial station } 3 \\
\text { (rotor inlet) }\end{array}$ \\
\hline 11 & 5 & RH (4) & RT (4) & $\begin{array}{c}\text { Open Area } \\
\text { Fraction (4) }\end{array}$ & & & & $\begin{array}{l}\text { FLOATING } \\
\text { POINT } \\
\end{array}$ & $\begin{array}{l}\text { Radii and blockage at axial station } 4 \\
\text { (rotor outlet) }\end{array}$ \\
\hline 12 & 6 & RH (5) & RT (5) & $\begin{array}{l}\text { Open Area } \\
\text { Fraction (5) }\end{array}$ & & & & $\begin{array}{l}\text { FLOATING } \\
\text { PONTT }\end{array}$ & $\begin{array}{l}\text { Radii and blockage at axial station } 5 \\
\text { (stage outlet) }\end{array}$ \\
\hline 13 & 7 & $\begin{array}{l}\text { Number of } \\
\text { Blades }\end{array}$ & $\begin{array}{l}\text { Axial Chord } \\
\text { (mm, in.) }\end{array}$ & $\operatorname{tmax} / c$ & $\begin{array}{l}\text { Trailing-edge } \\
\text { Thickness } \\
\text { (mm, in.) }\end{array}$ & & & $\begin{array}{l}\text { INTEGER } \\
\text { FLOATING } \\
\text { POINT }\end{array}$ & $\begin{array}{l}\text { Nozzle blade geometry. } \\
\text { Number of blades is an integer. }\end{array}$ \\
\hline 14 & 8 & $\begin{array}{l}\text { Number of } \\
\text { Blades }\end{array}$ & $\begin{array}{l}\text { Axial Chord } \\
\text { (mm, in.) }\end{array}$ & $\operatorname{tmax} / c$ & $\begin{array}{l}\text { Trailing-edge } \\
\text { Thickness } \\
\text { (mm, in.) }\end{array}$ & $\begin{array}{l}\text { Tip Clearance } \\
\text { (mm, in.) }\end{array}$ & $\begin{array}{l}\text { Number of } \\
\text { Seals }\end{array}$ & $\begin{array}{l}\text { INTEGER } \\
\text { FLOATING } \\
\text { PONNT }\end{array}$ & $\begin{array}{l}\text { Rotor blade geometry. } \\
\text { Number of blades is an integer. } \\
\text { If Number of Seals }=0 \text {, the rotor is taken as } \\
\text { unshrouded. }\end{array}$ \\
\hline 15 & 9 & $\begin{array}{c}\text { M(BC1) } \\
\text { Nozzle film } \\
\text { cooling }\end{array}$ & $\begin{array}{c}\text { M(BC2) } \\
\text { Nozzle t.e. } \\
\text { ejection }\end{array}$ & $\begin{array}{c}\text { M(BC3) } \\
\text { Rotor film } \\
\text { cooling }\end{array}$ & $\begin{array}{l}\text { M(BC4) } \\
\text { Rotor t.e. } \\
\text { ejection }\end{array}$ & $\begin{array}{l}\text { M(DC3) } \\
\text { Upstream } \\
\text { disk face }\end{array}$ & $\begin{array}{c}\text { M(DC4) } \\
\text { Downstream } \\
\text { disk face } \\
\end{array}$ & $\begin{array}{l}\text { FLOATING } \\
\text { PONT }\end{array}$ & $\begin{array}{l}\text { Blade and disk cooling flows for the stage, } \\
\text { expressed as fractions of the machine inlet } \\
\text { mass flow rate. }\end{array}$ \\
\hline 16 & 10 & $\begin{array}{l}\text { M(HC2) } \\
\text { Nozzle hub } \\
\text { cooling }\end{array}$ & $\begin{array}{l}\text { M(TC2) } \\
\text { Nozzle tip } \\
\text { cooling }\end{array}$ & $\begin{array}{l}\text { M(TC3) } \\
\text { Rotor tip } \\
\text { cooling } \\
\text { (upstream) }\end{array}$ & $\begin{array}{c}\text { M(TC4) } \\
\text { Rotor tip } \\
\text { cooling } \\
\text { (downstream) }\end{array}$ & & & $\begin{array}{l}\text { FLOATING } \\
\text { PONT }\end{array}$ & Hub and tip cooling flows for the stage. \\
\hline 17 & 11 & $\begin{array}{l}\text { To(BC1) } \\
(\mathrm{K}, \mathrm{K}) \\
\end{array}$ & $\mathrm{To}(\mathrm{BC} 2)$ & To(BC3) & $\mathrm{To}(\mathrm{BC} 4)$ & To(DC3) & To(DC4) & & $\begin{array}{l}\text { Total temperatures for the specified cooling } \\
\text { flows. Zero values can be used as place } \\
\text { holders if the cooling flow rates are zero. }\end{array}$ \\
\hline
\end{tabular}




\begin{tabular}{|c|c|c|c|c|c|c|c|c|}
\hline & & & & & & & & $\begin{array}{l}\text { Correct number of data values must be } \\
\text { present in the file in all cases. }\end{array}$ \\
\hline 18 & 12 & To(HC2) & To(TC2) & To(TC3) & To(TC4) & & & \\
\hline 19 & 13 & $\begin{array}{c}\text { Po(BC1) } \\
\text { (kPa, psia) }\end{array}$ & Po(BC2) & Po(BC3) & $\mathrm{Po}(\mathrm{BC} 4)$ & Po(DC3) & Po(DC4) & $\begin{array}{l}\text { Total pressures for the specified cooling } \\
\text { flows. As with total temperatures, zero values } \\
\text { can be used as place holders if the cooling } \\
\text { flow rates are zero. }\end{array}$ \\
\hline 20 & 14 & Po(HC2) & Po(TC2) & Po(TC3) & Po(TC4) & & & \\
\hline 21 & 15 & $\mathrm{~K}(\mathrm{Yp})$ & $\bar{K}(\mathbf{Y s})$ & K(Ytet) & & & & $\begin{array}{l}\text { Loss coefficient multipliers for the nozzle } \\
\text { blades. Used to modify the losses predicted } \\
\text { by the loss system. } K()=1.0 \text { to obtain } \\
\text { unchanged losses. }\end{array}$ \\
\hline 22 & 16 & $\overline{K(Y p)}$ & $\mathrm{K}\left(\mathrm{Y}_{\mathbf{s}}\right)$ & K(Ytet) & $\overline{\mathrm{K}(\mathrm{Ytc})}$ & & & $\begin{array}{l}\text { Loss coefficient multipliers for the rotor } \\
\text { blades. }\end{array}$ \\
\hline 23 & 17 & $\overline{\mathbf{K}(45)}$ & & & & & & $\begin{array}{l}\text { Total pressure loss coefficient for duct } \\
\text { downstream of rotor. }\end{array}$ \\
\hline 24 & 18 & $\begin{array}{l}\text { Option for } \\
\text { Specifying } \\
\text { Performance }\end{array}$ & & & & & & $\begin{array}{l}\text { Specify which of four stage performance } \\
\text { options is to be used. See next line. }\end{array}$ \\
\hline \multirow[t]{3}{*}{25} & 19 & $\begin{array}{l}\text { Performance } \\
\text { Parameter A } \\
\text { (1) } \Delta \mathrm{Ho} \\
\text { (2) } \Delta \mathrm{Ho} \\
\text { (3) } \mathrm{PR} \\
\text { (4) } \mathrm{PR}\end{array}$ & $\begin{array}{c}\text { Performance } \\
\text { Parameter B } \\
\\
\text { Reaction } \\
\text { Alpha (4) } \\
\text { Reaction } \\
\text { Alpha (4) }\end{array}$ & & & & & $\begin{array}{l}\text { Specification of stage performance. } \\
\text { Four options available, as indicated. } \\
\text { Units for } \Delta \mathrm{Ho}: \mathrm{kJ} / \mathrm{kg}, \mathrm{CHU} / \mathrm{lbm} \text {. }\end{array}$ \\
\hline & & & & & & & & REPEAT FOR NEXT STAGE \\
\hline & & & & & & & & REPEAT FOR NEXT CASE \\
\hline
\end{tabular}


TMLD Working Fluid Options

\begin{tabular}{|c|c|c|}
\hline $\begin{array}{c}\text { Number for } \\
\text { TMLD input file }\end{array}$ & Working Fluid & Comments \\
\hline 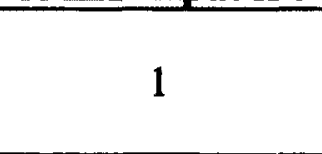 & Exhaust Gases & $\begin{array}{l}\text { This fluid is assumed to be an ideal gas. A correlation with temperature is used to } \\
\text { estimate the specific heat at constant pressure at every station. All other properties are } \\
\text { calculated. }\end{array}$ \\
\hline 2 & Dry Air & \multirow{3}{*}{$\begin{array}{l}\text { These fluids are assumed to be ideal gases. Fluid property subroutines are used to } \\
\text { estimate the specific heat at constant pressure and the isentropic exponent at every } \\
\text { station and the viscosity where necessary. All other properties are calculated. }\end{array}$} \\
\hline 3 & Nitrogen & \\
\hline 4 & Carbon Dioxide & \\
\hline 6 & Nitrogen & \multirow{2}{*}{$\begin{array}{l}\text { These are real fluids. Fluid property subroutines are used to estimate all of the } \\
\text { properties at every station. The same subroutines are used to perform conversions } \\
\text { between total and static conditions. }\end{array}$} \\
\hline 7 & Carbon Dioxide & \\
\hline
\end{tabular}




\section{Appendix B}

\section{TMLO Blade Geometry Input Data File Format}

\begin{tabular}{|c|c|c|c|c|c|c|c|}
\hline \multicolumn{2}{|c|}{$\begin{array}{c}\text { Line } \\
\text { Number }\end{array}$} & \multicolumn{4}{|c|}{ Input Data } & $\begin{array}{c}\text { Type/ } \\
\text { Format } \\
\end{array}$ & Comments \\
\hline 1 & 1 & $\begin{array}{l}\text { Nozzle } \\
\text { LE We } \\
\text { (deg) }\end{array}$ & $\begin{array}{c}\text { Nozzle } \\
d_{L E} / \mathrm{s}\end{array}$ & $\begin{array}{c}\text { Rotor } \\
\text { LE We } \\
\text { (deg) }\end{array}$ & $\begin{array}{l}\text { Rotor } \\
d_{L E} / s\end{array}$ & $\begin{array}{l}\text { FLOATING } \\
\text { PONTT }\end{array}$ & $\begin{array}{l}\text { (i) Leading edge wedge angle of the } \\
\text { nozzle in deg (use at least one decimal } \\
\text { place) } \\
\text { (ii) Leading edge diameter to spacing } \\
\text { ratio of the nozzle (use at least one } \\
\text { decimal place) } \\
\text { (iii) Leading edge wedge angle of the } \\
\text { rotor in deg (use at least one decimal } \\
\text { place) } \\
\text { (iv) Leading edge diameter to spacing } \\
\text { ratio of the rotor (use at least one } \\
\text { decimal place) }\end{array}$ \\
\hline & & & & & & & REPEAT FOR NEXT STAGE \\
\hline
\end{tabular}

Inputting a value of 0.0 for either We or $d_{L E} / s$ will cause TMLO to use the default value of that parameter. The current default values are $\mathrm{We}=40^{\circ}$ and $\mathrm{d}_{\mathrm{LE}} / \mathrm{s}=0.10$. 


\title{
Appendix C
}

\section{Example TMLD Output File}

\author{
$\forall * * * * * * * * * * * * * * * * * * * * * * * * * * * * * * * * * * * * * * * * * * * * * * * * * * * * * * * * * * * * * * * * * * * * * * *$ \\ Rolls-Royce Gas Turbine Engines (Canada) Inc. \\ GTE-TMLD \\ Turbine Mean-Line analysis for Design-point operation \\ Title: Machine design for inlet $\mathrm{Z}$ of 0.90 \\ Description: Real fluid case

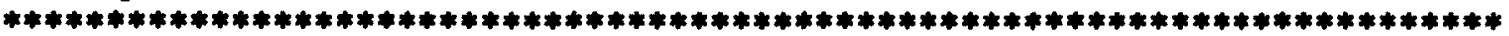

\section{SPECIFIED DATA FOR MACHINE}

Working Fluid: Carbon Dioxide Real Fluid

Number of Stages: 1

Rotational Speed: $60.0 \mathrm{revs} / \mathrm{s}$

Gas Constant: $188.92 \mathrm{~J} /(\mathbf{k g} . \mathrm{K})$

Inlet Fuel-Air Ratio: $\quad 0.0000$

Inlet Mass Flow Rate: $1500.00 \mathrm{~kg} / \mathrm{s}$

Inlet Total Pressure: $11500.00 \mathrm{kPa}$ 
Inlet Total Temperature: $470.0 \mathrm{~K}$

Inlet Flow Angle: $0.0 \mathrm{deg}$

\section{CALCULATED DATA FOR MACHINE}

Total Pressure Ratio: 1.3909

Isentropic Efficiency: $\quad 90.47 \%$

Gross Shaft Power: $34536 . \mathrm{kW}$

Specific Fuel Consumption: $0.000000 \mathrm{~kg} /(\mathrm{kW} . \mathrm{s})$

$* * * * * * * * * * * *$

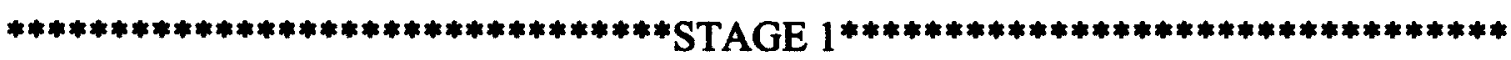

$* * * * * * * * * * *$

\section{STAGE PERFORMANCE SUMMARY}

Total Enthalpy Drop: $23.024 \mathrm{~kJ} / \mathrm{kg}$

Total Pressure Ratio: 1.3909

Flow Coefficient: 0.7427

Work Coefficient: 1.8000

Reaction (based on P): $\quad 0.1000$

Reaction (based on h): 0.1000

Isentropic Efficiency: $\quad 90.47 \%$

Gross Shaft Power: 34536. kW 


\section{AXIAL STATION DATA}

\begin{tabular}{|c|c|c|c|c|c|c|c|}
\hline & \multicolumn{7}{|c|}{ AXIAL STATION } \\
\hline & 1 & $2 u$ & $2 m$ & 3 & $4 u$ & $4 \mathrm{~m}$ & 5 \\
\hline \multicolumn{8}{|l|}{ GEOMETRY } \\
\hline Hub Radius [mm] & 262.8 & 252.7 & 252.7 & 252.7 & 250.4 & 250.4 & 250.4 \\
\hline Tip Radius [mm] & 333.1 & 340.8 & 340.8 & 340.8 & 342.5 & 342.5 & 342.5 \\
\hline Mean Radius [mm] & 300.0 & 300.0 & 300.0 & 300.0 & 300.0 & 300.0 & 300.0 \\
\hline Area $\left[\mathrm{mm}^{\wedge} 2\right]$ & 131490. & 164340. & 164340. & 164340. & 171491. & 171491. & 171491. \\
\hline Design Angle [deg] & 0.00 & N/A & N/A & 47.13 & N/A & N/A & N/A \\
\hline Metal Angle [deg] & $\mathbf{N} / \mathbf{A}$ & 70.46 & N/A & N/A & -57.94 & N/A & N/A \\
\hline \multicolumn{8}{|l|}{ GAS PROPERTIES } \\
\hline Gamma & 1.1863 & 1.1937 & 1.1937 & 1.1937 & 1.1953 & 1.1953 & 1.1953 \\
\hline $\mathrm{Cp}[\mathrm{kJ} /(\mathrm{kg} . \mathrm{K})]$ & 1.2032 & 1.1642 & 1.1642 & 1.1642 & 1.1564 & 1.1564 & 1.1564 \\
\hline Fuel-Air Ratio & 0.0000 & 0.0000 & 0.0000 & 0.0000 & 0.0000 & 0.0000 & 0.0000 \\
\hline \multicolumn{8}{|l|}{ AERODYNAMICS } \\
\hline Mass Flow $[\mathrm{kg} / \mathrm{s}]$ & 1500.0 & 1500.0 & 1500.0 & 1500.0 & 1500.0 & 1500.0 & 1500.0 \\
\hline Discharge Coeff. & 0.980 & 0.980 & 0.980 & 0.980 & 0.980 & 0.980 & 0.980 \\
\hline Speed of Sound [m/s] & 322.8 & 310.28 & 310.28 & 310.28 & 308.79 & 308.79 & 308.79 \\
\hline Mach Number & 0.2602 & 0.7098 & 0.7098 & 0.7098 & 0.2720 & 0.2720 & 0.2720 \\
\hline Rel Mach Number & & & & 0.3979 & 0.4562 & 0.4562 & \\
\hline Flow Angle [deg] & 0.00 & 67.58 & 67.58 & 67.58 & 0.00 & 0.00 & 0.00 \\
\hline Rel Angle [deg] & & & & 47.13 & -53.40 & -53.40 & \\
\hline Blade Speed [m/s] & & & & 113.10 & 113.10 & 113.10 & \\
\hline Velocity $[\mathrm{m} / \mathrm{s}]$ & 84.00 & 220.22 & 220.22 & 220.22 & 84.00 & 84.00 & 84.00 \\
\hline Axial Vel $[\mathrm{m} / \mathrm{s}]$ & 84.00 & 84.00 & 84.00 & 84.00 & 84.00 & 84.00 & 84.00 \\
\hline Whirl Vel [m/s] & 0.00 & 203.57 & 203.57 & 203.57 & 0.00 & 0.00 & 0.00 \\
\hline \multirow[t]{2}{*}{$\operatorname{Rel}$ Vel $[\mathrm{m} / \mathrm{s}]$} & & & & 123.46 & 140.88 & 140.88 & \\
\hline & & & & 123 & & & \\
\hline
\end{tabular}


Rel Ax Vel [m/s]

Rel Wh Vel [m/s]

Po [kPa]

$\mathrm{P}[\mathrm{kPa}]$ rel Po $[\mathrm{kPa}]$

To [K]

$\mathrm{T}[\mathrm{K}]$

rel To $[K]$

density $\left[\mathrm{kg} / \mathrm{m}^{\wedge} 3\right]$ $\begin{array}{rrrr}11500.00 & 11335.97 & 11335.97 & 113 \\ 11002.69 & 8286.43 & 8286.43 & 82\end{array}$

$\begin{array}{lll}470.0 & 470.0 & 470.0\end{array}$

$\begin{array}{lll}465.6 & 439.3 & 439.3\end{array}$

$\begin{array}{lll}138.58 & 110.88 & 110.88\end{array}$

0.903

\subsection{0}

$$
90.47
$$

11335.97

8286.43

9166.86

470.0

439.3

449.0

110.88

0.901

$\begin{array}{rrr}84.00 & 84.00 & \\ -113.1 & -113.1 & \\ 8268.07 & 8268.07 & 8268.07 \\ 7885.64 & 7885.66 & 7885.66 \\ 8997.96 & 8997.99 & \\ 440.2 & 440.2 & 440.2 \\ 435.7 & 435.7 & 435.7 \\ 448.4 & 448.4 & \\ 106.25 & 106.25 & 106.25 \\ 0.902 & 0.902 & 0.902\end{array}$

NOZZLE AND ROTOR BLADE DATA

$\begin{array}{rrr} & & \\ \text { GEOMETRY } & \text { Nozzle } & \text { Rotor } \\ \text { Chord [mm]: } & 31.02 & \\ \text { Axial Chord [mm]: } & 19.05 & 21.61 \\ \text { Number of Blades: } & 67 & 21.31 \\ \text { s/c: } & 0.9070 & 146 \\ \text { h/c: } & 2.5531 & 0.5974 \\ \text { tmax/c: } & 0.2000 & 4.1694 \\ \text { TED [mm]: } & 0.762 & 0.2000 \\ \text { TED/s: } & 0.0271 & 0.762 \\ \text { o/s: } & 0.3814 & 0.0590 \\ \text { TED/o: } & 0.0710 & 0.5963 \\ \text { tc/h: } & & 0.0990 \\ \text { Tip Clearance [mm]: } & 0.85 \\ \text { Number of Seals: } & & 0.0095 \\ \text { Stagger [deg]: } & 52.1 & 3 \\ & & 9.5\end{array}$




$\begin{array}{rrrrrr}\text { LOSSES } & & \mathrm{K} & & \mathrm{K} \\ \text { Rec: } & 3.275 \mathrm{E}+07 & & 1.414 \mathrm{E}+07 & \\ \text { Yprofile: } & 0.01009 & 1.0 & 0.02440 & 1.0 \\ \text { Ysecondary: } & 0.03200 & 1.0 & 0.07003 & 1.0 \\ \text { Ytet: } & 0.01172 & 1.0 & 0.01271 & 1.0 \\ \text { Ytc: } & & & 0.04192 & 1.0 \\ \text { Ytotal: } & 0.05381 & & 0.14906 & \end{array}$

LOADING

$\begin{array}{lll}\text { Zweifel: } & 1.0416 & 1.0439\end{array}$

COOLING FLOW DATA

$\begin{array}{rcccc} & \text { \% of Min } & \mathrm{kg} / \mathrm{s} & \text { To }[\mathrm{K}] & \text { Po }[\mathrm{kPa}] \\ \text { Nozzle Blade Film: } & 0.0000 & 0.00 & 0.0 & 0.00 \\ \text { Nozzle Trailing-Edge: } & 0.0000 & 0.00 & 0.0 & 0.00 \\ \text { Nozzle Exit Hub Film: } & 0.0000 & 0.00 & 0.0 & 0.00 \\ \text { Nozzle Exit Tip Film: } & 0.0000 & 0.00 & 0.0 & 0.00 \\ & & & & \\ \text { Rotor Blade Film: } & 0.0000 & 0.00 & 0.0 & 0.00 \\ \text { Rotor Trailing-Edge: } & 0.0000 & 0.00 & 0.0 & 0.00 \\ \text { Rotor Inlet Tip Film: } & 0.0000 & 0.00 & 0.0 & 0.00 \\ \text { Rotor Exit Tip Film: } & 0.0000 & 0.00 & 0.0 & 0.00 \\ \text { Upstream Disk Face: } & 0.0000 & 0.00 & 0.0 & 0.00 \\ \text { Downstream Disk Face: } & 0.0000 & 0.00 & 0.0 & 0.00\end{array}$




\begin{tabular}{|c|c|c|c|c|c|}
\hline & & SP & WISE STA & ION & \\
\hline & (hub) & & (mean) & & (tip) \\
\hline & 1 & 2 & 3 & 4 & 5 \\
\hline AXIAL STATION 1 (Noz & le Inlet) & & & & \\
\hline Radius [mm]: & 262.8 & 282.0 & 300.0 & 317.0 & 333.1 \\
\hline Axial Velocity [m/s]: & 84.00 & 84.00 & 84.00 & 84.00 & 84.00 \\
\hline Whirl Velocity [m/s]: & 0.00 & 0.00 & 0.00 & 0.00 & 0.00 \\
\hline Flow Angle [deg]: & 0.0 & 0.0 & 0.0 & 0.0 & 0.0 \\
\hline Mach Number: & 0.2602 & 0.2602 & 0.2602 & 0.2602 & 0.2602 \\
\hline Pressure [kPa]: & 11002.69 & 11002.69 & 11002.69 & 11002.69 & 11002.69 \\
\hline WXIAL STATION $2 \mathrm{~m}$ (No & zzle Outlet) & & & & \\
\hline Radius [mm]: & 252.7 & 277.4 & 300.0 & 321.1 & 340.8 \\
\hline Axial Velocity [m/s]: & 84.00 & 84.00 & 84.00 & 84.00 & 84.00 \\
\hline Whirl Velocity [m/s]: & 241.70 & 220.20 & 203.57 & 190.22 & 179.19 \\
\hline Flow Angle [deg]: & 70.8 & 69.1 & 67.6 & 66.2 & 64.9 \\
\hline Mach Number: & 0.8374 & 0.7645 & 0.7098 & 0.6669 & 0.6323 \\
\hline Pressure [kPa]: & 7384.74 & 7902.39 & 8286.43 & 8582.41 & 8817.30 \\
\hline AXIAL STATION 3 (Roto & Inlet) & & & & \\
\hline Radius [mm]: & 252.7 & 277.4 & 300.0 & 321.1 & 340.8 \\
\hline Blade Speed [m/s]: & 95.26 & 104.56 & 113.10 & 121.04 & 128.49 \\
\hline Axial Velocity [m/s]: & 84.00 & 84.00 & 84.00 & 84.00 & 84.00 \\
\hline Whirl Velocity [m/s]: & 241.70 & 220.20 & 203.57 & 190.22 & 179.19 \\
\hline Rel Whirl Vel [m/s]: & 146.44 & 115.64 & 90.47 & 69.18 & 50.71 \\
\hline Flow Angle [deg]: & 70.8 & 69.1 & 67.6 & 66.2 & 64.9 \\
\hline Rel Flow Angle [deg]: & 60.2 & 54.0 & 47.1 & 39.5 & 31.1 \\
\hline & & & & 120 & \\
\hline
\end{tabular}




$\begin{array}{rrrrrr}\text { Mach Number: } & 0.8374 & 0.7645 & 0.7098 & 0.6669 & 0.6323 \\ \text { Rel Mach Number: } & 0.5525 & 0.4636 & 0.3979 & 0.3490 & 0.3135 \\ \text { Pressure [kPa]: } & 7384.74 & 7902.39 & \mathbf{8 2 8 6 . 4 3} & \mathbf{8 5 8 2 . 4 1} & \mathbf{8 8 1 7 . 3 0}\end{array}$

$\begin{array}{crrrrr}\text { AXIAL STATION 4m (Rotor Outlet) } & & & & \\ \text { Radius [mm]: } & 250.4 & 276.3 & 300.0 & 321.9 & 342.5 \\ \text { Blade Speed [m/s]: } & 94.40 & 104.17 & 113.10 & 121.37 & 129.11 \\ \text { Axial Velocity [m/s]: } & 84.00 & 84.00 & 84.00 & 84.00 & 84.00 \\ \text { Whirl Velocity [m/s]: } & 0.00 & 0.00 & 0.00 & 0.00 & 0.00 \\ \text { Rel Whirl Vel [m/s]: } & -94.40 & -104.17 & -113.10 & -121.37 & -129.11 \\ \text { Flow Angle [deg]: } & 0.0 & 0.0 & 0.0 & 0.0 & 0.0 \\ \text { Rel Flow Angle [deg]: } & -48.3 & -51.1 & -53.4 & -55.3 & -57.0 \\ \text { Mach Number: } & 0.2720 & 0.2720 & 0.2720 & 0.2720 & 0.2720 \\ \text { Rel Mach Number: } & 0.4092 & 0.4334 & 0.4562 & 0.4780 & 0.4988 \\ \text { Pressure [kPa]: } & 7885.66 & 7885.66 & 7885.66 & 7885.66 & 7885.66\end{array}$

SPANWISE VARIATION IN PERFORMANCE PARAMETERS

$\begin{array}{rrrrrr}\text { Reaction (based on H): } & -0.2687 & -0.0530 & 0.1000 & 0.2142 & 0.3027 \\ \text { Flow Coefficient: } & 0.8818 & 0.8034 & 0.7427 & 0.6940 & 0.6538 \\ \text { Work Coefficient: } & 2.5373 & 2.1060 & 1.8000 & 1.5716 & 1.3947\end{array}$




\section{Appendix D}

\section{Dependence of Total Enthalpy Drop on Blade Speed}

\section{and Work Coefficient}

Assuming the blade speeds at the rotor inlet and exit are equal the Euler Equation is,

$$
\Delta \mathrm{h}_{0}=\mathrm{U} \Delta \mathrm{C}_{\mathrm{W}}
$$

where, $\Delta h_{0}$ is the total enthalpy drop across the stage, $U$ is the blade speed, and $\Delta C_{W}$ is the change in whirl velocity. As shown in Figure 4.17 if $U$ is increased by some amount $\Delta \mathrm{C}_{\mathrm{W}}$ will decrease by the same amount. Likewise, decreasing $\mathrm{U}$ will cause $\Delta \mathrm{C}_{\mathrm{W}}$ to increase. Therefore, if $U$ is changed by a small value $x$ the Euler equation becomes,

$$
\Delta \mathrm{h}_{0}=(\mathrm{U}+\mathrm{x})\left(\Delta \mathrm{C}_{\mathrm{w}}-\mathrm{x}\right)
$$

Expanding and rearranging Equation 5.1,

$$
\Delta \mathrm{h}_{0}=\mathrm{U} \Delta \mathrm{C}_{\mathrm{w}}+\left(\Delta \mathrm{C}_{\mathrm{w}}-\mathrm{U}\right) \mathrm{x}-\mathrm{x}^{2}
$$

Taking the partial derivative of Equation 5.2,

$$
\frac{\partial \Delta h_{0}}{\partial x}=\Delta C_{w}-U-2 x
$$


In order for the total enthalpy drop to increase,

$$
\begin{gathered}
\frac{\partial \Delta \mathrm{h}_{0}}{\partial \mathrm{x}}>0 \therefore \Delta \mathrm{C}_{\mathrm{w}}-\mathrm{U}-2 \mathrm{x}>0 \\
\therefore \Delta \mathrm{C}_{\mathrm{w}}>\mathrm{U}+2 \mathrm{x} \\
\frac{\Delta \mathrm{C}_{\mathrm{w}}}{\mathrm{U}}>1+\frac{2 \mathrm{x}}{\mathrm{U}}
\end{gathered}
$$

Assuming $\mathrm{x}$ is significantly smaller than $\mathrm{U}$,

$$
\frac{\Delta \mathrm{C}_{\mathrm{w}}}{\mathrm{U}}>1
$$

and from the constant blade speed assumption mentioned previously,

$$
\frac{\Delta \mathrm{h}_{0}}{\mathrm{U}^{2}}=\frac{\mathrm{U} \Delta \mathrm{C}_{\mathrm{w}}}{\mathrm{U}^{2}}=\frac{\Delta \mathrm{C}_{\mathrm{w}}}{\mathrm{U}}
$$

Therefore, Equation 5.7 becomes,

$$
\psi>1
$$

where, $\psi$ is the work coefficient. Therefore, if the work coefficient at the current operating condition is greater than 1.0 increasing the blade speed will increase the total enthalpy drop. 


\section{Appendix E}

\section{Leading-Edge Wedge Angle and Leading-Edge}

\section{Diameter-to-Spacing Ratio Data}

This appendix provides the leading-edge geometry data mentioned in Section 4.4.4. The data consists of the leading-edge wedge angle, We, and leading-edge diameter-tospacing ratio, $\mathrm{d}_{\mathrm{LE}} / \mathrm{s}$, of 21 airfoils from open source literature. 


\begin{tabular}{|c|c|c|}
\hline Reference & $\begin{array}{c}\text { We } \\
\text { (degrees) }\end{array}$ & $\mathbf{d}_{\mathbf{L E}} / \mathrm{s}$ \\
\hline \multirow{2}{*}{ Benner et al. (1997) } & 52.4 & 0.085 \\
\hline & 43 & 0.151 \\
\hline Yamamoto and Nouse (1988) & 29 & 0.267 \\
\hline Jouini (2000) & 38 & 0.035 \\
\hline Corriveau (2005) & 38 & 0.035 \\
\hline Jefferies (2000) & 75.4 & 0.196 \\
\hline Jouini (2000) & 38 & 0.086 \\
\hline \multirow{4}{*}{$\begin{array}{c}\text { Taremi et al. }(2010 \mathrm{a} \& \mathrm{~b}) \text { and } \\
\text { Taremi }(2010)\end{array}$} & 40 & 0.100 \\
\hline & 44 & 0.081 \\
\hline & 52 & 0.107 \\
\hline & 50 & 0.099 \\
\hline Hodson and Dominy (1987) & 25 & 0.057 \\
\hline \multirow{3}{*}{ Perdichizzi and Dossena (1993) } & 57.1 & 0.281 \\
\hline & 57.1 & 0.223 \\
\hline & 57.1 & 0.187 \\
\hline \multirow{2}{*}{ Aronov et al. (1975) } & 34.5 & 0.100 \\
\hline & 12.5 & 0.039 \\
\hline Vijayaraghavan and Kavanagh (1988) & 46 & 0.105 \\
\hline \multirow{3}{*}{ Benner (2003) } & 25 & 0.110 \\
\hline & 18.5 & 0.055 \\
\hline & 8.5 & 0.055 \\
\hline
\end{tabular}

Table A.1 Airfoil Leading-Edge Geometry Data 